\title{
Ramgen Power Systems for Military Engine Applications
}

Franklin H. Holcomb, Chang W. Sohn, Gunnar Tamm, Daniel Brown, Daniel Mahoney, Peter Baldwin, Karen Belshaw, Aaron Koopman, and Dennis Witmer
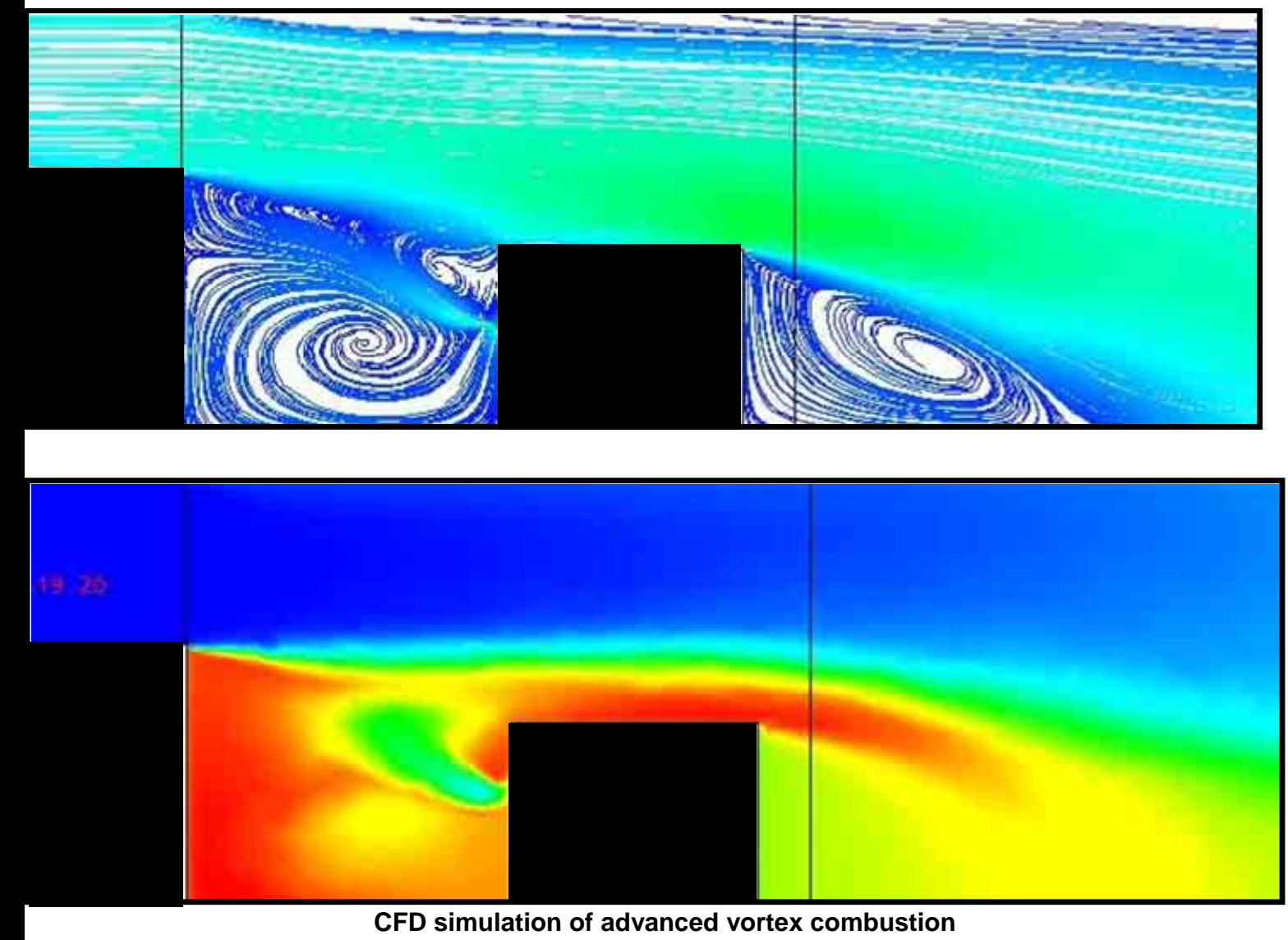


\section{Ramgen Power Systems for Military Engine Applications}

Franklin H. Holcomb and Chang W. Sohn

Construction Engineering Research Laboratory (CERL) U.S. Army Engineer Research and Development Center 2902 Newmark Dr.

Champaign, IL 61824

Gunnar Tamm, Daniel Brown, and Daniel Mahoney

U.S. Military Academy (USMA)

West Point, NY 10996

Peter Baldwin, Karen Belshaw, and Aaron Koopman

Ramgen Power Systems, Inc.

11808 Northup Way, Suite W-190

Bellevue, WA, U.S.A. 98005

Dennis Witmer

University of Alaska-Fairbanks

Fairbanks, AK 99775

Final Report

Approved for public release; distribution is unlimited.

Prepared for U.S. Army Corps of Engineers

Washington, DC 20314-1000

Under Work Unit 14J9LB 


\begin{abstract}
Ramgen Power Systems, Inc. (RPS) is developing two high efficiency gas turbine engine concepts that combine many of the proven features of supersonic compression and expansion systems, commonly used in supersonic flight inlet and nozzle designs, with conventional axial flow turbo-machinery practices to create two entirely new gas turbine engines. The superior efficiency is a result of high pressure shock wave compression and supersonic expansion phenomena to produce high component efficiencies, and a unique engine configuration that minimizes flow stream turning losses throughout the engine. The RPS engine concept can be configured as a high pressure ratio simple-cycle design for propulsion applications, or as a low pressure ratio recuperated engine either as a standalone component or combined with a hybrid fuel cell for stationary power applications. The anticipated compression and expansion efficiencies, decreased footprint, and reduced part count of the RPS technologies promise revolutionary new power generation and propulsion systems with decreased heat signatures resulting from lower exhaust temperatures. These unique aerodynamic features will open new options for engine designers and package integrators. This report documents research and development of the RAMGEN technology and potential applications toward military operations including warfighter applications.
\end{abstract}

DISCLAIMER: The contents of this report arenot to beused for advertising, publication, or promotional purposes. Citation of trade names does not constitute an official endorsement or approval of the use of such commercial products. All product names and trademarks cited are the property of their respective owners. The findings of this report are not to be construed as an official Department of the Army position unless so designated by other authorized documents. 


\section{Contents}

Figures and Tables...............................................................................................................

Preface .....................................................................................................................................

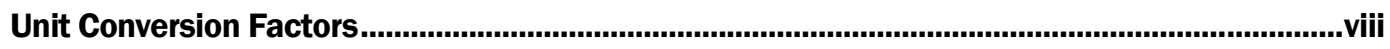

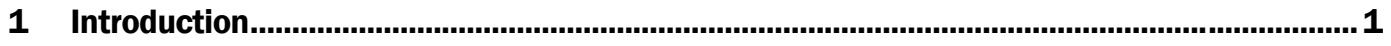

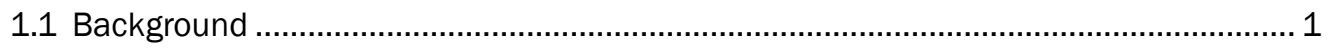

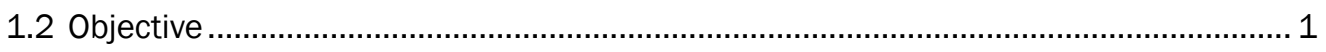

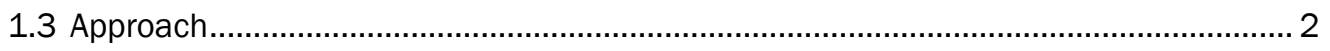

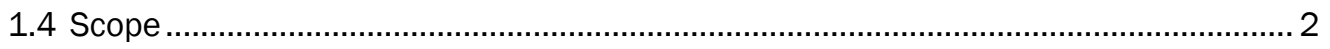

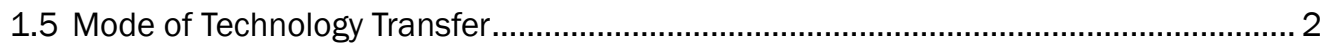

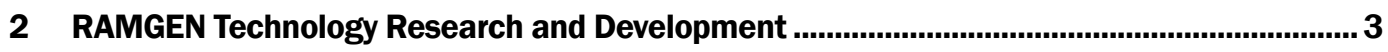

2.1 Compression Technology - Rampressor .................................................................... 3

2.2 Expansion Technology - Ram Expander ....................................................................... 7

2.3 Combustion Technology - Advanced Vortex Combustion ............................................ 9

2.4 Technology Development Programs and Status...................................................... 13

3 Applied Research - Military Applications ..........................................................................29

3.1 Technology and Application Development Roadmap...............................................29

3.2 Compression Opportunities..................................................................................... 31

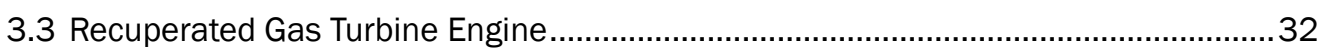

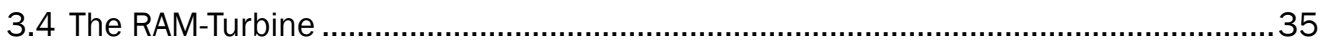

3.5 Simple Cycle Gas Turbine Advanced Supersonic Component Engine.........................37

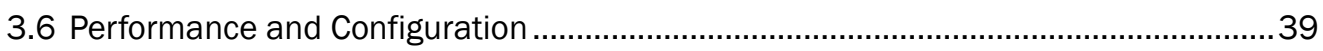

3.7 Military Applications.................................................................................................. 43

3.8 Advanced Vortex Combustion Opportunities ........................................................46

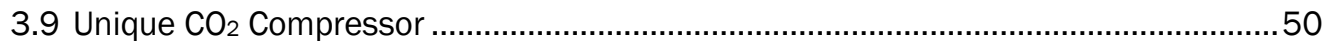

4 Potential Warfighter Applications ......................................................................................58

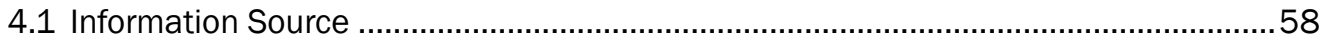

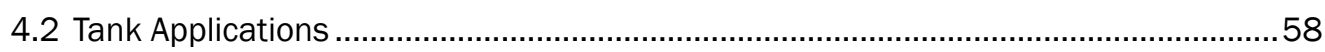

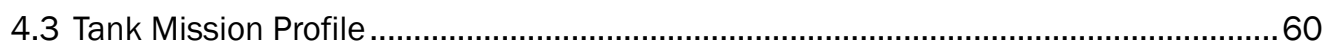

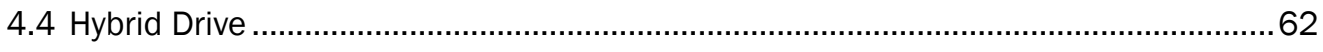

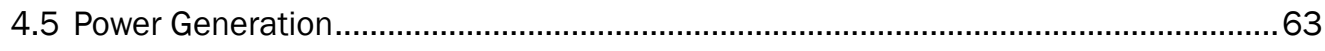

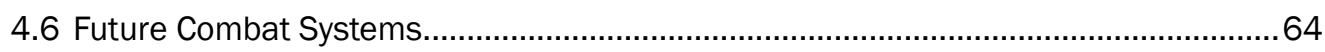

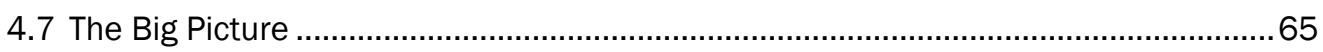

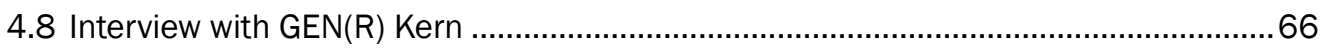

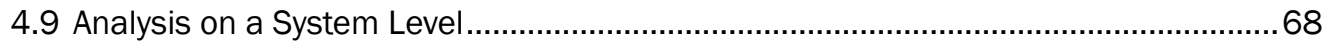

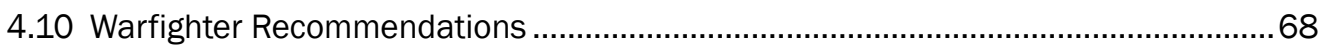

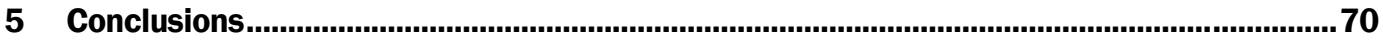

5.1 Conclusions .......................................................................................................... 70

5.2 Future Direction..................................................................................................... 70 


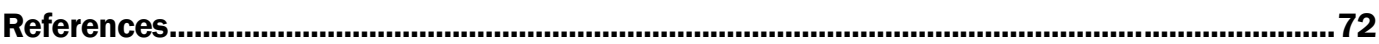

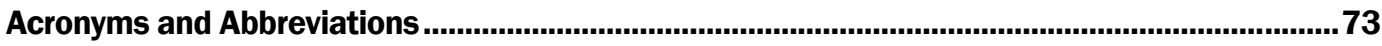

Report Documentation Page............................................................................................................. 75 


\section{Figures and Tables}

\section{Figures}

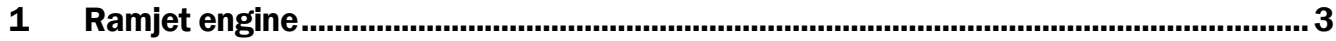

2 Picture and location of F-15 Supersonic Inlet (Photos Courtesy U.S. Air Force) ............ 4

3 F-15 Supersonic inlet cross section detail ...................................................................... 5

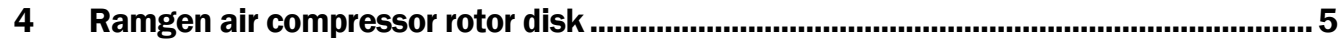

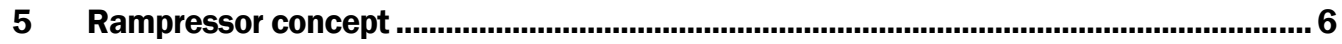

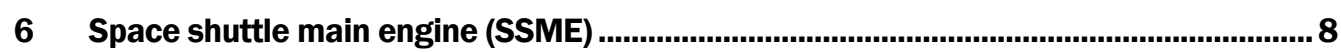

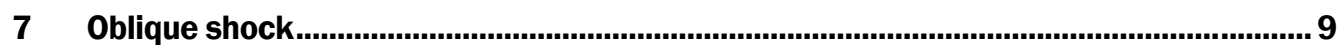

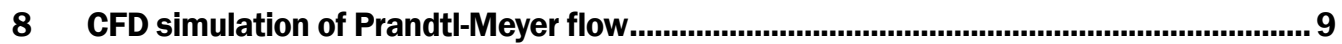

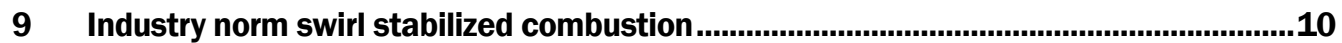

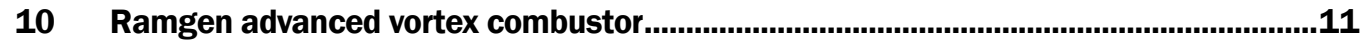

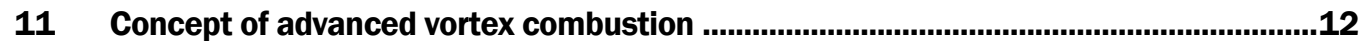

12 CFD simulation of advanced vortex combustion ......................................................13

13 Rampressor-1 test rig installed in test cell ............................................................15

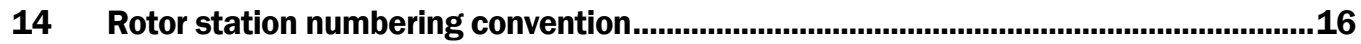

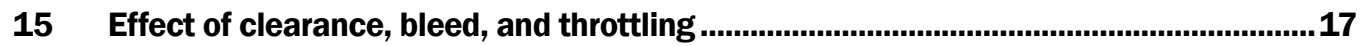

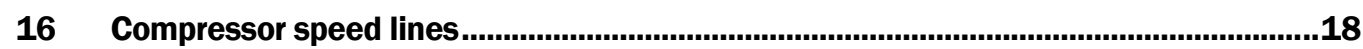

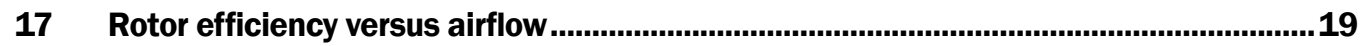

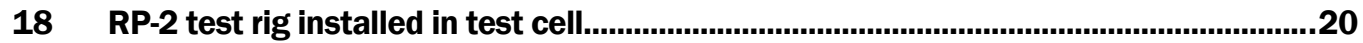

19 RP-2 rotor configuration ...................................................................................................21

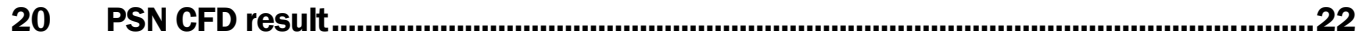

21 RP-2 PSN CFD predictions vs. experimental data .....................................................22

22 Mach profiles in candidate flow-path design ...................................................................24

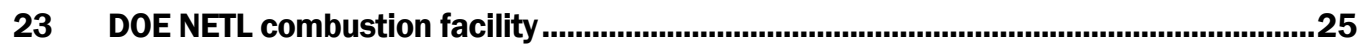

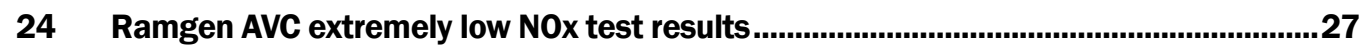

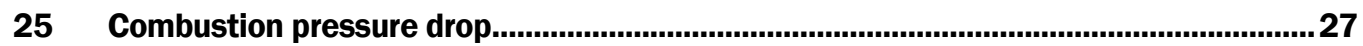

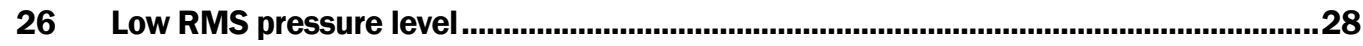

27 Ramgen technology and application development roadmap............................................29

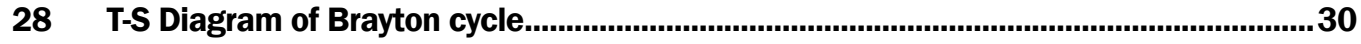

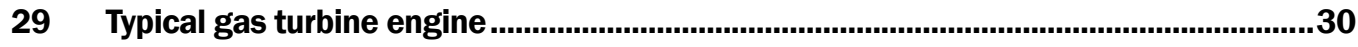

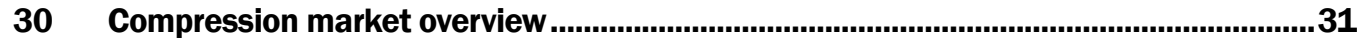

31 Trade-offs of efficiency gains and recuperator cost ..................................................33

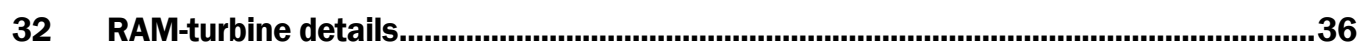




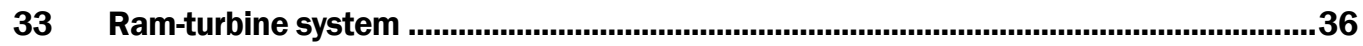

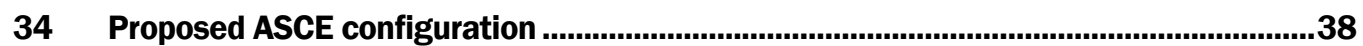

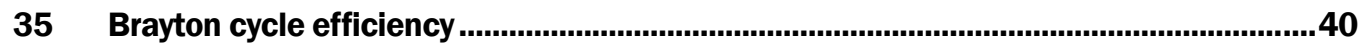

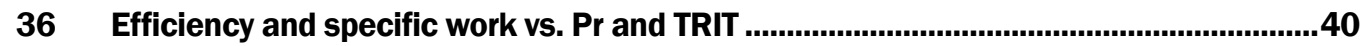

37 Thermal efficiency vs. rated power .....................................................................................41

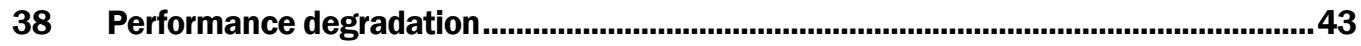

39 Comparison of ASCE and available turbine systems......................................................43

40 Impact of two spools on engine performance...........................................................44

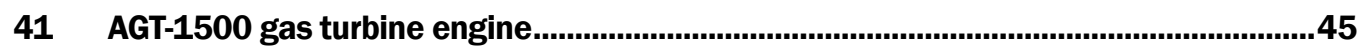

42 Caterpillar C32TA V-12 - 740kWe ..................................................................... 47

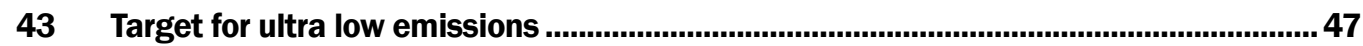

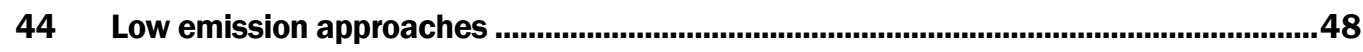

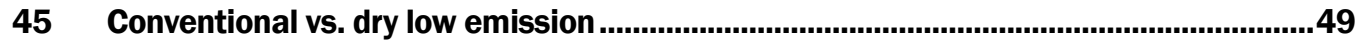

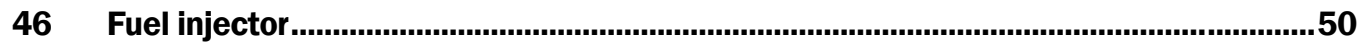

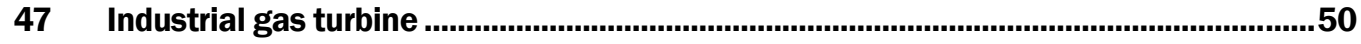

48 Ramgen's super-sonic shock wave Co2 compressor ...................................................51

49 MAN Turbo 10-stage 200:1 $\mathrm{CO}_{2}$ compressor .......................................................53

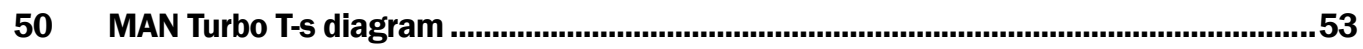

51 Elliott centrifugal compressor designs .....................................................................54

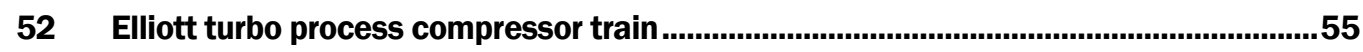

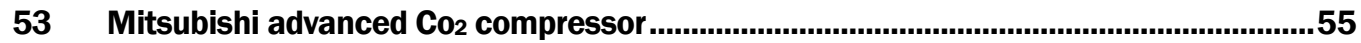

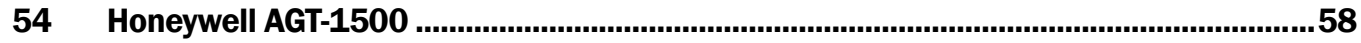

55 Power system benchmarks...................................................................................................64

\section{Tables}

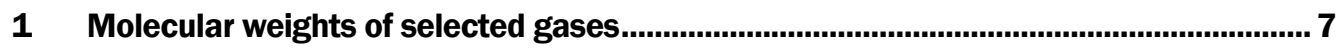

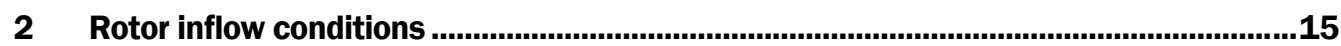

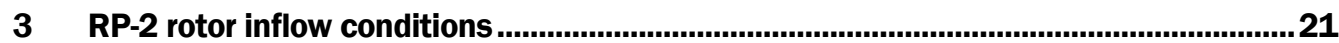

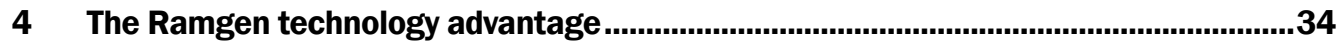

5 Comparison of Ramgen $\mathrm{CO}_{2}$ compressor to conventional machines............................57

6 AGT1500 system specifications …...........................................................................59

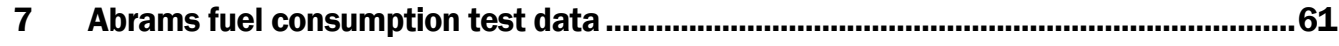

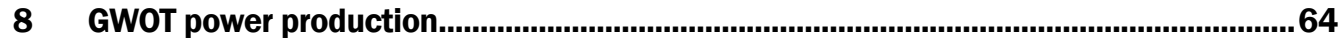




\section{Preface}

This study was conducted for the Office of the Director, Defense, Research, and Engineering (ODDR\&E) under "Ramgen/ Fuel Cell Hybrid Generating System." The technical monitor was Mr. Robert Boyd, ODDR\&E.

The work was performed by the Energy Branch (CF-E) of the Facilities Division $(\mathrm{CF})$, Construction Engineering Research Laboratory (CERL). The CERL Principal Investigator was Franklin H. Holcomb. Special thanks to GEN(R) Paul Kern, former Army Materiel Commander for his insight into the acquisition process, design planning, current and future Army materiel needs; Dr. Dick McClelland, Director of the Tank Automotive Research, Development and Engineering Center (TARDEC) for his discussion on the tank as a system of systems, comments and information concerning FCS vehicles, and his contacts for additional information regarding the FCS; to Mr. Tim Milanov, Chief Engineer for Abrams testing, for providing us with the operation mode, mission profile, and testing specifics for the Abrams tank. Thanks also to LTC Andrew Backus, MAJ Rob Ells, and CPT J ames Boyette with the 249th Engineers (Prime Power) regarding their information on Army stationary power generation sets. Thanks to Mr. Peter Meiner from NASA's Glenn Research Center in Cleveland, Ohio. Mr. Meiner was able to offer a variety of information from his 30 years of experience in propulsion research. Thanks to Mr. Ernest Schwarz, Team Leader for Engines at TARDEC, for providing us with information regarding the power plant in FCS vehicles, comparisons to the Bradley power plant, and plans for implementation of hybrid drive or APUs into FCS vehicles. Dr. Thomas J . Hartranft is Chief, CEERD-CF-E, and L. Michael Golish is Chief, CEERD-CF. The associated Technical Director was Martin J. Savoie, CEERD-CF-F. The Director of CERL is Dr. Ilker R. Adiguzel.

CERL is an element of the U.S. Army Engineer Research and Development Center (ERDC), U.S. Army Corps of Engineers. The Commander and Executive Director of ERDC is COL Richard B. J enkins, and the Director of ERDC is Dr. James R. Houston. 


\section{Unit Conversion Factors}

\begin{tabular}{|c|c|c|}
\hline Multiply & By & To Obtain \\
\hline British thermal units (International Table) & $1,055.056$ & joules \\
\hline cubic feet & 0.02831685 & cubic meters \\
\hline cubic inches & 1.6387064 E-05 & cubic meters \\
\hline cubic yards & 0.7645549 & cubic meters \\
\hline degrees (angle) & 0.01745329 & radians \\
\hline degrees Fahrenheit & $(\mathrm{F}-32) / 1.8$ & degrees Celsius \\
\hline feet & 0.3048 & meters \\
\hline foot-pounds force & 1.355818 & joules \\
\hline gallons (U.S. liquid) & 3.785412 E-03 & cubic meters \\
\hline horsepower (550 foot-pounds force per second) & 745.6999 & watts \\
\hline inches & 0.0254 & meters \\
\hline inch-pounds (force) & 0.1129848 & newton meters \\
\hline ounces (U.S. fluid) & $2.957353 \mathrm{E}-05$ & cubic meters \\
\hline pints (U.S. liquid) & 4.73176 E-04 & cubic meters \\
\hline pounds (force) & 4.448222 & newtons \\
\hline pounds (force) per foot & 14.59390 & newtons per meter \\
\hline pounds (force) per inch & 175.1268 & newtons per meter \\
\hline pounds (force) per square foot & 47.88026 & pascals \\
\hline pounds (force) per square inch & 6.894757 & kilopascals \\
\hline pounds (mass) & 0.45359237 & kilograms \\
\hline square feet & 0.09290304 & square meters \\
\hline square inches & 6.4516 E-04 & square meters \\
\hline square miles & $2.589998 \mathrm{E}+06$ & square meters \\
\hline square yards & 0.8361274 & square meters \\
\hline tons (force) & $8,896.443$ & newtons \\
\hline tons (2,000 pounds, mass) & 907.1847 & kilograms \\
\hline tons ( 2,000 pounds, mass) per square foot & $9,764.856$ & kilograms per square meter \\
\hline yards & 0.9144 & meters \\
\hline
\end{tabular}




\section{Introduction}

\subsection{Background}

As part of the Department of Defense (DoD) investigation of stationary fuel cell technology, U.S. Army Engineer Research and Development Center Construction Engineering Research Laboratory (ERDC-CERL) manages several important research activities, including the Department of Defense (DOD) Fuel Cell Program, which has installed and evaluated fuel cell power plant technologies at many DOD installations (DODFuelCell ERDC/ CERL Projects website 2007). The development of a Ramgen Fuel Cell hybrid system is one of the major efforts under the fuel cell research and development projects involving the University of Alaska at Fairbanks (UAF) in conjunction with Ramgen Power Systems (RPS)* in the DOD project that plans to build and test a fuel cell turbine hybrid system using the best available fuel cell technology in combination with Ramgen's supersonic component-based compressor and expander technologies.

The hybrid system is designed to use high temperature waste heat from fuel cell for additional power generation through a gas turbine. The gas turbine requires a compressor. Gas compression is a fundamental process employed in many military operations as well as general industrial applications. Typically, gas compression is done through positive displacement of gas or conversion of kinetic energy into static pressure. This project is investigating a novel mechanism using oblique shocks to generate high gas pressure. Gas compression technology based on the oblique shock phenomenon has been studied for several years (Lawlor et al. 2004; Lawlor and Baldwin 2005; Lawlor and Steele 2004). This work will further the technology by developing an oblique shock based Rampressor technology, "Advanced Supersonic Component Engine" (ASCE), and will explore potential warfighter and stationary military applications of the Rampressor based power technology.

\subsection{Objective}

The primary objective of this work is to document research and development activities by Ramgen Power Systems, Inc. (RPS) in developing two

\footnotetext{
* For more information, see the Ramgen Power Systems website: http://www.ramgen.com/index.html
} 
high efficiency gas turbine engine concepts that combine many of the proven features of supersonic compression and expansion systems, commonly used in supersonic flight inlet and nozzle designs, with conventional axial flow turbo-machinery practices to create two new gas turbine engines. Further objectives were to explore potential applications to military operations including warfighter applications and to discuss future directions for this project.

\subsection{Approach}

This work consists of a review and analysis of development, and planning for implementation of Ramgen technologies. Chapters 2 and 3 (contributed by Ramgen Power Systems) discuss specific Ramgen technologies. Chapter 4 (contributed by U.S. Military Academy staff) analyzes the potential implementation of the Ramgen technology to warfighter applications. Chapter 5 draws conclusions regarding work to date in this area, and discusses future research directions.

\subsection{Scope}

This information described in this report is limited to the review of Rampressor and Ramgen power system technologies. Although the Ramgen power system can be used as an additional power generator in tandem with a fuel cell power plant for improved efficiency of a fuel cell hybrid system, a broader discussion of fuel cell technology and the DoD fuel cell demonstration program is beyond the scope of this report. This information is available through the ERDC-CERL DOD website (DODFuelCell ERDC/ CERL Projects 2007).

Note that this report summarizes research and development (R\&D) activities involving the Ramgen Power System applied to the efficient gas turbine engine. Any reference to commercial products herein are meant as part of informational technical discussion; no commercial endorsement or recommendation is stated or implied.

\subsection{Mode of Technology Transfer}

A summary of this report was presented to the $25^{\text {th }}$ Army Science Conference, Orlando, FL, 27-30 November 2006 (Sohn et al. 2006). This report will be made accessible through URLs:

http://www.cecer.army.mil

http://www.dodfuelcell.com 


\section{RAMGEN Technology Research and Development}

\subsection{Compression Technology - Rampressor}

\subsubsection{Shock Compression - "What is it?"}

Since the sound barrier was broken in the late 1940s, ramjet engines have been widely used as a means to propel aerospace vehicles at supersonic speeds. The technology is very well understood and fully characterized.

All conventional, subsonic jet engines feature discrete compression, combustion, and turbine/ expansion sections to create the thrust used to propel an aircraft. In operation, hot pressurized exhaust gas expands through the turbine to drive the compressor, and then further expands through a nozzle, creating forward thrust.

Ramjet engines feature these same discrete compression, combustion, and expansion sections (Figure 1). The significant difference in ramjet engines is that the compressor section does not rotate and the turbine section is therefore eliminated. There are no rotating components in the engine. At supersonic velocities, air is ingested into the engine and flows around a fixed obstructing body in the center of the engine duct, "ramming" the air flow into channels between the center-body and the engine's sidewall. Inside these channels, the airflow is almost instantaneously slowed to subsonic speeds, creating "shock waves." These shock waves are associated with a dramatic increase in pressure, i.e., "shock compression." As with conventional subsonic turbine engines, fuel is then added and the hot, pressurized exhaust gas expands through a nozzle to create forward thrust.

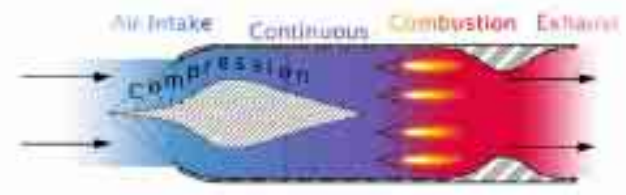

Figure 1. Ramjet engine.

Although ramjets are simple (they have no moving parts), the aircraft must be moving at supersonic speeds to initiate the shock necessary for effective operation. As a result, all ramjet experience has been in the context of supersonic planes and missiles. 
One well-known application of shock compression is its use in the F-15 fighter jet. Figure 2 shows how a supersonic shock compression inlet acts to boost the inlet pressure, while simultaneously reducing the air flow to the subsonic velocity required by the combustor. Figure 3 shows the F- 15 supersonic inlet cross section detail.

\subsubsection{Ramgen's Technology Breakthrough}

Ramgen's primary technical innovation has been to apply ramjet engine concepts in a stationary compressor application (Figure 5).Ramgen's core design, the Rampressor, is a relatively simple device (Figure 4). It features a rotating disk operating at the high peripheral speeds necessary to achieve supersonic effect in a stationary environment. The rim of the disk has three raised sections and cavities that mimic the effect of the centerbody and channels of a conventional ramjet inlet. Air enters through a common inlet and is then ingested into the annular space between the supersonically spinning disk and the outer edge of the casing. When the flow of air enters this space, the raised sections of the disk rim generate oblique shock waves and air compression in a manner completely analogous to ramjet inlets on supersonic aerospace vehicles. The efficiency of this compression process is very high because the compressor has very few aerodynamic leading edges and minimal drag.
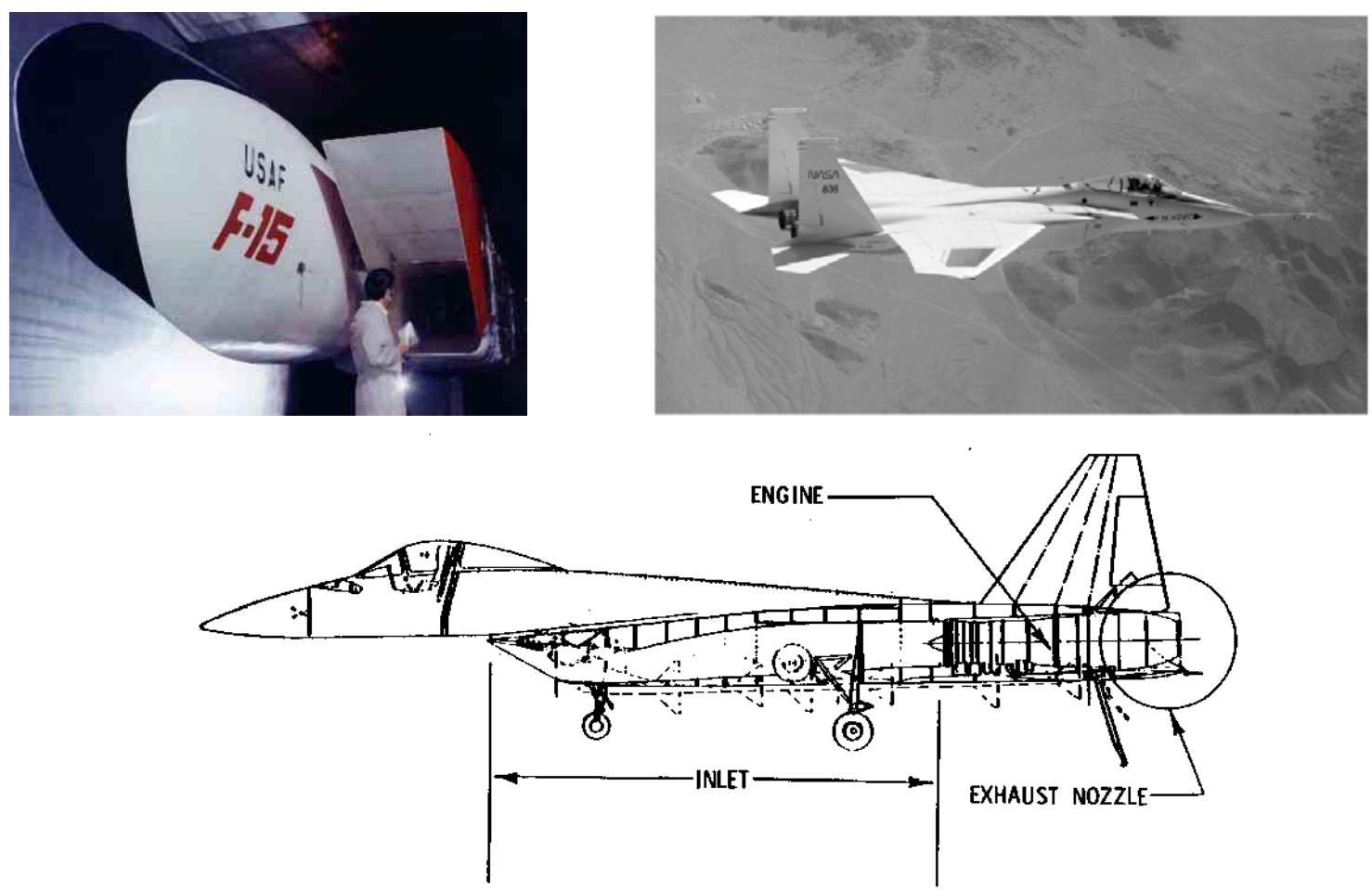

Figure 2. Picture and location of F-15 Supersonic Inlet (Photos Courtesy U.S. Air Force). 

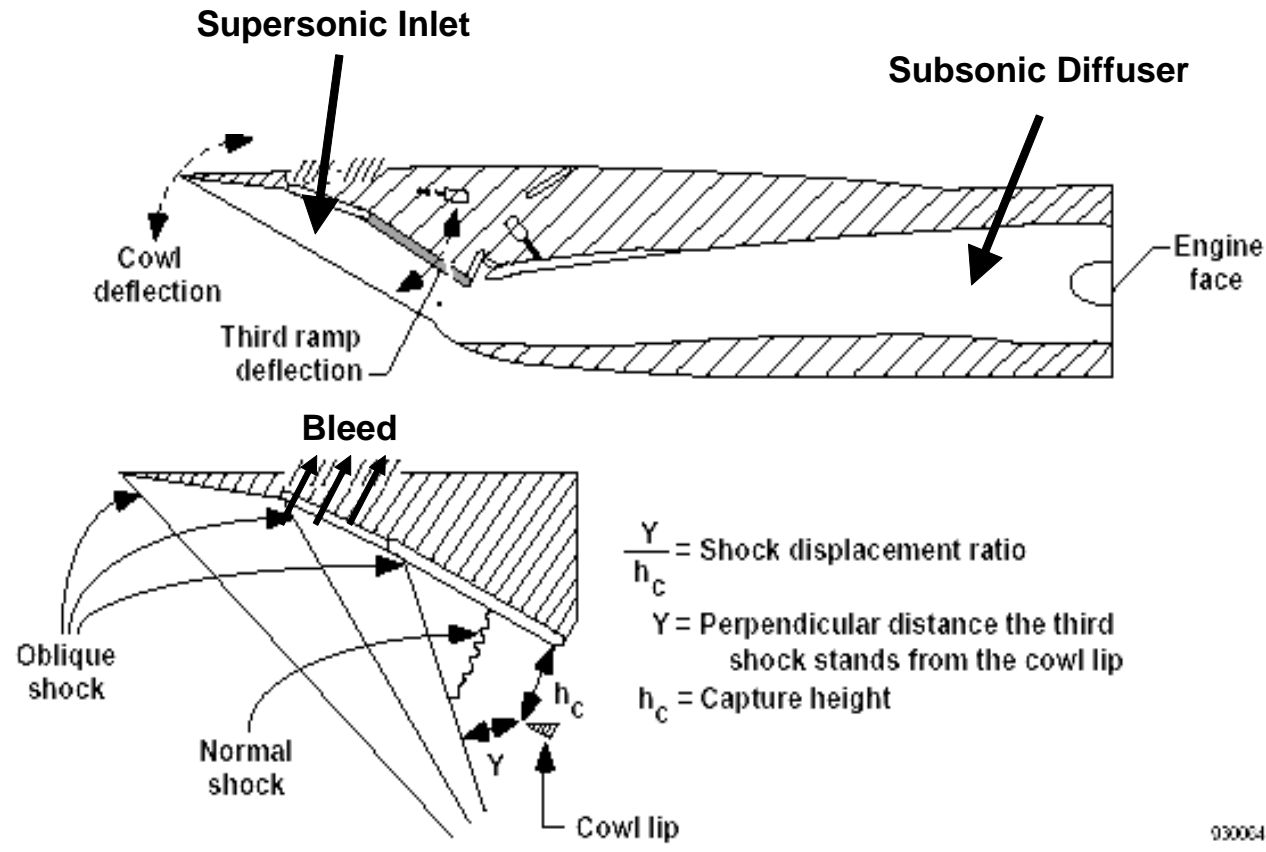

Figure 3. F-15 Supersonic inlet cross section detail.

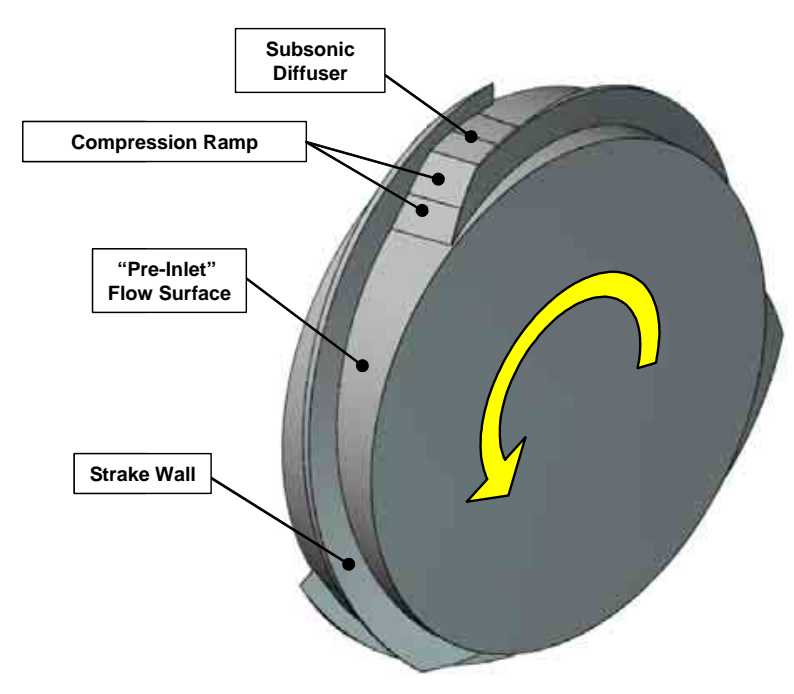

- Rotor Flow Path:

- 3 Supersonic Compression Inlet Flow Paths On Disk Rim

- High Efficiency, Compact Compression

- Minimal Number of Leading Edges

- Flow Path Geometry Similar For Different Pressure Ratios

- Combination of Supersonic Flight Inlet \& Conventional Axial Flow Compressor Aerodynamics:

- Rotor Rim Radius Change Produces Compression

- 3 “Blades" (Strakes) Do Minimal Flow Work

- Axial Inflow/Outflow

Figure 4. Ramgen air compressor rotor disk. 


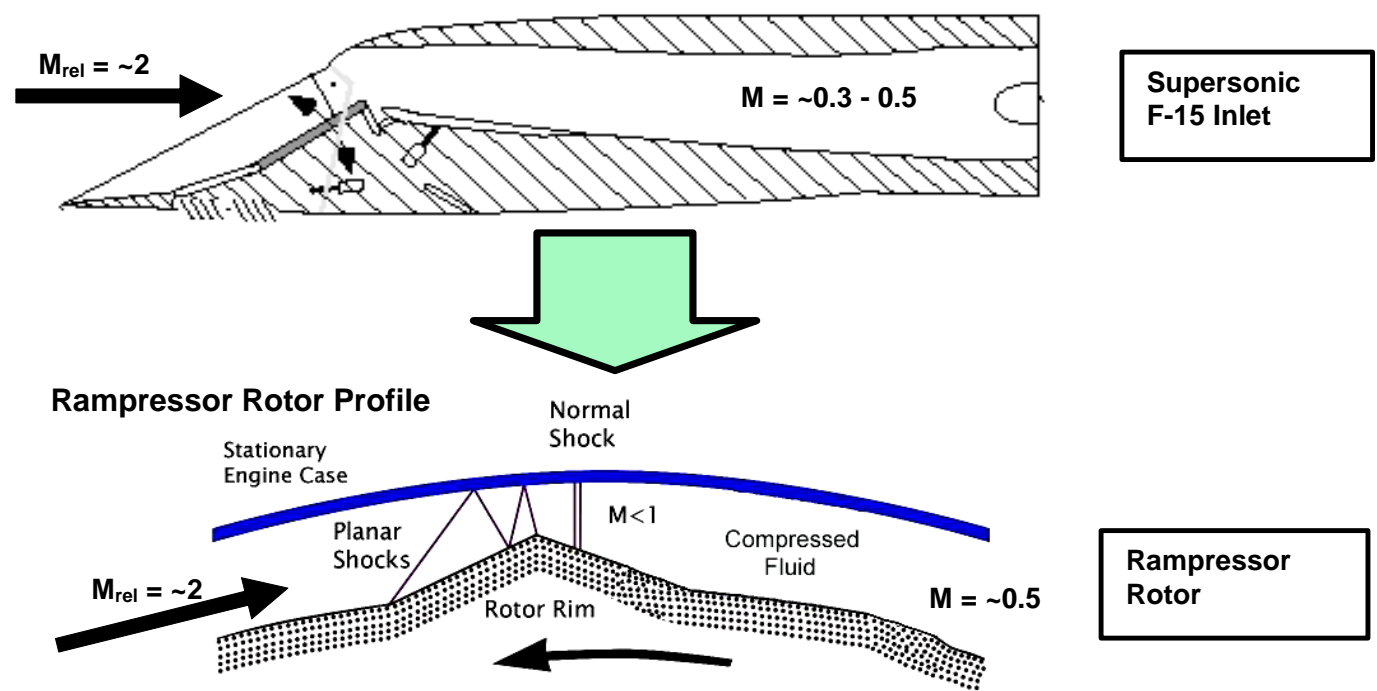

Figure 5. Rampressor concept.

Shock waves begin at the speed of sound. Higher Mach numbers produce shock waves capable of higher pressure ratio. The strength of the shock thus depends on the disc speed and the particular gas and its properties ingested into the Rampressor. The formula for the speed of sound is:

$$
c=\sqrt{k g \bar{R} T / M W}
$$

where:

$$
\begin{array}{lll}
\mathrm{c}= & \text { sonic velocity } \\
\mathrm{k}= & \text { ratio of specific heats } \mathrm{Cp} / \mathrm{Cv} \\
\mathrm{g}= & \text { gravitational constant } \\
\bar{R}= & \text { Universal Gas Constant } \\
\mathrm{T}= & \text { gas temperature } \\
\mathrm{MW}= & \text { mole weight of the gas. }
\end{array}
$$

As can be seen, sonic velocity is inversely proportional to the square root of the mole weight of the gas. A heavier gas will have a lower speed of sound, or sonic velocity, and conversely, a lighter gas will have a higher speed of sound. This is an important consideration in accommodating changes in ambient inlet temperature and matching various gas compression applications. Table 1 lists the molecular weights of selected gases. 
Table 1. Molecular weights of selected gases.

\begin{tabular}{|l|r|c|}
\hline \multicolumn{1}{|c|}{ Gas } & $\begin{array}{c}\text { Molecular } \\
\text { Weight }\end{array}$ & $\begin{array}{c}\text { Mach 1 } \\
\text { (ft/sec) }\end{array}$ \\
\hline Hydrogen & 2.020 & 4290 \\
\hline Methane & 16.043 & 1440 \\
\hline Ammonia & 17.030 & 1410 \\
\hline Water (water vapor or steam) & 18.015 & 1400 \\
\hline Air & 28.959 & 1130 \\
\hline CO 2 & 44.010 & 880 \\
\hline Propane & 44.096 & 880 \\
\hline R410a & 72.582 & 700 \\
\hline R22 & 86.468 & 600 \\
\hline R134a & 102.030 & 550 \\
\hline R12 & 120.910 & 490 \\
\hline R245fa & 134.050 & 530 \\
\hline R123 & 152.930 & 440 \\
\hline
\end{tabular}

The strength of the shock wave, and hence the amount of compression, increases exponentially with the Mach number as shown in Eq 2 below.

Available “Relative Pressure Ratio," $\frac{P_{2}}{P_{0}}$ is:

$$
\frac{P_{2}}{P_{0}}=\Pi \times\left[1+\left(\frac{\gamma-1}{2}\right) \times M_{0}^{2}\right]^{\gamma / \gamma-1}
$$

For example, in the air at Mach 1.6, a compression ratio of 3.5:1 is achieved, while at Mach 2.4, compression reaches approximately 15:1. The higher Mach number is achieved by spinning the disc faster.

Why are higher efficiency and a less expensive form of compression important? Air compression is a critical element in determining the efficiency of all types of combustion engines, as well as hybrid fuel cells. Gas compression is the key to the transportation of natural gas through pipelines as well as to air-conditioning and refrigeration processes. In addition, cost effective and efficient $\mathrm{CO}_{2}$ compression is increasingly seen as a key component of dealing with green house gases.

\subsection{Expansion Technology - Ram Expander}

J ust as supersonic flight inlets are commonly used to efficiently decelerate and compress an air stream for use by a jet engine or other propulsion cy- 
cle, supersonic nozzles are routinely used in ramjet and rocket systems to achieve the expansion and acceleration of gas streams in a wide variety of propulsion systems. Figure 6 the Space Shuttle Main Engine (SSME) during a full power test. When operating at its design point, the bell shaped nozzle of this rocket engine efficiently expands the high pressure and high temperature gases in the SSME combustion chamber from 3000 psia to 9 psia generating a high velocity exhaust stream that is the source of the thrust for the vehicle.

J ust as the shock compression features of the supersonic flight inlet were incorporated into the rim of the supersonic compression stage, the planar expansion surface of the supersonic nozzle can be incorporated into the rim of a supersonic expansion stage (Figure 7).

Ramgen will use computational fluid dynamics (CFD) simulations to develop supersonic compression stages that are well matched in mass flow and pressure ratio/ expansion ratio capability to these expansion stages. Figure 8 shows a CFD simulation of Prandtl-Meyer flow. This is an important requirement in an integrated engine system that must accomplish both processes efficiently to generate useable power.

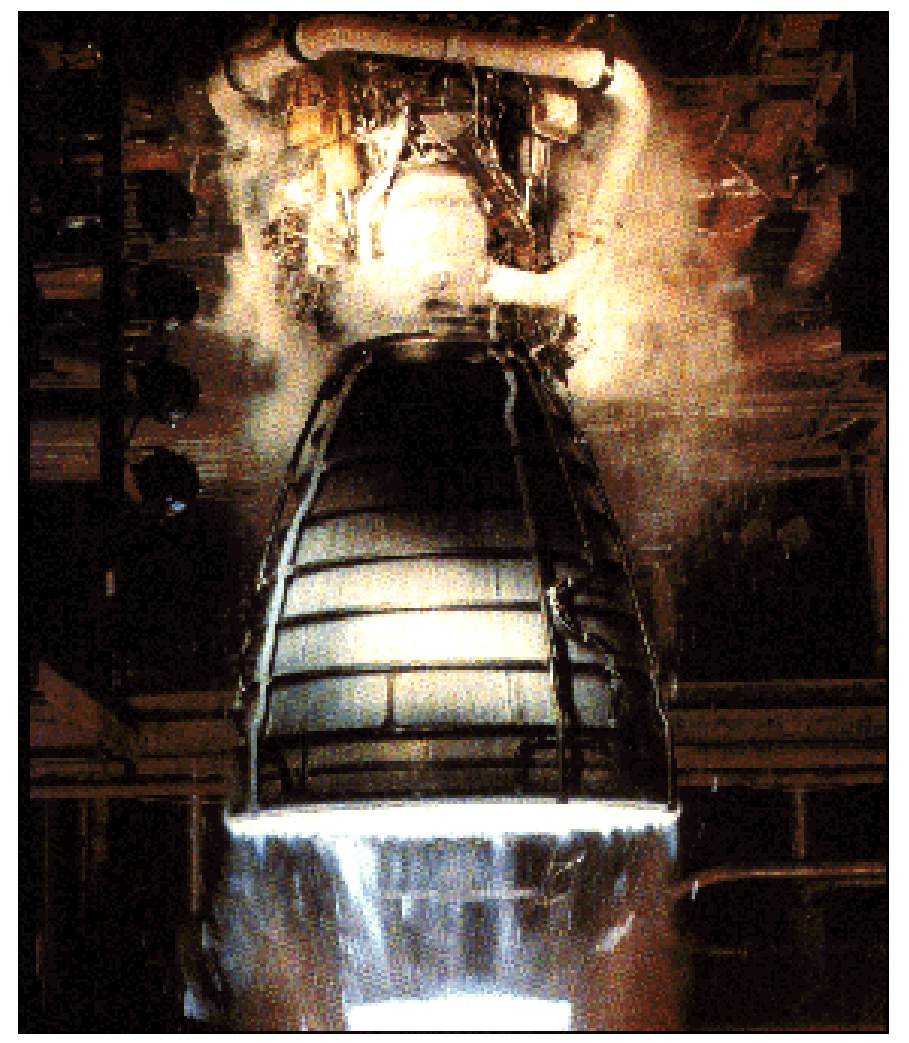

Figure 6. Space shuttle main engine (SSME). 

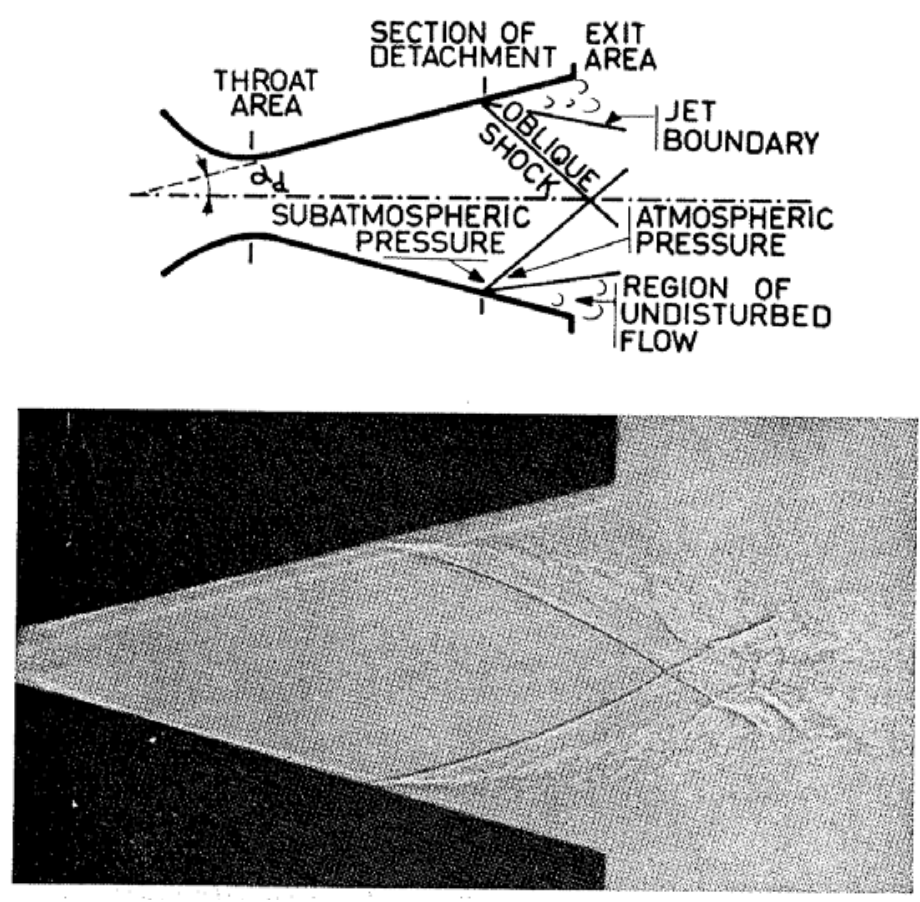

Figure 7. Oblique shock.
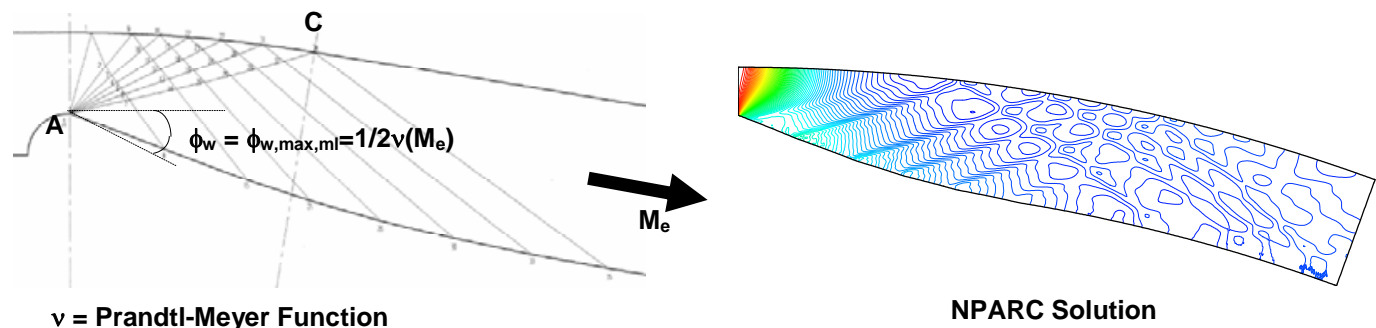

NPARC Solution

Figure 8. CFD simulation of Prandtl-Meyer flow.

Ramgen is in the early stages of identifying high value applications for its expander technology. The high efficiency and expansion ratio capability of the expander will yield designs that are more compact and less costly than comparable conventional turbine expanders.

\subsection{Combustion Technology - Advanced Vortex Combustion}

Ramgen has developed an advanced, high-velocity combustor technology that can have a significant impact on conventional gas turbine and plant design as well the design and operation of advanced hydrogen-based fuel cells and fuel cell systems.

In recent years, gas turbine equipment manufacturers have made significant progress on lean pre-mix combustor designs as a method of achieving 
extremely low emissions on natural gas fired combustion turbines. These lean pre-mix designs almost always rely on "swirl-stabilized" combustion zones combined with staged secondary mixing to achieve low NOx and acceptable levels of $\mathrm{CO}$.

Figure 9 shows the principal design feature of a swirl-stabilized combustor design in which the primary swirl zone is close coupled to the through flow velocity and therefore tuned to achieve these performance levels for a specific fuel. This approach generally requires additional space within an already constrained envelope and is therefore limited in its ability to convert the field population of machines. Conversion kits are available, but are relatively high cost because they are not "drop-in" replacements; they generally require casing modifications to install.

In contrast, Ramgen has developed a patented Advanced Vortex Combustor (AVC) that stabilizes the pilot zone in a physical cavity that is generally not sensitive to changes in throughput velocity of the main fuel and air flow, as are the swirl stabilized concepts. This is done by injecting a portion of the fuel/air mixture into these cavities separately, which allows for independent control of the pilot zone, as well as the main fuel and air flow (Figure 10).

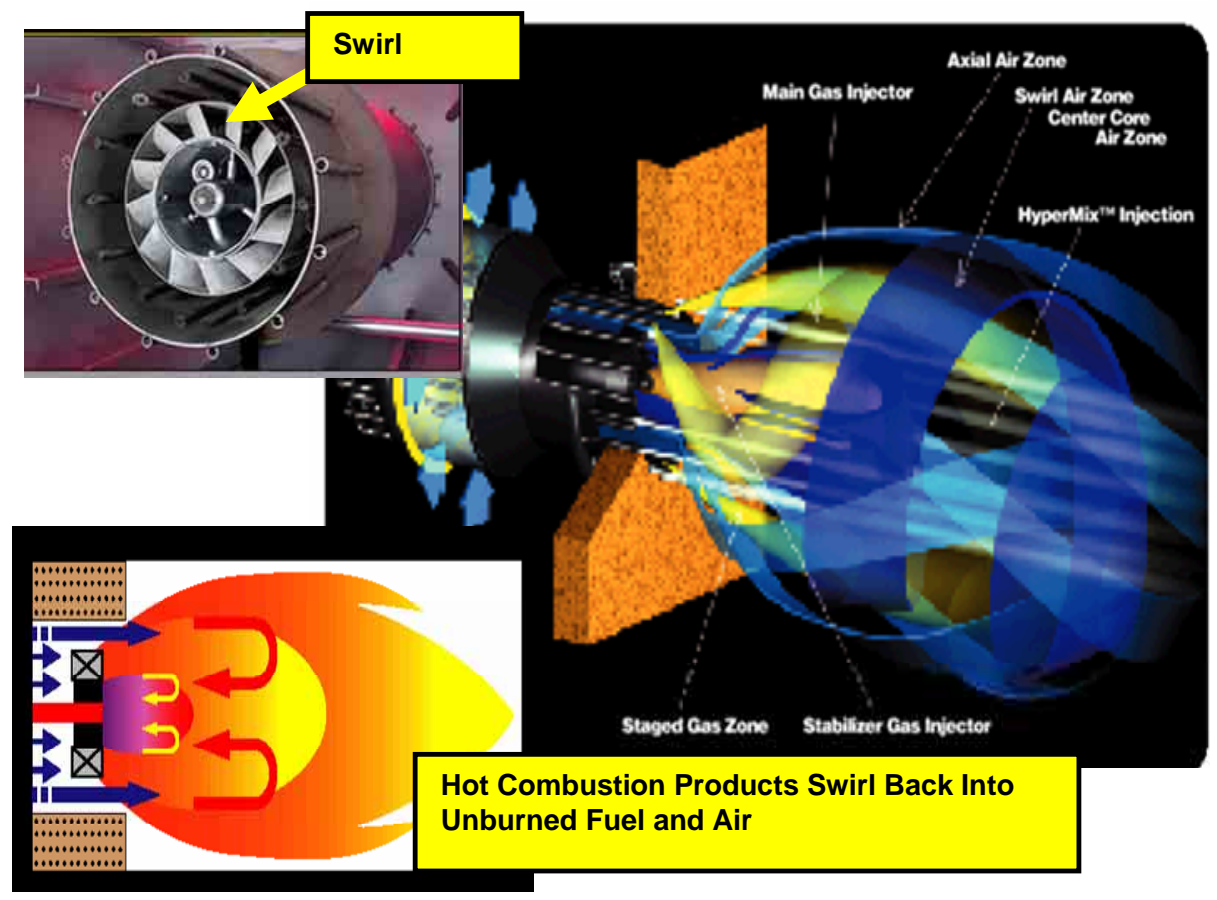

Figure 9. Industry norm swirl stabilized combustion. 


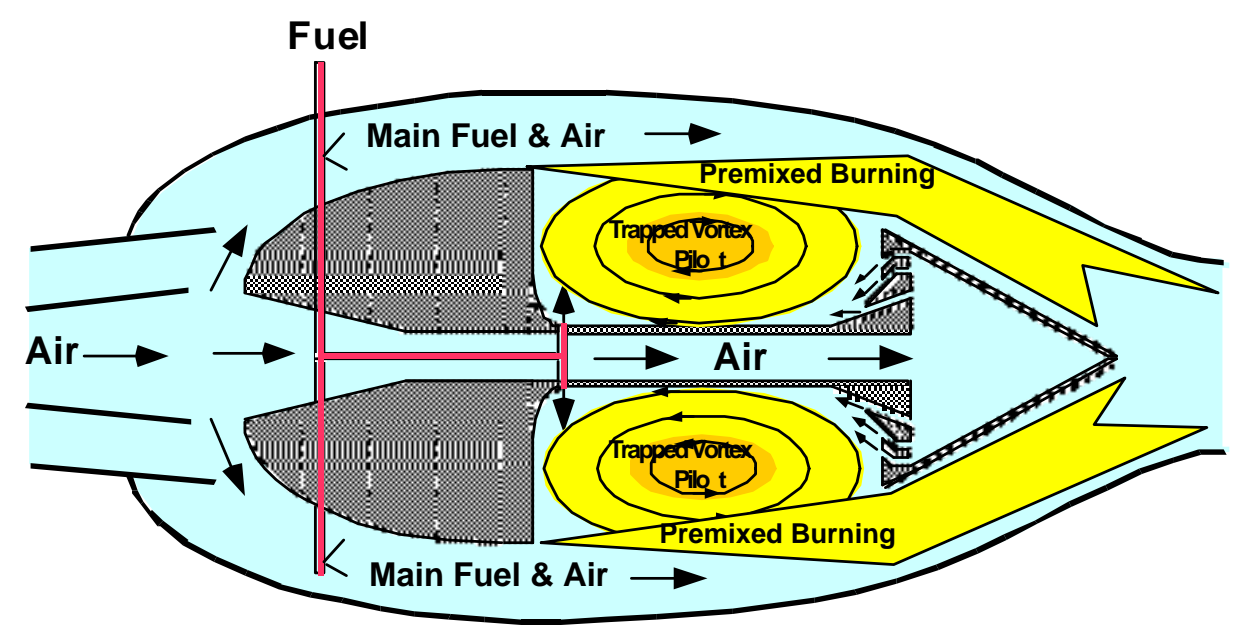

Figure 10. Ramgen advanced vortex combustor.

The AVC appears to have the potential to achieve low NOx levels within a smaller dimensional envelope and may be able to offer drop-in solutions without the need to modify the casing.

The AVC is a unique lean pre-mix concept capable of handling the high velocity through-flow, a phenomenon associated with hydrogen-rich fuels. The technology has proven to be very stable and exhibits both low pressure drop and low acoustic coupling throughout its operating range. High hydrogen content fuels present a particular problem in that the flame speed of the hydrogen is approximately six times that of natural gas. To prevent flashback, the through flow velocity needs to be greater than the flame speed, but this creates problems in establishing and maintaining the swirlstabilized effect. This problem is compounded in lean pre-mix designs since flashback of the flame into the fuel injector (cf. Figure 10) will cause severe damage to the hardware and potential engine failure. As a result of these factors there are currently no lean pre-mix gas turbines in operation anywhere in the industry on high hydrogen synthetic gas (syngas) fuel.

In contrast to conventional combustion systems, which rely on swirl stabilization, the AVC employs cavities to stabilize the flame. Much of the literature on cavity flows examines the flow field dynamics established by the cavities, as demonstrated in aircraft wheel wells, bomb bay doors and other external cavity structures. Cavities have also been studied as a means of cooling and reducing drag on projectiles, for scramjets and for waste incineration.

The actual stabilization mechanism facilitated by the AVC is relatively simple. A conventional bluff or fore body is located upstream of a smaller 
bluff body - commonly referred to as an aft body. The flow issuing from around the first bluff body separates as normal, but instead of developing shear layer instabilities, which in most circumstances is the prime mechanism for initiating blowout, the alternating array of vortices are conveniently trapped or locked between the two bodies.

In an AVC concept (Figure 11) the re-circulation of hot products into the main fuel-air mixture is accomplished by incorporating two critical features. First, a stable recirculation zone must be generated adjacent to the main fuel-air flow. If the vortex region, or cavity region, is designed properly, the vortex will be stable and no vortex shedding will occur. This stable vortex is generally used as a source of heat, or hot products of combustion.

The second critical design feature involves transporting and mixing the hot combustion products from the vortex, or cavity, region into the main flow. This is accomplished by using wake regions generated by bodies immersed in the main flow. This approach ignites the incoming fuel-air mixture by lateral mixing, instead of a back-mixing process. By using geometric features to ignite the incoming fuel-air mixture, instead of pure aerodynamic features, the AVC concept has the potential to be less sensitive to instabilities and process upsets. This is particularly important near the lean flame extinction limit, where small perturbations in the flow can lead to flame extinction.

The very stable, yet more energetic, primary/ core flame zone is now very resistant to external flow field perturbations, extending the lean and rich blowout limits relative to its simple bluff body counterpart. Early research has demonstrated that the AVC configuration can withstand through-put velocities near Mach 1. Figure 12 shows a CFD simulation of AVC.

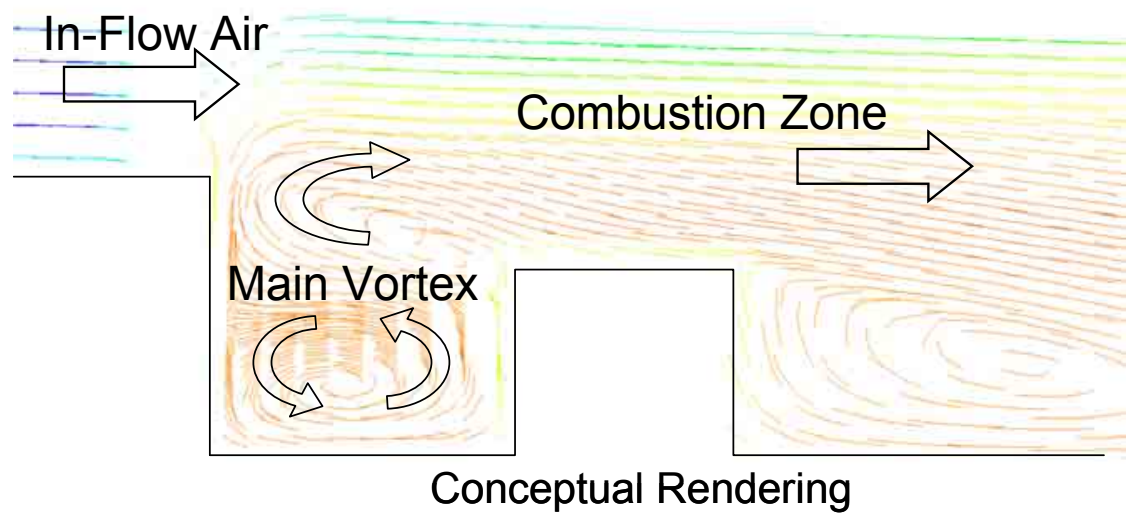

Figure 11. Concept of advanced vortex combustion. 

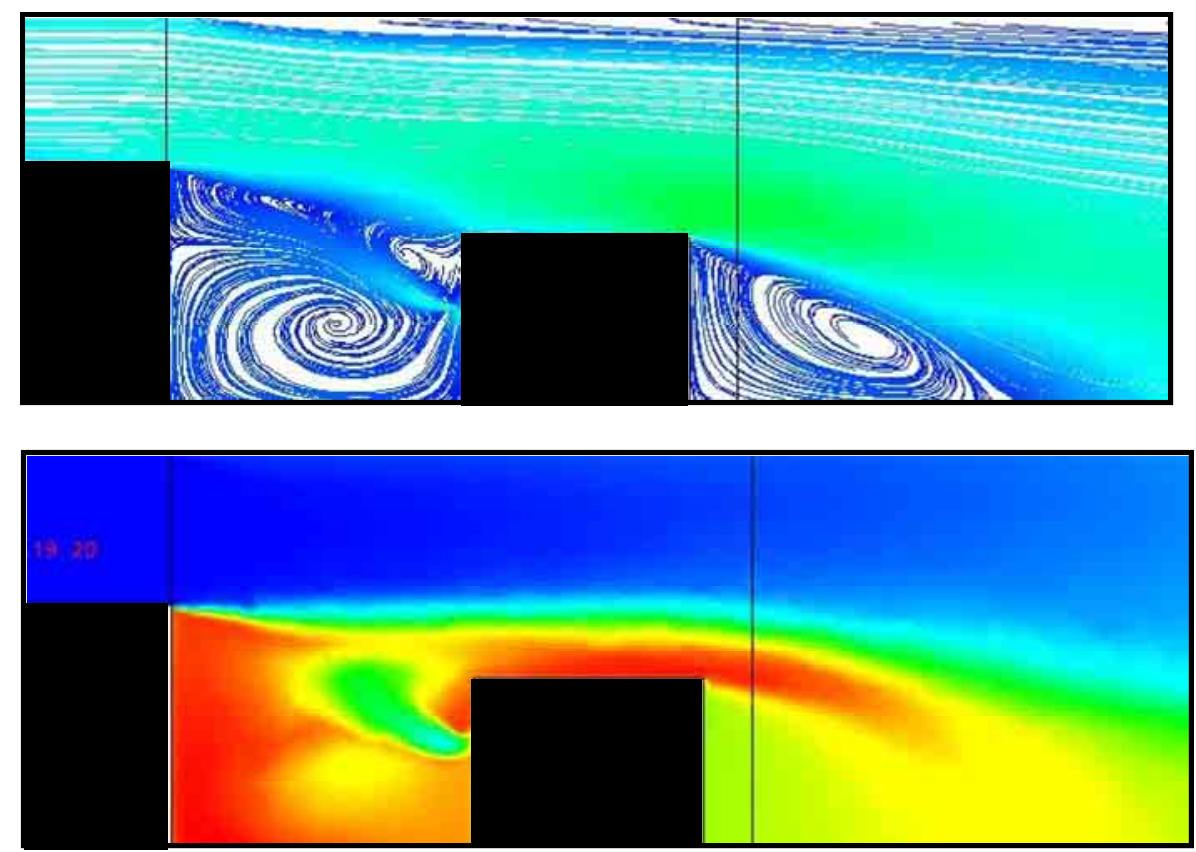

Figure 12. CFD simulation of advanced vortex combustion.

This system configuration also has greater flame holding surface area and hence will facilitate the more compact primary/core flame zone essential to promoting high combustion efficiency and reduced $\mathrm{CO}$ emissions.

\subsection{Technology Development Programs and Status}

The stationary application of the ramjet technology was successfully demonstrated for the first time in early 1999 at a test site in Tacoma, WA. The proof-of-concept test "rig" was in fact, an integrated, pre-prototype Ramgen 10MW Engine designed for electric power generation. The design and test results attracted considerable attention from the U.S. Department of Energy (DOE), which then sent scientific teams to assess the technology and the test results. The scientists' consistently positive assessments have since led the DOE to become a critical partner for Ramgen, both in terms of technical assistance and funding.

This pre-prototype Ramgen Engine operated through early 2001, by which time the Company had secured the data supporting further development of its technology. A high level of funding was needed to overcome the challenges of operating a Ramgen engine with fully integrated compression, combustion, and nozzle stages. The collapse of the private and public new energy sector equity markets in the summer and fall of 2001 effectively prevented the Company from securing the funding it required under the plan it was then pursuing. In early 2002, Ramgen began re-evaluating its 
options for commercializing its technologies in light of the harsh realities of the financial markets.

This process was accelerated in April 2002 when the DOE sponsored a formal Design Review that included Ramgen, DOE, NASA, and DOD scientists. This design review team confirmed the scientific validity of the Ramgen technology and developed an approach in which essential components of the overall technology were to be systematically completed in staged development phases. The shock wave-based compressor technology and the AVC technology were identified as the first two priorities. It was agreed that the first and most logical step was to concentrate on the compressor development. It was universally recognized that the advantages and value of Ramgen's technology could be achieved at a fraction of the investment capital, in a shorter time period, and with considerably less technical risk, by developing a compressor technology that could be operated as a standalone product or inserted as a component in larger and more highly integrated gas turbine and compressor designs. This commercialization path would take full advantage of the basic efficiency improvements achieved through ramjet shock wave compression.

\subsubsection{Rampressor Technology}

\subsubsection{Rampressor-1 Test Program}

Ramgen has successfully demonstrated the proof-of-concept of its Rampressor supersonic compressor in a 12-month testing program conducted at the Boeing Company's Nozzle Test Facility (NTF), located in Seattle, WA. Figure 13 shows the installation of the first Rampressor test rig (RP1). These test results, combined with our performance prediction tools, confirmed expectations and validated the preliminary performance and operational claims of the Rampressor technology.

The principal goal of this test was to demonstrate the successful adaptation of supersonic flight inlet designs and performance methods to the rotating environment found on a compressor disc. A 2.5:1 pressure ratio Rampressor rotor was extensively instrumented to measure the performance and operational characteristics of the test rotor. This relatively low pressure ratio was chosen to allow construction of a lower-cost one-piece machined rotor, while still generating meaningful test results. Analytical performance prediction tools were also constructed and refined with the experimental results. 


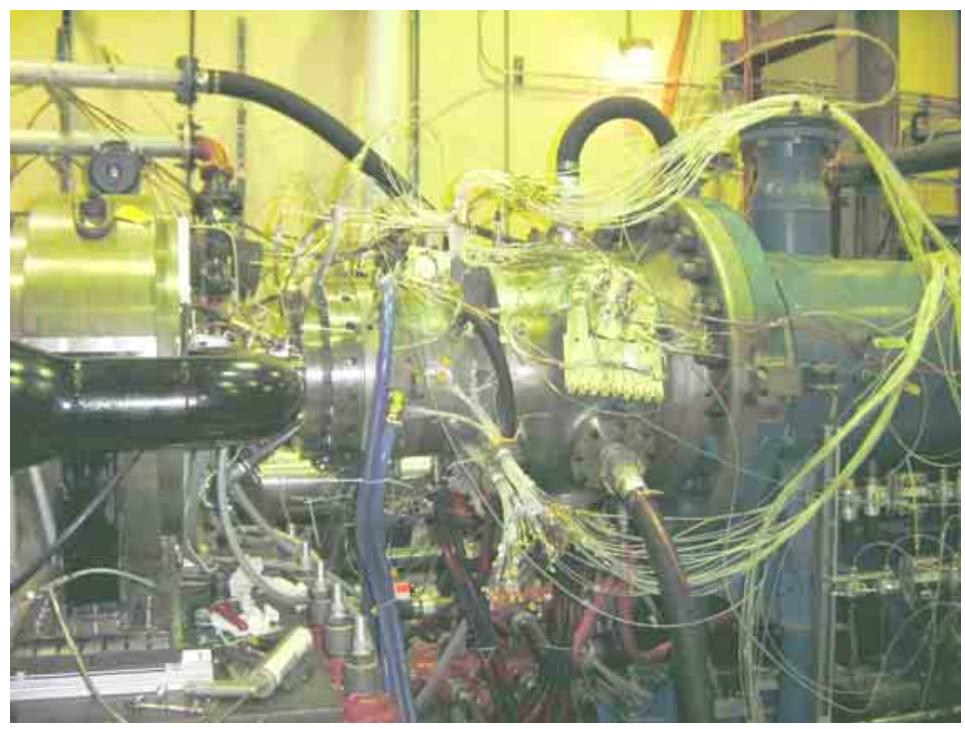

Figure 13. Rampressor-1 test rig installed in test cell.

Ramgen's team of scientists and engineers have extensive and varied experience in the development and testing of turbo compressors, and led the design of experiment and the build efforts on both the test article and the test apparatus. Ramgen's team of 20 people began the design of the RP- 1 test rig in September 2002, and completed extensive testing in April 2004. Approximately $\$ 1,800,000$ of equipment and facility expenses were required to complete the program.

Figure 14 shows the compressor rotor flowpath. This "unwrapped" view of the rotor, together with the pre-swirl cascade, was used to establish the rotor inflow field in the RP-1 test.

Table 2. Rotor inflow conditions.

\begin{tabular}{|c|c|c|c|}
\hline \begin{tabular}{|l} 
Rotor Speed \\
Shroud Radius \\
Rim Radius \\
Mass Flow
\end{tabular} & $\begin{array}{l}(\mathrm{rpm}) \\
(\mathrm{cm}) \\
(\mathrm{cm}) \\
(\mathrm{kg} / \mathrm{s})\end{array}$ & $\begin{array}{l}21,100 \\
14.51 \\
12.78 \\
1.43\end{array}$ & \\
\hline \multicolumn{2}{|c|}{ Reference Frame } & $\begin{array}{c}\text { Inertial } \\
\text { Reference } \\
\text { Frame }\end{array}$ & $\begin{array}{l}\text { Relative } \\
\text { Reference } \\
\text { Frame }\end{array}$ \\
\hline$T$ & (K) & 260 & 260 \\
\hline$\rho$ & $\left(\mathrm{kg} / \mathrm{m}^{3}\right)$ & 1.312 & 1.312 \\
\hline$M$ & (---) & 0.70 & 1.61 \\
\hline$v$ & $(\mathrm{~m} / \mathrm{s})$ & 225.9 & 225.9 \\
\hline$V_{\text {axial }}$ & $(\mathrm{m} / \mathrm{s})$ & 68.9 & 68.9 \\
\hline$v_{\text {tan }}$ & $(\mathrm{m} / \mathrm{s})$ & 215.1 & 215.1 \\
\hline$P_{t}$ & $(k P a)$ & 145.14 & 430.32 \\
\hline$T_{t}$ & (K) & 287 & 398 \\
\hline
\end{tabular}




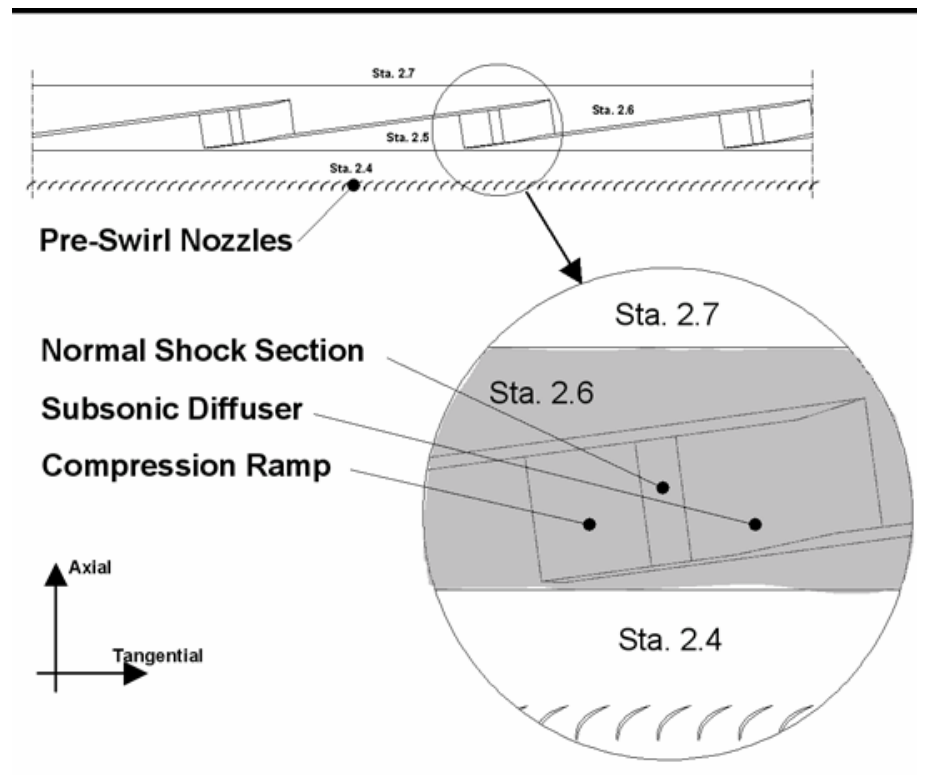

Figure 14. Rotor station numbering convention.

The design rotor speed in the RP-1 program was 21,100 rpm. Figure 14 defines the basic flow-path stations surrounding the rotor (shown in grey in the inset). The direction of rotation of the rim shown in Figure 14 is right to left. The combination of the rotor speed and the pre-swirl from the upstream cascade of pre-swirl nozzles create a rotor inflow that is supersonic relative to the moving rotor. Table 2 lists some details of the flowfield.

Ramgen conducted over 300 hours of spin testing during a 7-month test sequence at the Boeing Nozzle Test Facility (NTF). The NTF's world-class support ensured consistent and repeatable test results and provided additional oversight to Ramgen's industry-standard approach to conducting the test.

The experiment successfully demonstrated that supersonic flight inlet design methods and performance predictions can be adapted to a rotating disc and that the operational characteristics of the technology are similar in nature to conventional approaches. Figure 15 shows data from a typical day of testing. Throttling (changing the back-pressure on the compressor), rotational speed, and tip clearance were all varied to determine the impact of compressor performance and operating characteristics. 


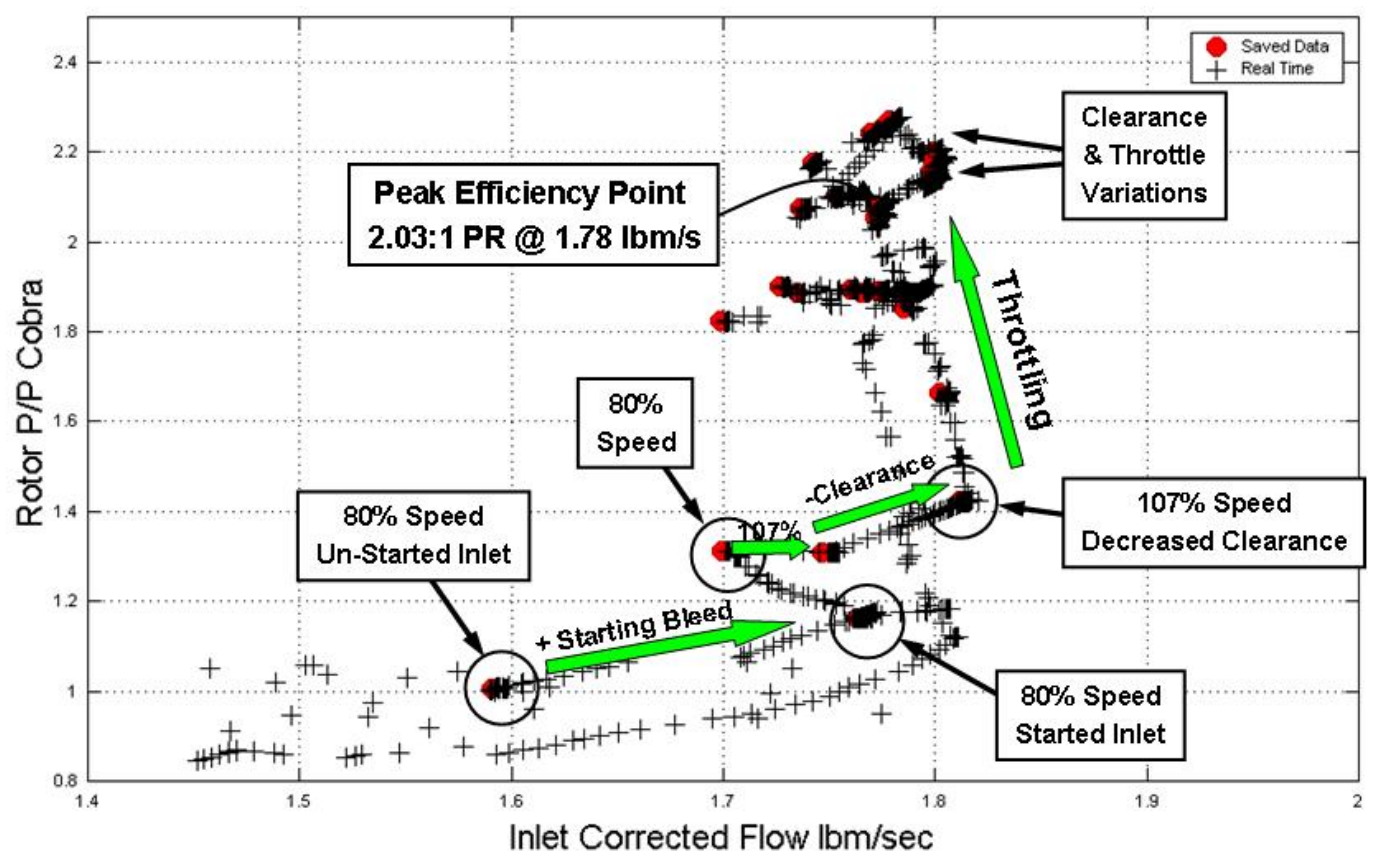

Figure 15. Effect of clearance, bleed, and throttling.

The data progression starts in the lower left corner of the figure and was obtained as the rotor accelerated to a specified test speed. At 80 percent speed, the compressor variables were adjusted to achieve supersonic flow - referred to as "starting" in supersonic inlet technology. When started, the compressor immediately moved up and to the right on the figure, as it was able to process more airflow when operating supersonically. The discharge pressure was raised by throttling the discharge, followed by a tip clearance adjustment. These variables were then varied as part of the test sequence to explore the range of efficiencies and the operating envelope.

Figure 16 shows the compressor characteristics at speeds ranging from 30 to 110 percent, and the expected decrease in mass flow with increasing pressure. These characteristics were generated with relatively tight tip clearances. The lower speed lines were extrapolated from limited data.

The "star" on Figure 16 corresponds to the peak adiabatic compression efficiency observed in the test program. This peak efficiency value was $\sim 83$ percent and was viewed as good performance, particularly considering that there had been minimal effort to optimize the flow-path efficiency. Further refinement of the flow-path geometry would have resulted in further increases. The efficiency of the rotor did not drop-off significantly with decreased speed and/ or flow. 


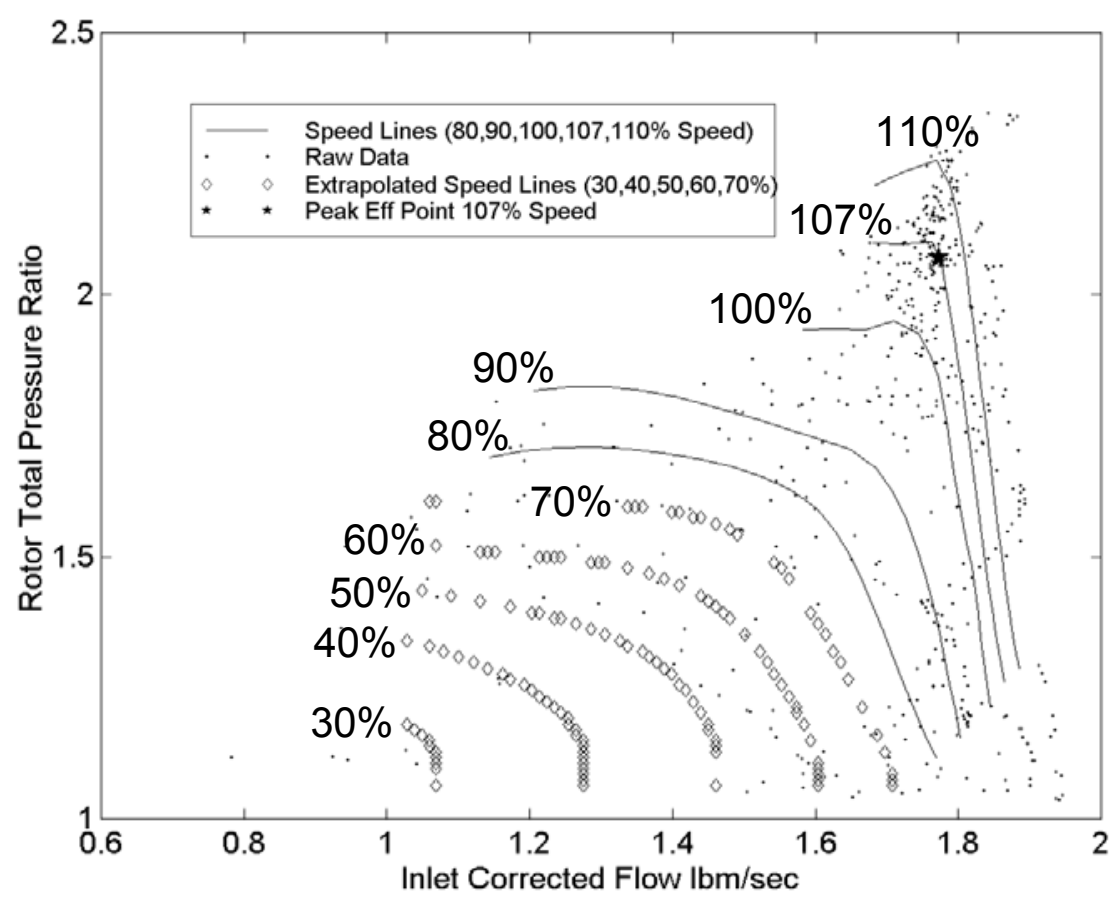

Figure 16. Compressor speed lines.

Several important discoveries were made during testing that advanced understanding of the Rampressor operating characteristics. Perhaps the most significant is that the compressor is self-aspirating. That is, it does not require an impeller or blower to feed air to the rotor. During the course of the test program the air supply system was disconnected to allow the compressor to draw air directly from the room to verify this behavior. Elimination of an impeller or blower stage significantly decreases the cost and complexity of the future Rampressor product.

An important measure of compressor stability is the resistance to "surge," or the tendency for flow to suddenly (often violently) reverse through the compressor. Although we did establish the surge line in test, we did not experience a sudden surge event as do conventional turbo compressors. The unique nature of the shock wave compression process and the rotor geometry led to a gradual and benign surge that was also easily corrected. This is a substantial improvement over traditional, highly loaded turbocompressors.

For clarity, the individual data points in this figure have been reduced to a series of solid lines representing measured speed lines and a series of hollow diamonds for extrapolated data; each series represents the behavior of the compressor at different rotational speed (referred to as a speed line). 
The RP-1 Test also confirmed that the Rampressor does maintain its efficiency across a range of airflow rates (Figure 17). This counteracts "conventional wisdom," which holds that such acoustically-based technologies can only operate at their design point. This is an important feature for any compressor design to load follow.

The peak efficiency achieved during this test was $\sim 82$ percent. There is a large assortment of techniques available to increase the efficiency level to that required for subsequent testing and as well as any commercial application. These techniques are a product of Ramgen's developing performance prediction tools and include, but are not limited to, improvements in basic flowpath geometry, rotor tip clearance, and bleed optimization.

Ramgen has compared the experimental data to the predicted performance, and overall, the data agreed well with predictions. Several data disparities were discovered as a direct result of the test data. The modeling code has been calibrated and is now considered reliable in predicting performance of the RP-1 compressor.

Ramgen has presented a comprehensive review of the test program results to the scientific staff of the Department of Energy, who have given their approval and continued support to the program.

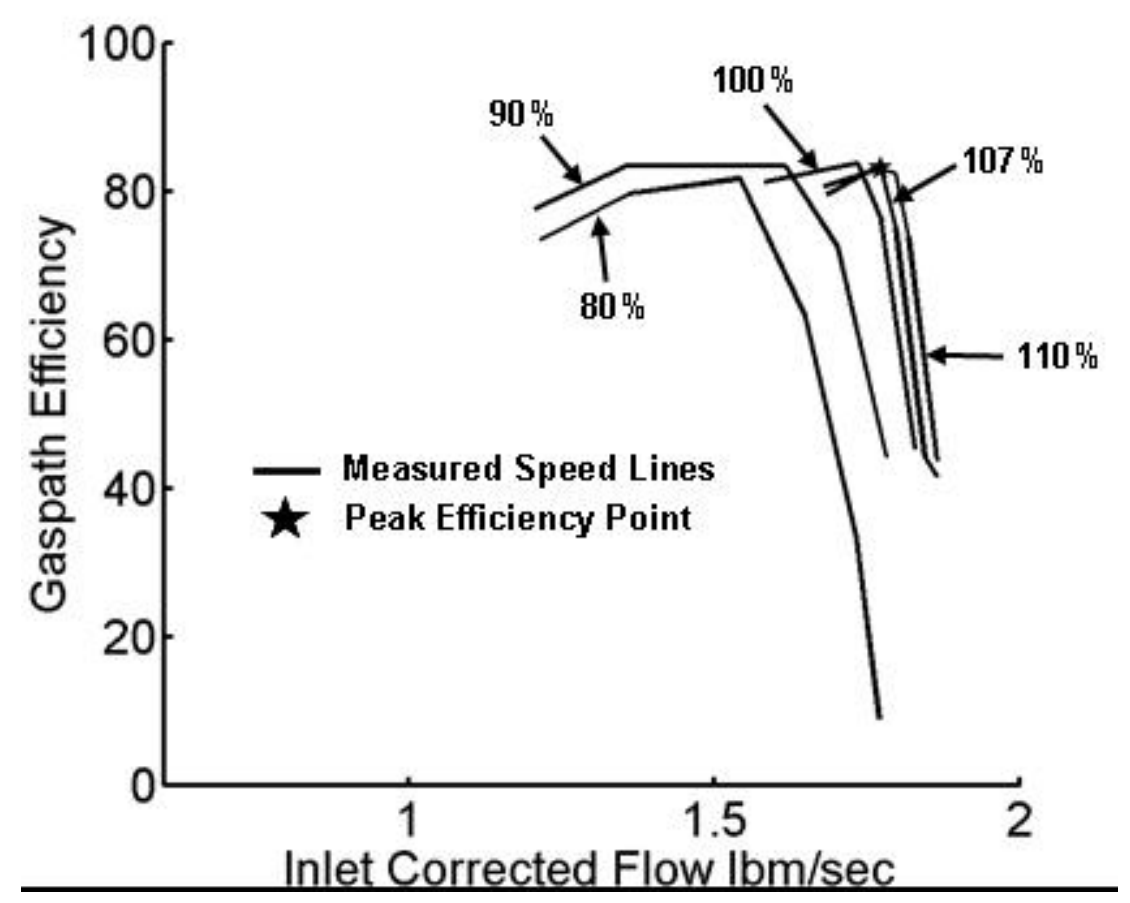

Figure 17. Rotor efficiency versus airflow. 


\subsubsection{Rampressor-2 Test Program}

As the RP-1 test concluded, Ramgen launched the Rampressor-2 (RP-2) test program with a goal of demonstrating supersonic rotor compression at higher pressure ratios. This test will again be overseen by Boeing's world-class Nozzle Test Facility in Seattle, WA. Approximately $\$ 2,000,000$ of equipment and facility expenses are projected for completing this test program. Figure 18 shows the RP- 2 rig design and installation schematic.

The RP-2 program represents a more sophisticated piece of equipment. Ramgen's team of 26 people began the design of the RP- 2 test rig in J anuary 2004 and was ready to test in December 2005. This highly professional and comprehensive effort includes: aerodynamic analysis and simulation, structural design and analysis, heat transfer and thermal analysis, rotor dynamics analysis, control and instrumentation design, system integration, fabrication, assembly and checkout. A new RP- 2 rotor with the best available aero flowpath was released to manufacturing in May 2005, and testing began in early December 2005 with the Pre-swirl Nozzle calibration testing.

In the meantime, Ramgen has continued to pursue its aerodynamic optimization efforts. This has resulted in a steady stream of performance improvement projections, as Ramgen developed a world-class set of CFD capabilities. The Company has made considerable investments in hardware and software to support these efforts, but most of the improvements are a direct result of Ramgen's efforts in applying these tools to the particular application.

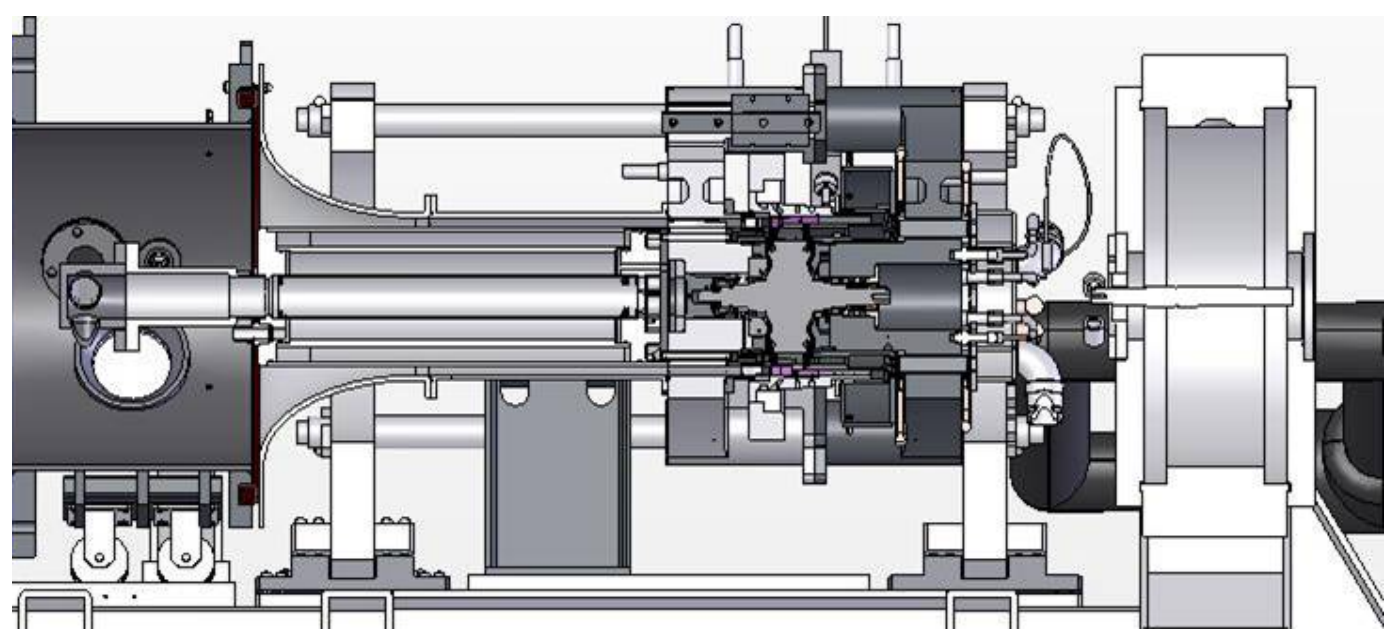

Figure 18. RP-2 test rig installed in test cell. 
Ramgen will continue with a follow-on test of the RP- 2 rotor in an effort to validate its CFD tools at a pressure ratio of 8:1. With the completion of this test, Ramgen should have sufficient information to evaluate the full performance potential of a supersonic compressor stage with a pressure ratio anticipated to be of commercial interest. The most important objective of the RP-2 test is to validate the rotor design and analysis tools with experimental test data.

Figure 19 shows the unwrapped view of the RP- 2 rotor with the pre-swirl nozzles upstream. The RP-2 requires far fewer pre-swirl nozzles than RP-1. Table 3 lists the flow field for RP-2. The design rotor speed is $\sim 41,000$ revolutions per minute (RPM). The flow path is designed to operate at a Mach number of 2.4, which is achieved through a combination of pre-swirl flow and rotor RPM.

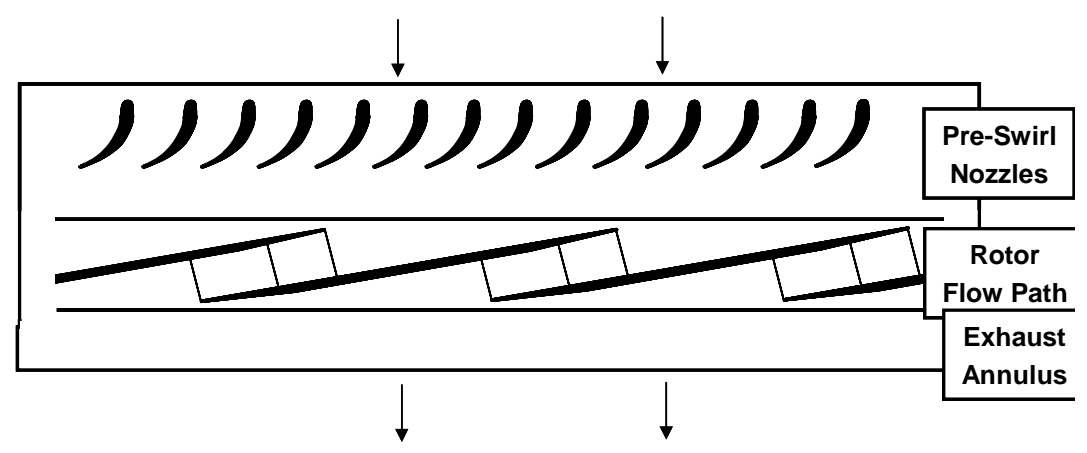

Figure 19. RP-2 rotor configuration.

Table 3. RP-2 rotor inflow conditions.

\begin{tabular}{|c|c|c|}
\hline Rotor Speed (rpm) & 41439 & \\
\hline Shroud Radius (inches) & 4.78 & \\
\hline Rim Radius (inches) & 5.45 & \\
\hline Mass Flow (Ib/s) & 2.68 & \\
\hline Property & $\begin{array}{c}\text { Inertial Reference } \\
\text { Frame }\end{array}$ & $\begin{array}{c}\text { Relative Reference } \\
\text { Frame }\end{array}$ \\
\hline$(\mathrm{F})$ & 5 & 5 \\
\hline $\begin{array}{ll}\rho & \left(\mathrm{lb} / \mathrm{ft}^{3}\right)\end{array}$ & 0.075 & 0.075 \\
\hline M & 0.694 & 2.4 \\
\hline $\mathrm{V} \quad(\mathrm{ft} / \mathrm{s})$ & 733.8 & 733.8 \\
\hline $\operatorname{Vaxial}(\mathrm{ft} / \mathrm{s})$ & 305.3 & 305.3 \\
\hline $\operatorname{Vtan}(\mathrm{ft} / \mathrm{s})$ & 667.2 & 667.2 \\
\hline $\begin{array}{ll}\mathrm{Pt} & \text { (psia) }\end{array}$ & 14.4 & 146.03 \\
\hline $\mathrm{Tt} \quad(\mathrm{F})$ & 50 & 534.6 \\
\hline
\end{tabular}

\subsubsection{Results}

Pre-swirl nozzle (PSN) testing was completed in J anuary 2006. The test objectives included comparing experimental test data to computational 
fluid dynamic (CFD) modeling, and defining the characteristics of the flow entering the RP- 2 rotor. Figure 20 shows a sample CFD result for the PSN. Figure 21 shows the comparison between PSN CFD predictions and the experimental data.

In general, the comparison indicates that the PSN behaves similar to the design intent. Differences between the experiment and design intent are present in some regions of the PSN blades. The rotor CFD predictions will be assessed with the actual PSN experimental data results.

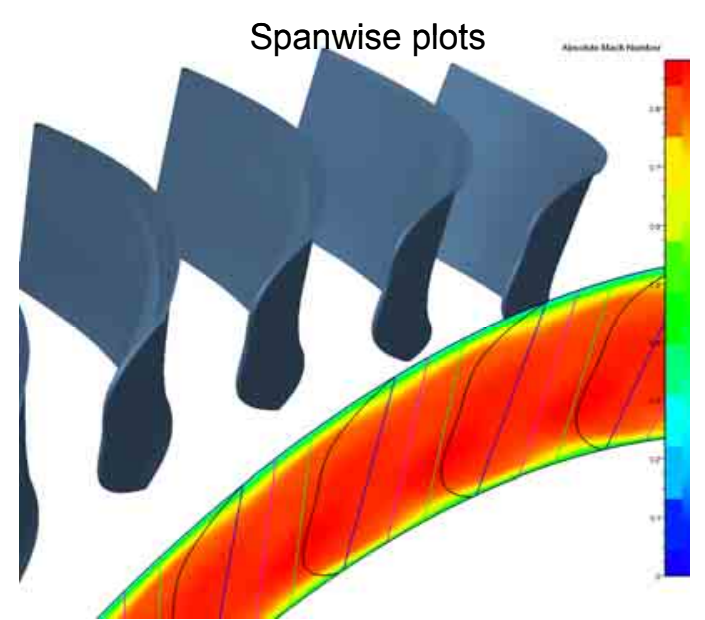

Figure 20. PSN CFD result.

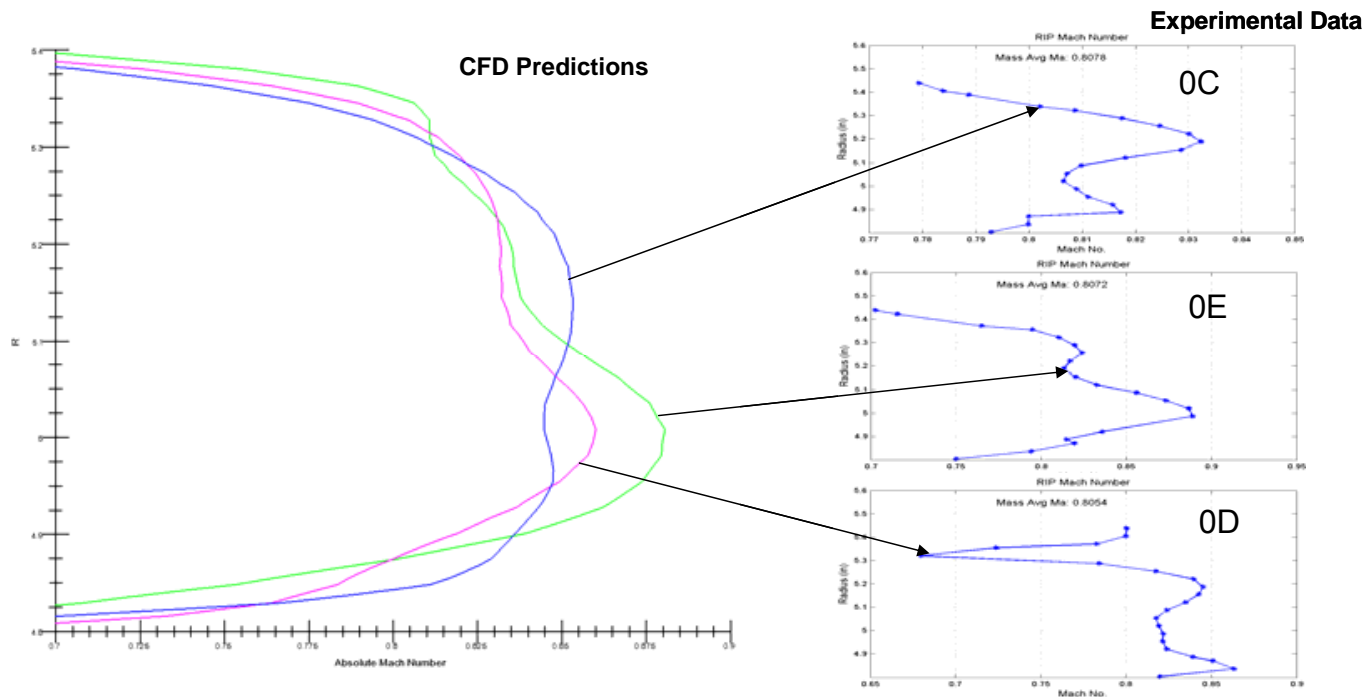

Figure 21. RP-2 PSN CFD predictions vs. experimental data.

The performance of the RP-2 rotor has been predicted using the "as-built" RP-2 configuration. As many minute rotor flowpath features as possible have been modeled in CFD. The modeled features include:

- the PSN flow data from experimentally modified CFD

- range of tip clearances from 0.001 " to 0.010 " 
- bleed flow ranges

- temperature levels and temperature gradients.

The CFD models for the detailed 3D analysis include some 22 million cells to represent the flowpath. The performance predictions include:

- pressure ratio

- flowpath adiabatic efficiency

- bleed rates.

Test conditions for the RP-2 rig will include a compressor map of mass flow and pressure ratio operating points. The "surge line" points and characteristics will be explored. The effect of tip clearance on performance will be investigated, as well as bleed levels required for starting and maximum efficiency. We also expect to investigate the effects of humidity on the operating characteristics of the rig. In addition to the "as-built" configuration being tested on the RP-2 test rig, Ramgen has performed extensive CFD modeling of many different flow-path configurations.

As an example, Figure 22 shows the results from a CFD analysis of a flowpath intended for operation with an inflow Mach number of 2.4. The image shows the Mach number profiles in three planes taken through the supersonic rotor flow-path. The oblique shock pattern created by the compression ramp, the oblique shock wave reflected from the stationary case and the normal shock generated in the throat region of the flow-path upstream of the subsonic diffuser are all apparent in this image. The flowpath shown in Figure 22 was designed for an average inflow Mach number of 2.4 and the simulation shown here produced a pressure ratio across the supersonic rotor of 13:1 with an adiabatic efficiency of 89.4 percent.

\subsubsection{AVC Technology}

The Ramgen AVC concept has been in development since 2000 with the first rig testing completed in 2002 at the General Applied Sciences Laboratory in New York. All the testing was performed at elevated pressures (18 $\mathrm{atm}$ ) and inlet temperatures (820 F) and at lean conditions representative of industrial power generation gas turbines. The tests were conducted on premixed methane fuel and air. The results indicated extremely stable flame conditions with corresponding combustion efficiencies above 99.9 percent and NOx/ CO/ Unburned hydrocarbon (UHC) levels as low as 9/9/0 ppmv. 


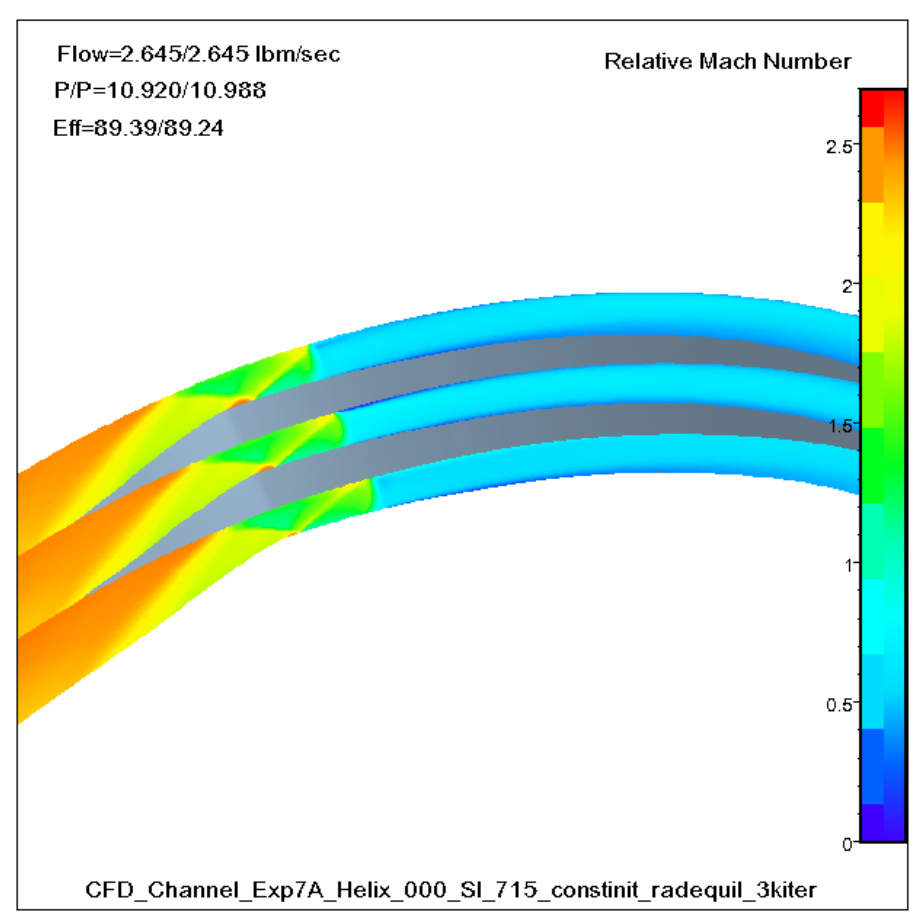

Figure 22. Mach profiles in candidate flow-path design.

The promising test results in 2002 led to a second phase in 2004 of testing funded by the California Energy Commission's Private Investment in Energy Resources Program (PIER) and in part by the DOE National Energy Technology Laboratory (NETL) Turbines Program. The objective of the test was to improve the design tested in 2002 and achieve ultra-low NOx emissions below 3 ppmv. All testing was performed on natural gas at combustor inlet conditions at pressures up to $10 \mathrm{~atm}$ and temperatures up to $620^{\circ} \mathrm{F}$ (Figure 23).

The AVC tests demonstrated less than 3 ppmv NOx and 20 ppmv CO at industrial gas turbine conditions, without the need for a stabilizing catalyst or exhaust after-treatment. These test results indicate the potential to achieve unprecedented emissions levels of 1 ppmv NOx and 9 ppmv CO at industrial gas turbine operating conditions. At these levels, the AVC technology offers the potential to meet the newest stringent state (CA, TX, NY) emission requirements without costly exhaust after-treatment.

In addition to the remarkable emissions results, NETL researchers have noted that the Ramgen's AVC concept is more stable than any comparable technology tested in their laboratory, exceeding expected stability performance. Flame instabilities and pressure oscillations have become more difficult to control as gas turbine manufacturers exhaust their technology options to meet continuing requirements for lower NOx emissions. 


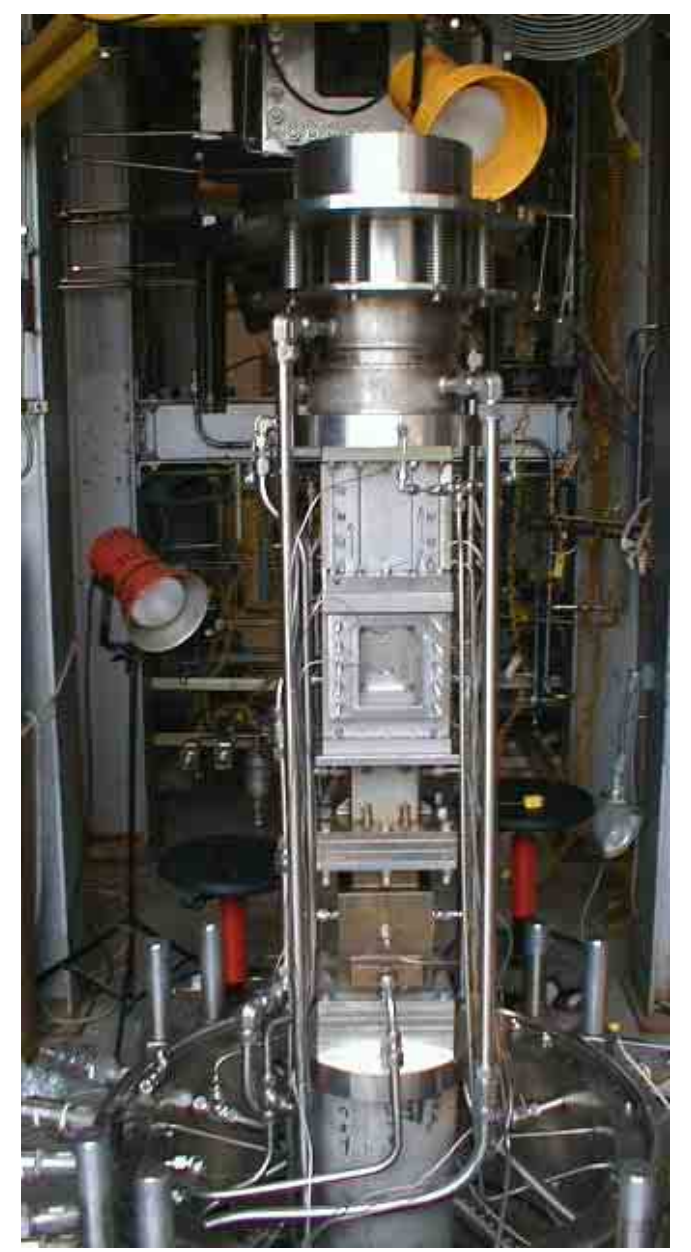

Figure 23. DOE NETL combustion facility.

Ramgen is taking the position that the AVC technology is fundamentally different from the industrially accepted swirl-stabilized combustors and that it has the potential to achieve unprecedented flame stability as well as low NOx emissions. The potential use of the AVC technology with industrial gas turbines can best be described as follows by researchers at the DOE NETL in Morgantown, WV, in the spring 2005 issue of Clean Coal Today:

Researchers at NETL's high pressure test combustion facility, in collaboration with Ramgen Systems, have completed testing of a fuel-flexible Advanced Vortex Combustion (AVC) concept that can achieve NOx emissions of less than 3 ppmv, and combustion efficiencies of over 99 percent. The Advanced Vortex Combustor is dynamically stable over a wide range of operating conditions, which makes this approach significantly more attractive than other lean premixed combustion approaches. In addition, the pressure drop associated with this combustion approach is significantly lower than a conventional gas turbine combustor, which translates 
into an improvement in the overall cycle efficiency. The relatively high velocities and low pressure drops achievable with this technology make the AVC approach an attractive alternative for hydrogen fuel applications.

The AVC technology has demonstrated four characteristics that make it a promising approach toward improving the capability and reliability of gas turbines:

1. Low Emissions. The potential of AVC technology to deliver less than 3 ppmv NOx emissions at dynamically stable engine conditions will eliminate the costly and highly toxic selective catalytic reduction (SCR) exhaust gas cleanup systems (see Figure 24). This system configuration also has greater flame holding surface area and hence will facilitate the more compact primary/ core flame zone essential to promoting high combustion efficiency and reduced $\mathrm{CO}$ emissions.

2. Low Combustion Pressure Drop. The Ramgen AVC design has been demonstrated to operate at half the pressure drop of a standard industrial gas turbine (see Figure 25). This feature translates into an increase of overall turbine efficiency and a decrease in operation fuel costs. Conventional industrial and marine gas turbines operating at pressure ratios of 10-14:1 are normally designed for pressure drops of 4 to 5 percent. A one percent point improvement in pressure drop will yield approximately one half point improvement in engine efficiency. The use of an AVC type combustor has the potential to improve existing engine efficiency by one full percentage point.

3. Low Acoustic Signature. The most significant feature of the Ramgen AVC design is the demonstration of extremely low acoustic levels. This feature promises to widen the range of engine operating conditions without compromising emissions and damage to hardware due to uncontrolled vibration. The very stable, yet more intense, primary/ core flame zone is now very resistant to external flow field perturbations, extending the lean and rich blowout limits relative to its simple bluff body counterpart.

The CO emission (primary y-axis) and the root mean square (RMS) pressure (secondary y-axis) as a function of NOx emissions in Figure 26 are for two main equivalence ratio sweeps. The RMS pressure values remain very low with increasing $\mathrm{CO}$, and for the majority of the operating range the RMS pressure is about an order of magnitude less than 
the typically accepted industrial level of 1.5 percent RMS. These RMS pressure levels are representative of the levels observed for all of the testing. In summary, no significant pressure oscillations were observed during the testing of the AVC.

4. High Throughput Velocity. The AVC approach will potentially play a critical role in the advancement of future Integrated Gasification Combined Cycle (IGCC) power plants that will require gas turbines to burn hydrogen enriched fuels at extremely low NOx emissions. Hydrogen burns at six times the rate of natural gas and will necessitate a high throughput velocity to prevent flashback.

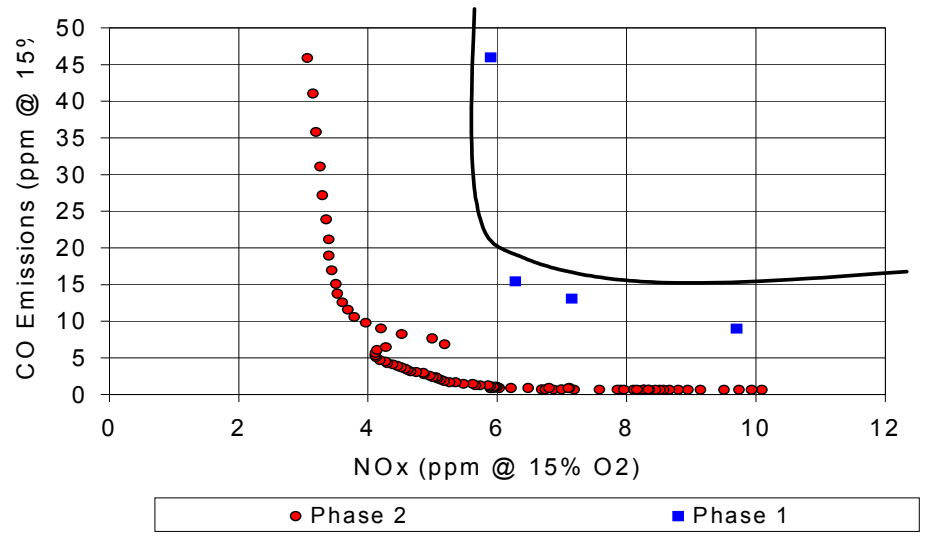

Figure 24. Ramgen AVC extremely low NOx test results.

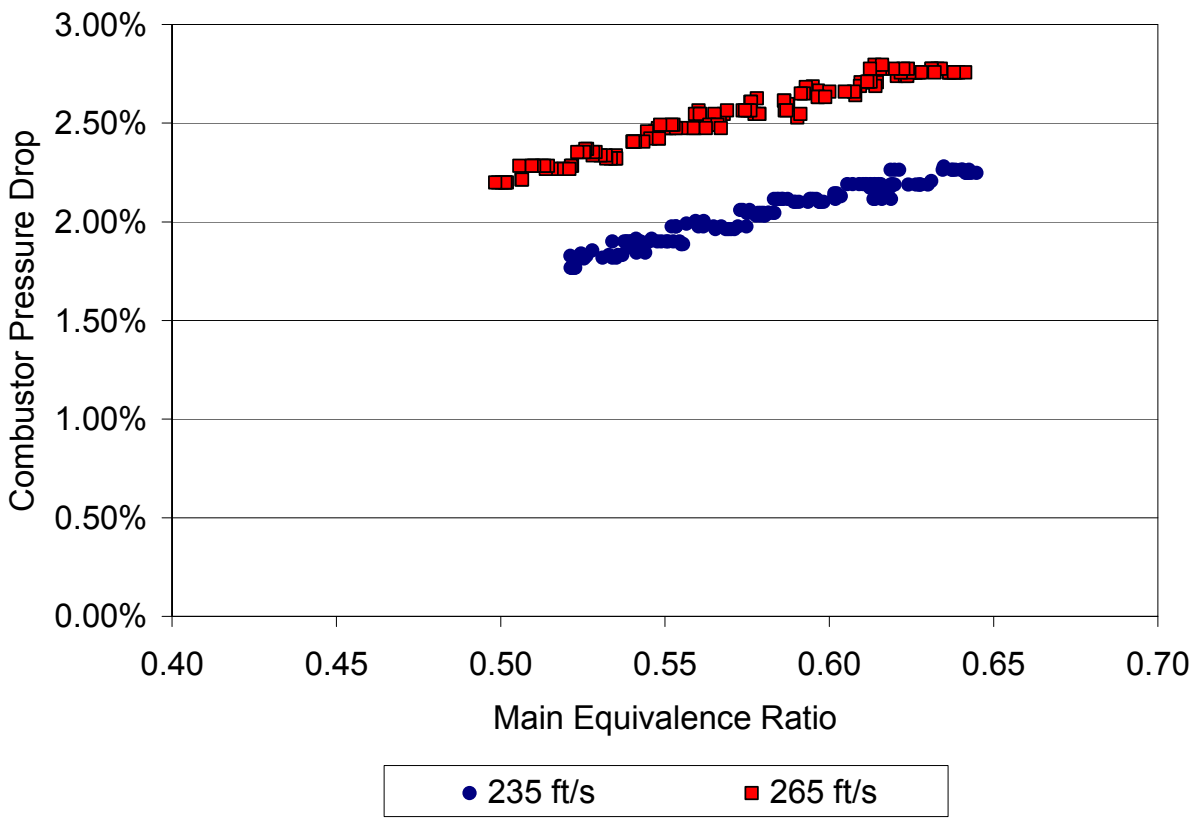

Figure 25. Combustion pressure drop. 


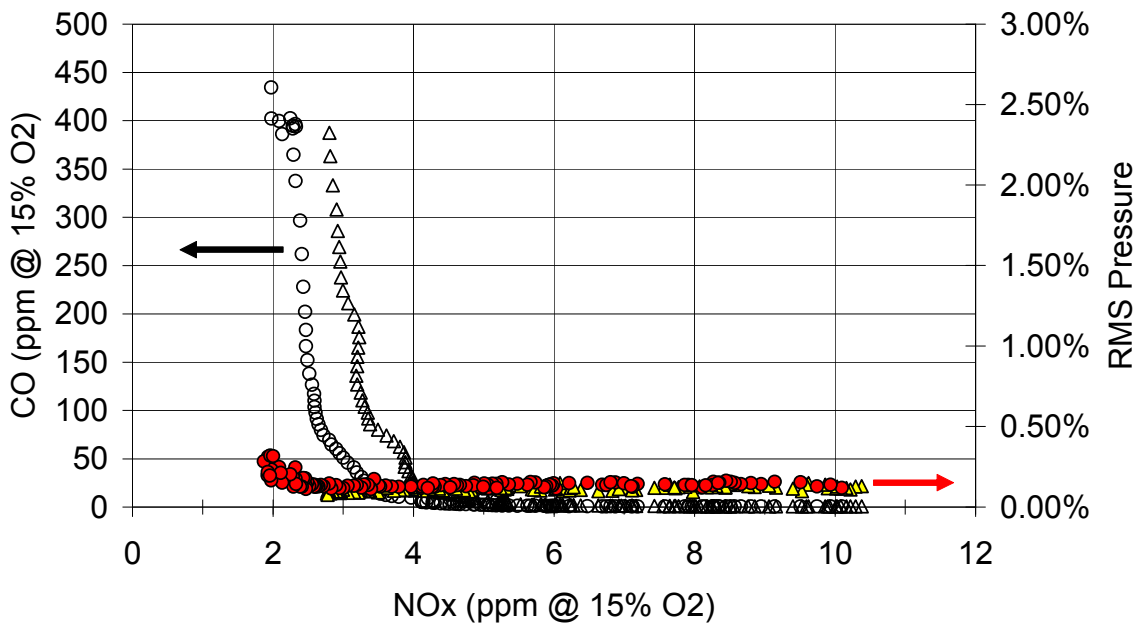

Figure 26. Low RMS pressure level. 


\section{Applied Research - Military Applications}

\subsection{Technology and Application Development Roadmap}

Ramgen's strategic focus is the development and commercialization of application-specific products, based on its large body of proprietary background information and know-how.

The three basic component technologies can be configured as products or components either separately or in combination, to create a variety of these application specific products (Figure 27). The Technology Roadmap indicates the Ramgen Technology platform, the planned configurations and the planned program sponsors as of this date.

All three of the Ramgen's technology platforms are directly applicable to Brayton Cycle designs. The Brayton Cycle represents the underlying thermodynamic principles embodied in all forms of "gas turbine" designs, and includes compression, heat addition, and expansion components as represented in the NASA Temperature-Entropy diagram (Figure 28).

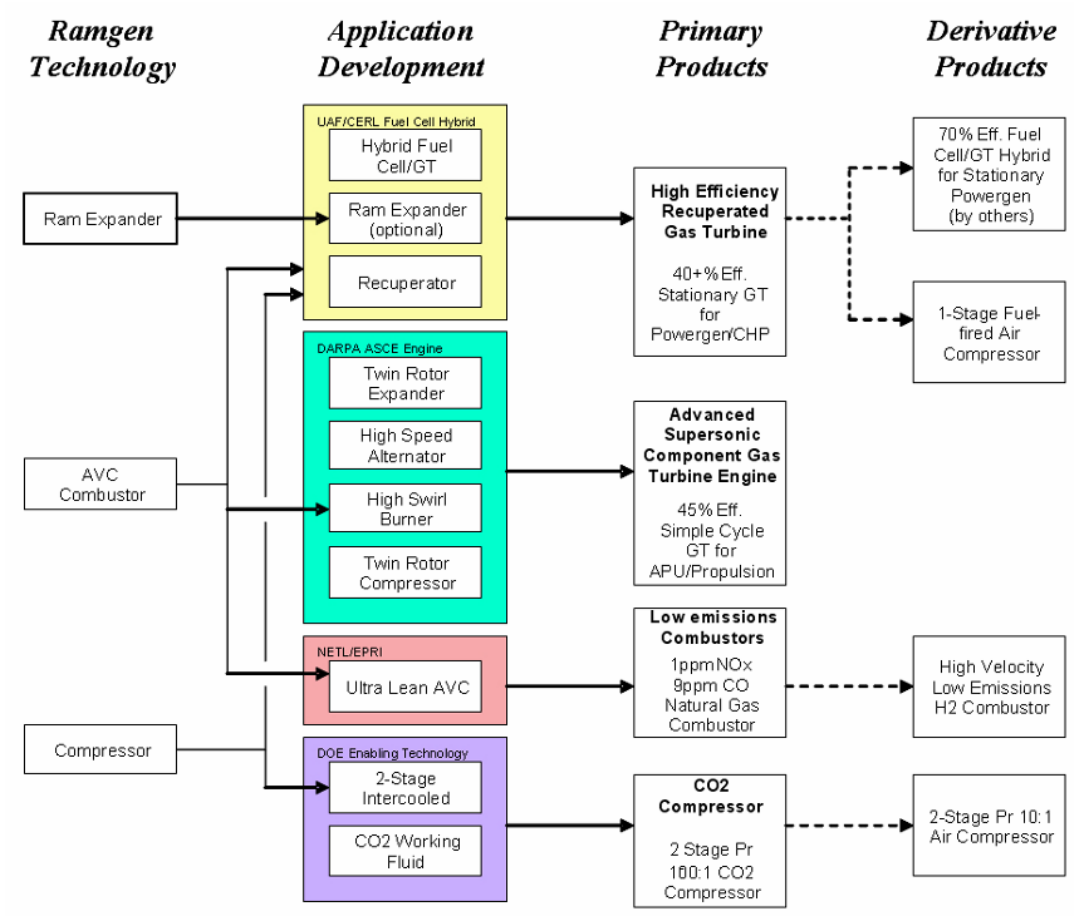

Figure 27. Ramgen technology and application development roadmap. 


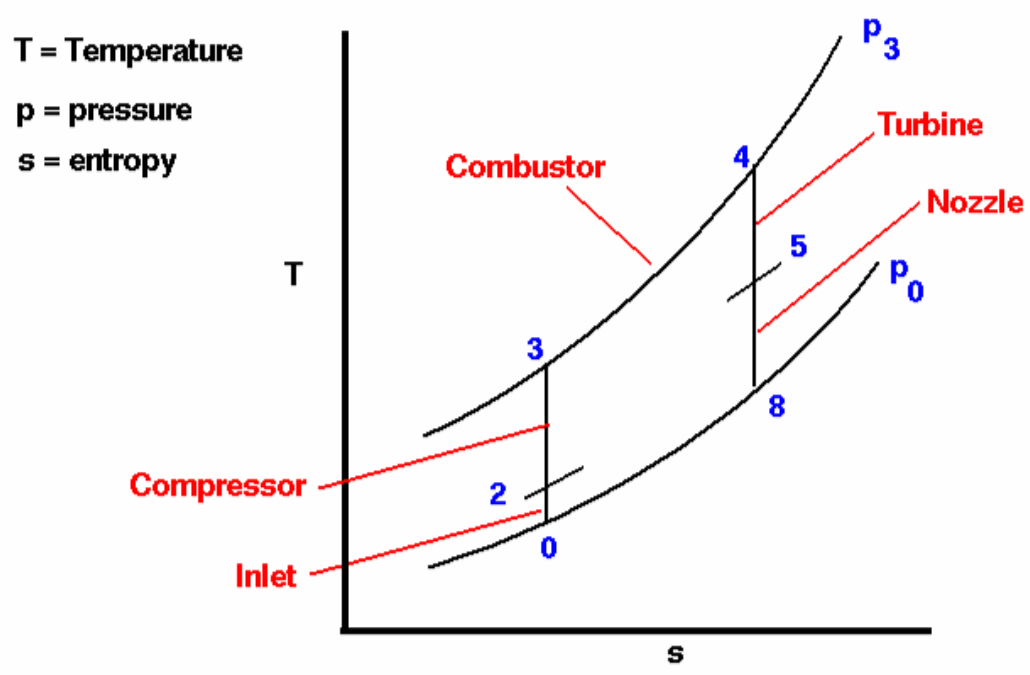

Figure 28. T-S Diagram of Brayton cycle.

Reduced to practice, these components can be configured into a typical gas turbine engine (Figure 29). Ramgen's technology platforms can be embodied within a gas turbine, either individually as components or as a group, in addition to their own discrete product applications. Ramgen is currently focused on four high value product opportunities:

1. A high efficiency, recuperated gas turbine engine for smaller stationary applications and fuel cell hybrid configurations

2. An ASCE for military, industrial and marine power generation applications

3. Low-emissions AVC combustor

4. $\mathrm{CO}_{2}$ compressor for large-scale carbon capture and storage systems.

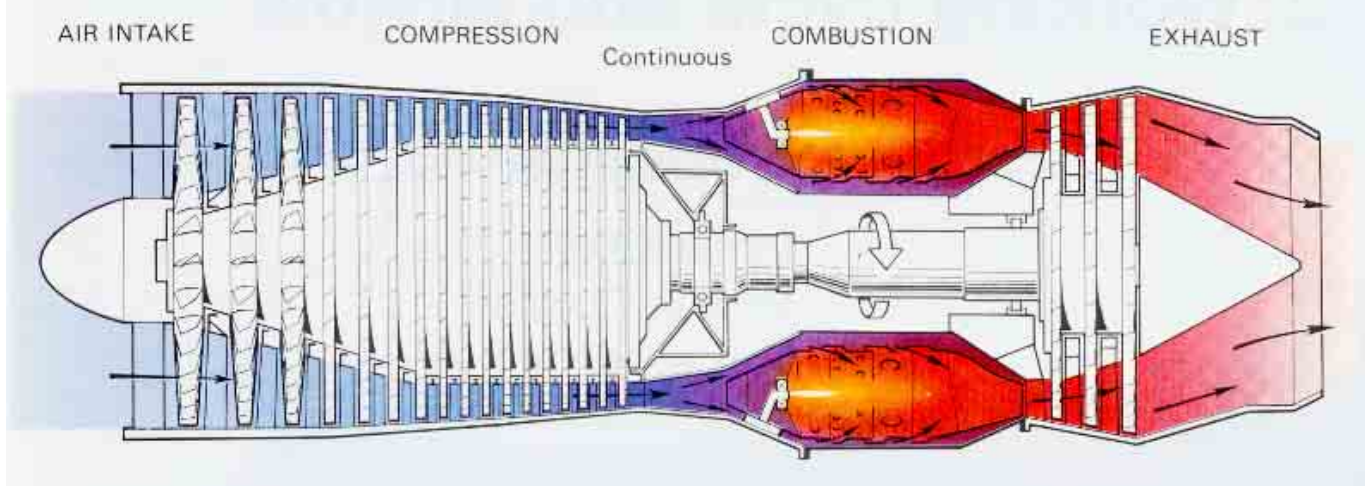

Figure 29. Typical gas turbine engine. 


\subsection{Compression Opportunities}

Ramgen's compression technology can be used across a wide range of current compressor applications as both a product and a component (Figure 30). The four principal competitive advantages of shock compression when compared to existing compressor technologies are:

- It can achieve exceptionally higher compression efficiency.

- It is capable of producing very high single stage compression ratios.

- Its simplicity and size make it less expensive to manufacture.

- It offers the opportunity for significant waste heat recovery.

Current large compressor markets are dominated by centrifugal and axial designs. Centrifugal compressors are typically applied at ratios of 1.8 to 2.8 per stage with adiabatic efficiencies that range from 82 to 85 percent. Centrifugal designs can be applied up to pressure ratios of 4.0 per stage in 17-4PH stainless steel with adiabatic efficiencies of 82 to 83 percent, and up to a pressure ratio of 4.5 per stage in titanium with adiabatic efficiencies of 75 to 80 percent. Although single stage axial efficiencies can be greater than 90 percent, their pressure ratios are limited to only 1.2 to 1.4 per stage. This limits them to very large applications where the cost of up to 20 blade rows can be justified. In contrast, Ramgen's shock compression has the potential to develop compression ratios from 2.0 to 15.0 per stage with an associated adiabatic efficiency of 85-90 percent.

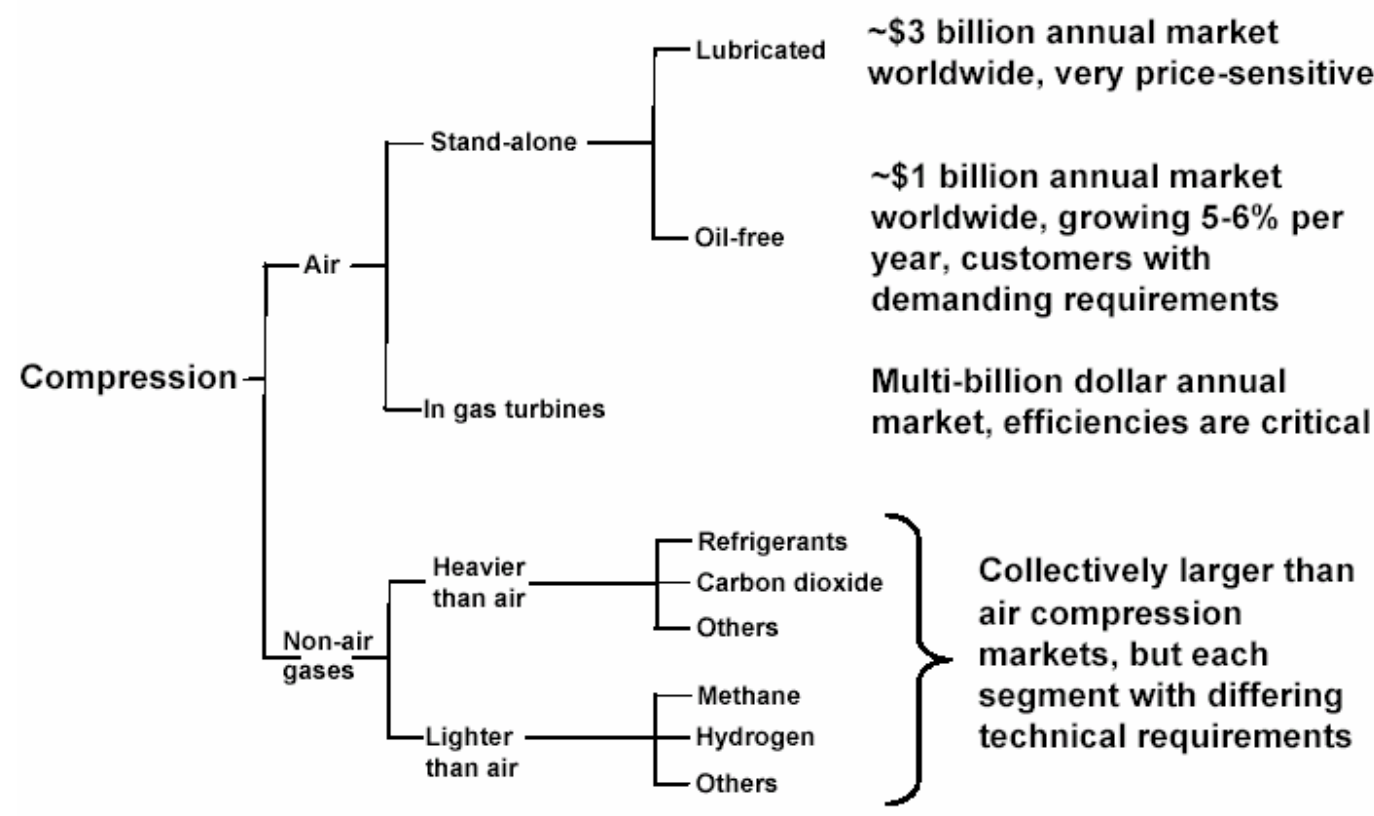

Figure 30. Compression market overview. 
Reduced to practice, the Ramgen compression technology can "de-stage" comparable industry product offerings, greatly simplifying a design and reducing Ramgen's costs versus competition, and do so without sacrificing efficiency.

The Ramgen technology is also not limited by inlet Mach number constraints, as are the other turbo-compressor technologies. This is particularly important in compressing heavy molecular weight gases such as $\mathrm{CO}_{2}$, and provides Ramgen with an exceptional, unique competitive advantage.

\subsection{Recuperated Gas Turbine Engine}

The commercial interest in this general class of products currently offered has reduced substantially in recent years due to the shifting dynamics of Distributed Power Generation concepts. This is largely a product of regulatory uncertainty, volatile and rising natural gas prices and the continued electric utility resistance to on-site generation, which is still seen by many utilities as a competitive threat.

These are not new phenomena, but their impact has been magnified by the general inability of the equipment developers to meet their original claimed efficiency and selling price targets. Today's microturbine is nominally a 28 percent LHV net electric efficiency device and it appears that, as currently designed, the best these units can achieve is 34 percent. This limits their practical application to CHP projects, and as a result, also limits the number of units sold.

One of the problems is that these recuperated simple cycle designs cannot use the full turbine rotor inlet temperature (TRIT) potential because of material cost vs. life limitations on the downstream recuperator. Turbine rotor inlet and exhaust gas temperatures are physically related through the turbine efficiency and expansion ratio design values. Additionally, expansion ratio is more or less the same as compressor pressure ratio.

The recuperator is a high temperature heat exchanger that serves to recycle the waste-heat from the turbine exhaust back to the working fluid at the compressor discharge, and before fuel addition. In current recuperated turbines, the recuperator inlet temperature is at or very near the metallurgical limit of type 347 stainless steel (SS), the generally preferred material for cost considerations. Alloys such as Inconel 625 have higher temperature capabilities, but they cost approximately three times more per pound than does 347 SS. A switch to such alloys will increase the overall cost of 
the turbine, which tends to negate the value of any potential efficiency gains. Figure 31 below provides insight into these trade-offs.

Table 4 lists a current industrial recuperated turbine configuration with the turbine inlet temperature (TRIT) limited to maintain the recuperated inlet temperature for $347 \mathrm{SS}$ at the design expansion ratio. With a 90 percent effective recuperator and standard assumptions on pressure drop of 1.5 percent on the air side and 3.5 percent on the gas side, the cycle efficiency optimizes at a pressure ratio of 3.0:1. To mitigate cost impacts, these machines are commonly designed at 4.0:1 or slightly higher, reducing component size and cost. Built into these optimizations, but less obvious, are assumptions on compressor and turbine efficiencies, at typical values of 83 and 85 percent, respectively.

Un-cooled metallic turbine rotors are commonly applied at TRIT between $950^{\circ} \mathrm{C}\left(1742^{\circ} \mathrm{F}\right)$ and $983^{\circ} \mathrm{C}\left(1800^{\circ} \mathrm{F}\right)$. The recuperator cost goals, however, compel the use of stainless steel alloys, but the 40,000 hour life in service objective limits the exhaust gas temperature (EGT) to between $625^{\circ} \mathrm{C}\left(1157^{\circ} \mathrm{F}\right)$ and $640{ }^{\circ} \mathrm{C}\left(1185^{\circ} \mathrm{F}\right)$. Unfortunately, this necessitates limiting the TRIT and therefore the turbine efficiency potential. In the current scenario, TRIT is limited to $893^{\circ} \mathrm{C}\left(1638{ }^{\circ} \mathrm{F}\right)$, which limits the turbine efficiency and results in a net electric efficiency of 34 percent and generates an uncompetitive manufacturing cost of $\$ 650$ per $\mathrm{kW}$.

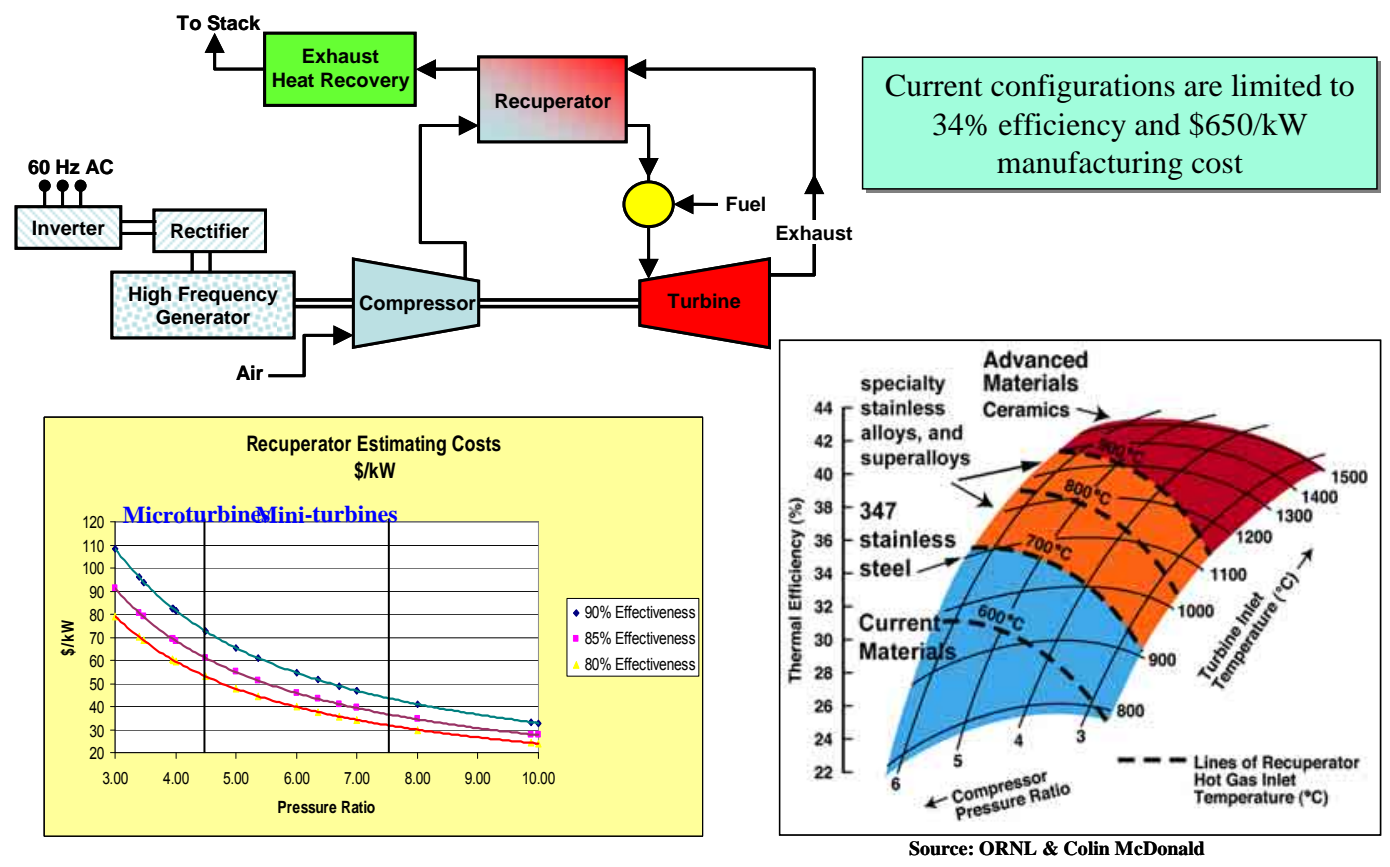

Figure 31. Trade-offs of efficiency gains and recuperator cost. 
Table 4. The Ramgen technology advantage.

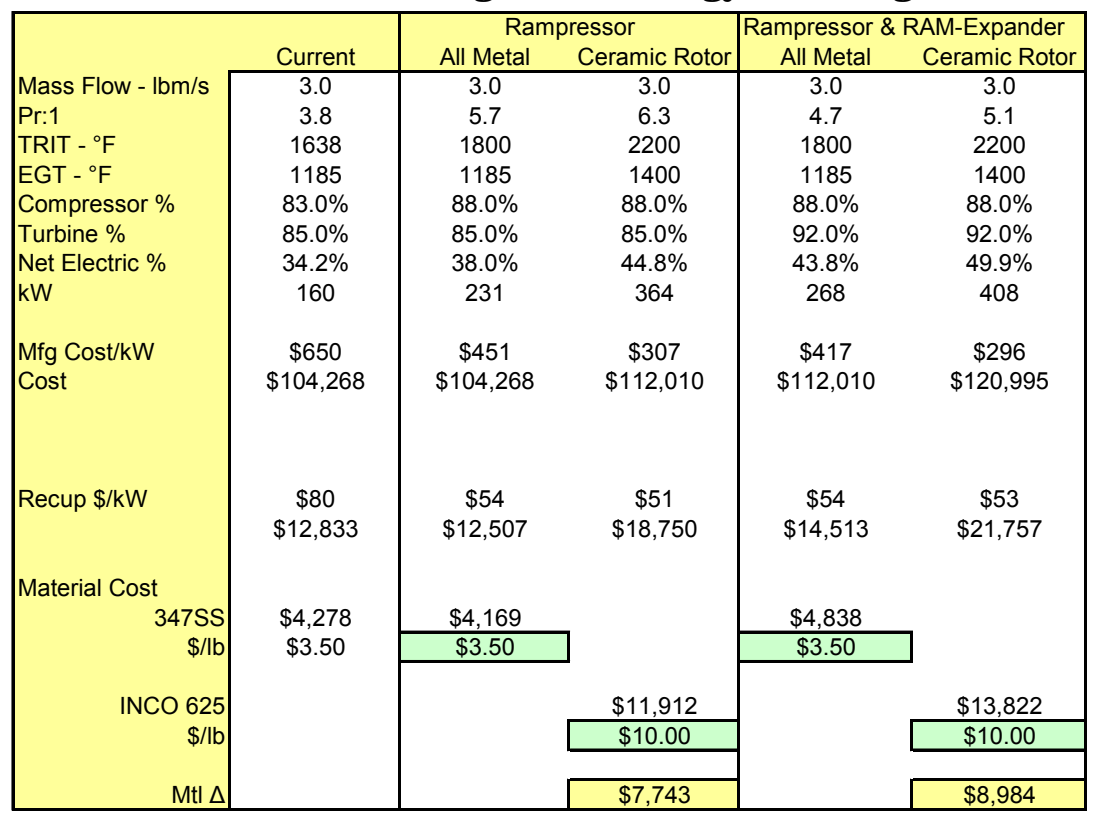

An approach to avoid high recuperator material costs is to decrease the turbine exhaust temperatures (EGT) by increasing the turbine expansion ratio, as well as turbine efficiency. Table 4 lists recuperated engine configurations that show the potential advantages of inserting the Ramgen compressor and expander technology into a micro turbine for greater net electric compression efficiency, higher specific power, and lower overall manufacturing costs.

The Rampressor could improve compressor adiabatic stage efficiency to 85 to 88 percent, and shift the optimum pressure ratio to 5.0 - 5.7, allowing full use of the $983^{\circ} \mathrm{C}\left(1800^{\circ} \mathrm{F}\right) \mathrm{TRIT}$ turbine rotor capability, without exceeding the 347SS recuperator limit. The cycle efficiency could be as high as 39 percent LHV net electric efficiency, without introducing the risk and cost of ceramic nozzles and turbine rotors. The increase in pressure ratio and TRIT results in a 48 percent increase in specific power and a reduction in manufacturing cost of 33 percent to $\$ 439$ per $\mathrm{kW}$. The increase in pressure ratio also decreases the manufacturing cost of the recuperator component per $\mathrm{kW}$.

This level of improved efficiency and deduction in manufacturing costs will greatly enhance the potential to meet the DOE advanced micro turbine program goals, as well as allow broader participation in the "power only" markets where the sales opportunity is several times larger than for combined heat and power (CHP) alone. 
The practical availability of ceramics allows significantly higher firing temperatures and can enable the turbine to achieve even higher efficiencies and specific power ratings. The significant increase in specific power will more than offset the incremental cost of a higher temperature recuperator and still yield an overall reduction in the overall manufacturing cost per $\mathrm{kW}$.

An increase in pressure ratio to 6.3 with a 90 percent efficient Rampressor, and a TRIT of $1205^{\circ} \mathrm{C}\left(2200^{\circ} \mathrm{F}\right)$ results in a net electric efficiency of $\sim 45$ percent and an additional increase in specific power of 56 percent. The added cost of the Inconel 625 recuperator is more than offset by this increased specific power. The result is an additional reduction in overall turbine manufacturing cost of 31 percent to $\$ 307$ per $\mathrm{kW}$, which is more than enough to support a viable commercial operation selling complete machines at $\$ 500$ per $\mathrm{kW}$.

Despite the development advances with ceramics, a number of challenges do remain before monolithic and composite designs will exhibit the long lifetimes required for production turbine applications. If ceramics were ever to achieve their promised potential, the net electric efficiencies could approach a full 15 percent improvement above the DOE advanced micro turbine program goal and significantly better than reciprocating engines in this size class.

The potential inclusion of the RAM-Expander can further extend these cost and efficiency impacts. Turbine efficiency exerts significant leverage on cycle performance as can be seen from the table, returning approximately 80 percent of any improvement directly to net electric efficiency. The cycle efficiency and product cost impacts could yield efficiencies close to the best high temperature fuel cells at 44 to 50 percent levels.

\subsection{The RAM-Turbine}

Ramgen intends to offer a RAM-turbine configuration that applies its supersonic compressor, AVC combustor and expander technologies in the 250-400kW range, low pressure ratio, recuperated cycle gas turbine. The engine will be a single spool configuration (Figures 32 and 33).

Product ratings and component sizing are still being determined, but the goal is to achieve some level of cross-platform component sharing with the ASCE engine, described in the following section, to leverage development cost and eventually manufacturing and field inventory. As such, the rat- 
ings and specific dimensions will change as these efforts continue to evolve.

The RAM-Turbine is intended to support independent operation in either PowerGen or Combined Heat and Power (CHP) configurations, as well as to operate as part of either direct or indirect hybrid fuel cell systems.

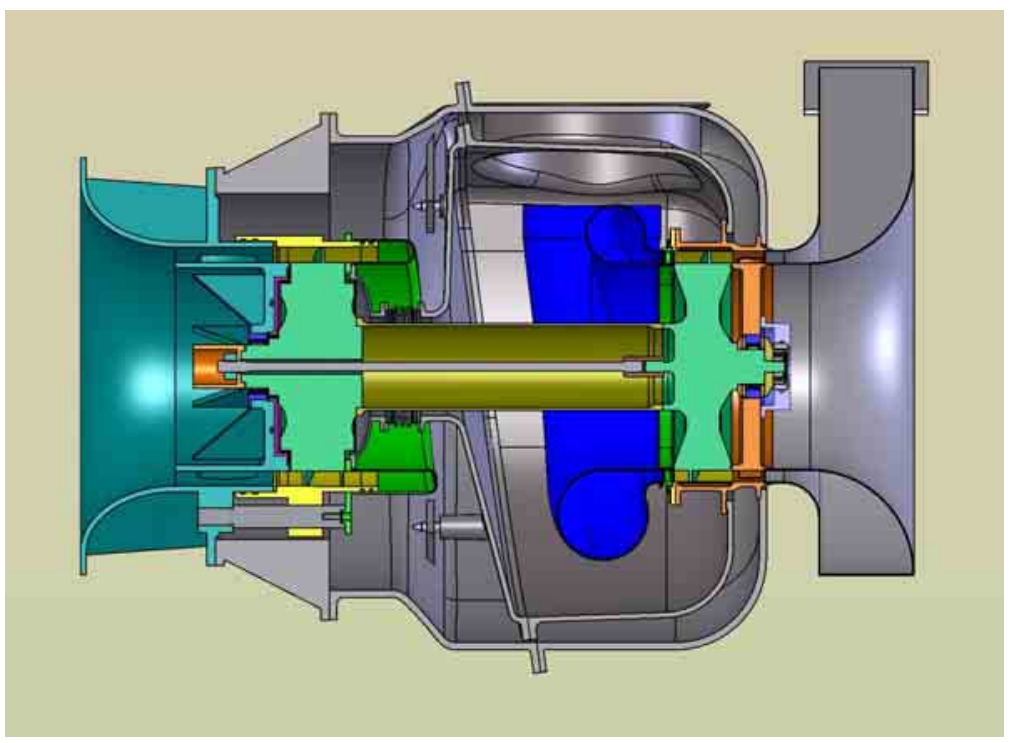

Figure 32. RAM-turbine details.

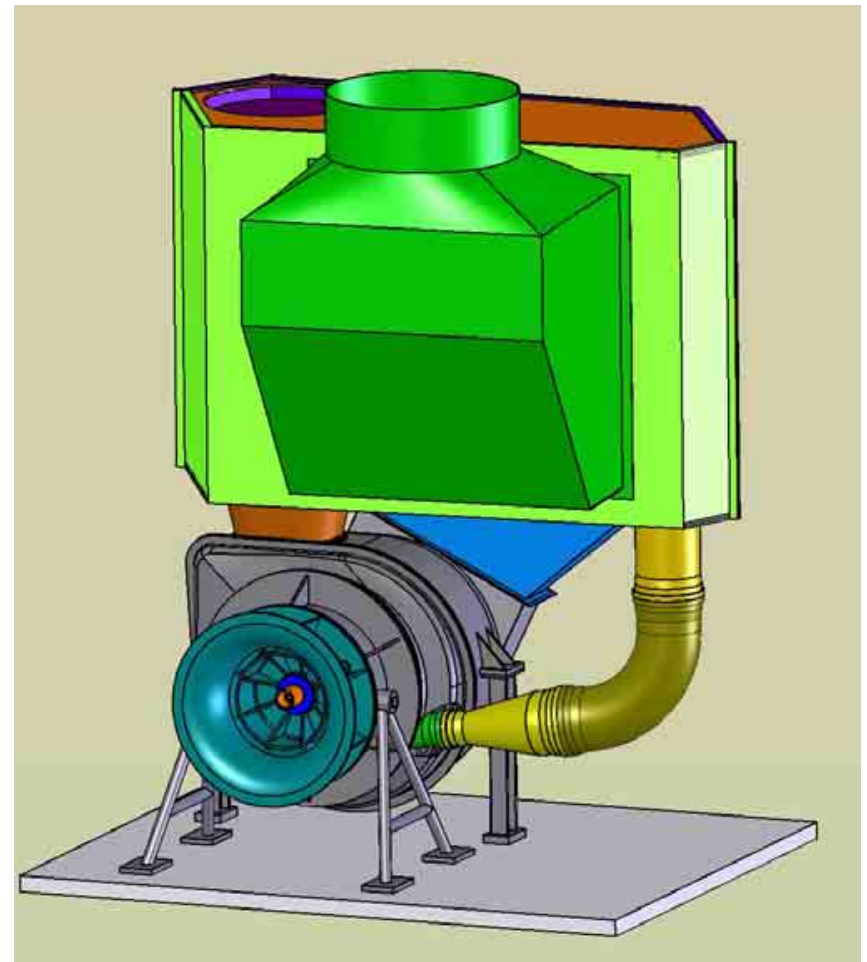

Figure 33. Ram-turbine system. 


\subsection{Simple Cycle Gas Turbine Advanced Supersonic Component Engine}

The gas turbine has always been the preferred alternative for marine propulsion applications, offering superior size, weight and maintenance advantages over reciprocating diesel engines, but is unable to compete at power levels less than 10MW due to its high fuel consumption.

At the same time, larger aero-derivative gas turbines are successfully applied at 25MW and above where the size and weight of diesel engines is prohibitive, despite the fact that the fuel consumption of the turbine is, at best, considered a compromise. Improvements in efficiency of these engines to the 40 percent level have been achieved through increases in both pressure ratio and firing temperature, which also results in a growth in rated engine output.

Recuperated gas turbines have been attempted for stationary power in sizes up to $5 \mathrm{MW}$ at 30 to 35 percent efficiency, but these are not considered reliable or compact enough for marine propulsion applications, or efficient enough to compete with reciprocating diesel engines.

Ramgen is proposing to develop a simple-cycle gas turbine engine that has the efficiency of a diesel, but with the size, weight and maintenance attributes of a gas turbine. This ASCE combines many of the proven features of shock wave compression and expansion systems, commonly used in supersonic flight inlet and nozzle designs, with turbo-machinery practices employed in conventional axial flow gas turbines. The superior efficiency of the ASCE is a result of high pressure shock wave compression and supersonic expansion phenomena to produce high component efficiencies, and a unique engine configuration designed to minimize flow stream turning losses throughout the engine.

The four technologies that make up the ASCE (Figure 34) are:

- rotating supersonic compressors

- high velocity flow combustor

- rotating supersonic expanders

- direct connect to high speed pm electric generator/motor. 


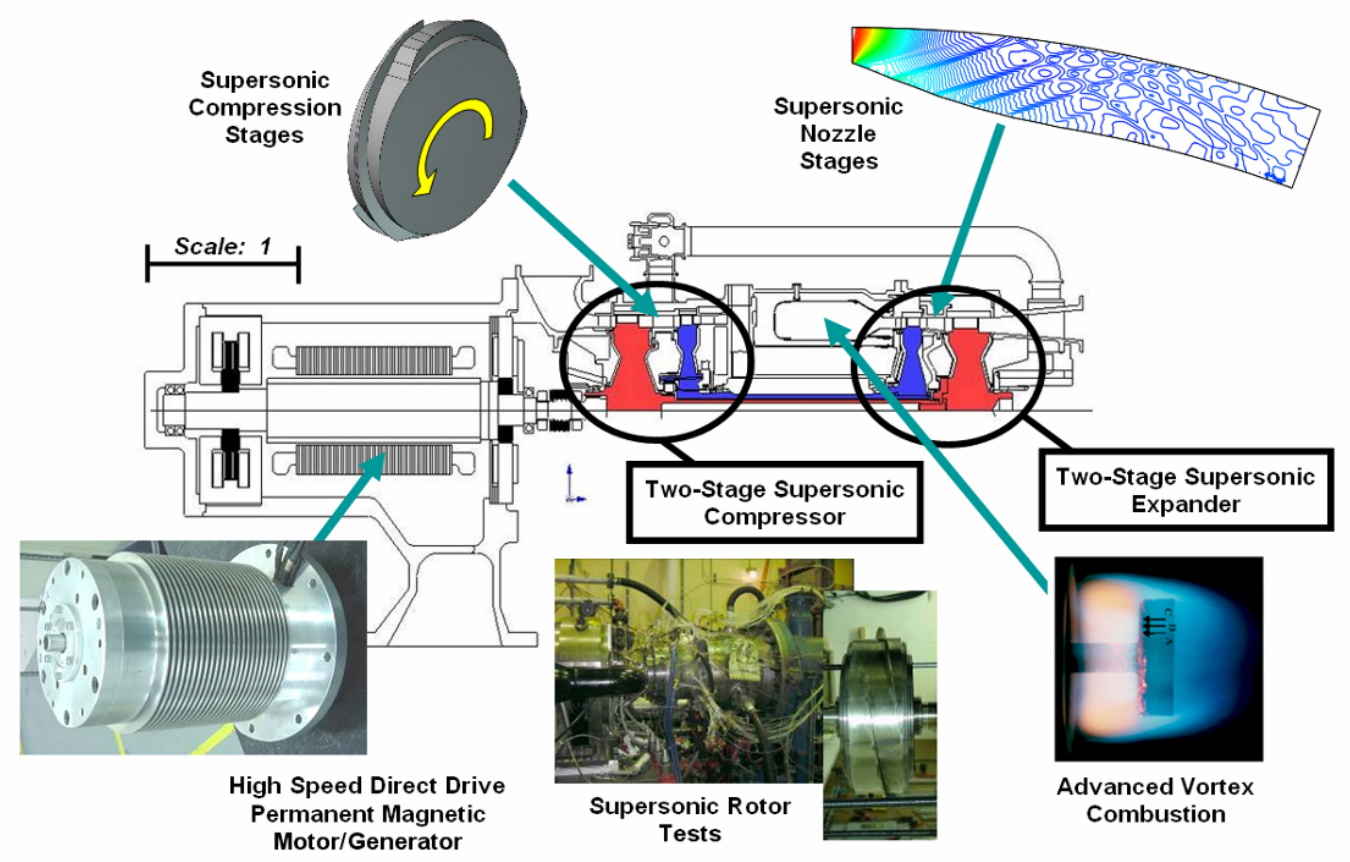

Figure 34. Proposed ASCE configuration.

The multi-fuel ASCE concept promises to revolutionize military and commercial surface, and sea power and propulsion systems and is scaleable from $300 \mathrm{hp}$ to 30,000 hp shaft power requirements. The scalability of the ASCE will make it competitive in both the diesel and gas turbine markets. RPS is proposing a $1000 \mathrm{hp}$ demonstration program as both a popular rating with immediate Naval manned and unmanned combatant craft applications, and a size that would offer a manageable financial exposure.

Additional military opportunities that have been identified are Army Tank and Automotive Command (TACOM)/Tank Automotive Research Development and Engineering Command (TARDEC) hybrid vehicles, U.S. Air Force (USAF) airborne electric power generation systems for the directed energy weapons systems and all branches of the U.S. Special Operations Command (USSOCOM). The engine can also be applied as both a fixed base or forward deployed stationary power generator within all the branch services.

The proposed $1000 \mathrm{hp}$ engine is a two stage counter-rotating, 30:1 pressure ratio, 45 percent simple cycle efficient engine, which drives a highspeed direct drive permanent magnet (PM) electric generator/ motor (see Figure 34) for either electric power generation or hybrid vehicle propulsion applications. The multi-fuel ASCE system promises a specific fuel consumption (SFC) equal to or better than the fuel consumption of current 
reciprocating diesel engines in this size range, but with a 10:1 weight reduction and a 4:1 improvement in time-between-overall maintenance. This is a 2:1 increase in fuel efficiency at full power over existing gas turbines in this size range.

The anticipated compression and expansion efficiencies, decreased footprint, and reduced part count of the RPS technologies promise revolutionary new power generation and propulsion systems with deceased heat signatures resulting from lower exhaust temperatures. These unique aerodynamic features will open up new and creative options for engine designers and package integrators that have never been realized or considered. In addition, the reduced footprint and the potential for vertical versus horizontal engine mounting will provide improvements and options to the costly intake and exhaust systems that are difficult to integrate into highly compact military vehicles and vessels.

The purpose of the project is to deliver a new engine that will meet future DOD requirements for long endurance, high efficiency, and long timebetween-overhaul power generating and propulsion applications. Although supersonic compression and expansion aerodynamics and highswirl/ high velocity stabilized combustion are fundamentally well established, these technologies have never been integrated into one cycle for generating shaft power.

\subsection{Performance and Configuration}

The ASCE concept integrates supersonic shock compression and expansion systems into a high pressure ratio, compact, high efficiency Brayton simple-cycle engine. Figure 35 shows the relationship between cycle pressure ratio and resulting system efficiency for existing Brayton Cycle, landbased and flight engine systems at their design Turbine Inlet Temperature (TRIT).

The solid red line shows the theoretical Brayton Cycle efficiency limit as a function of pressure ratio at a fixed TRIT of $2000^{\circ} \mathrm{F}$. Both the land-based and the flight engines have been plotted along with a Brayton Cycle efficiency estimate based on the component efficiency assumptions indicated. These "curve fits" indicate a reasonable agreement with those assumptions.

This type of analysis, although popular and easily performed, does overlook the impact of engine power rating. The current recipe for increasing 
gas turbine efficiency has been, and likely will remain, to increase the turbine firing temperature (TRIT), which focuses much of the research and development effort on increases in high temperature materials capability. For each TRIT, however, and for a given set of component efficiencies, there is also an optimum pressure ratio to achieve either maximum thermal efficiency, or maximum power density, expressed as specific work (Figure 36).

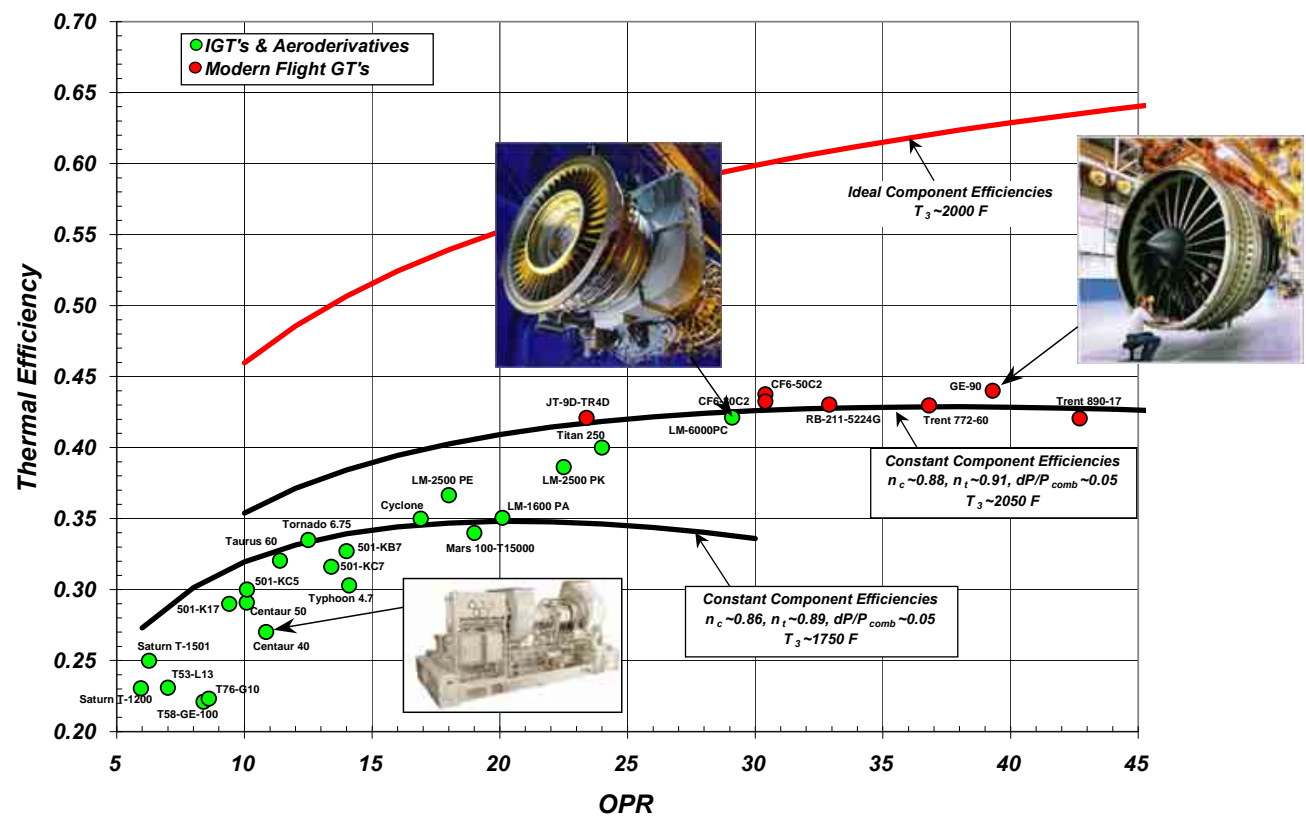

Figure 35. Brayton cycle efficiency.

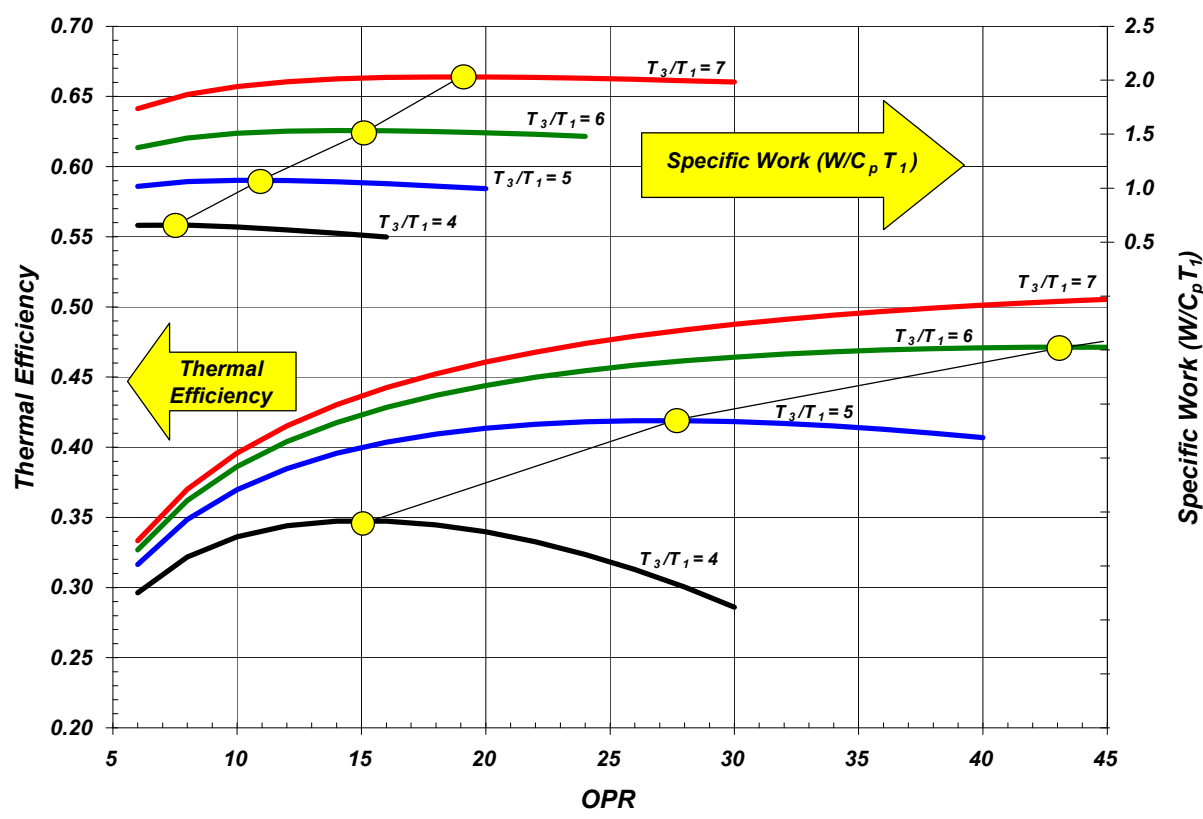

Figure 36. Efficiency and specific work vs. Pr and TRIT. 
As an example, the optimum pressure ratio to maximize thermal efficiency at a temperature ratio of 4:1 is $15: 1$. Temperature ratio is defined as the absolute TRIT divided by the absolute Engine Inlet Temperature, and a temperature ratio of $4: 1$ equates to a TRIT of $2017^{\circ} \mathrm{F}$. The compressor and turbine component efficiency in this representation are 85 and 90 percent respectively, but without any system pressure losses included.

The important understanding from such analyses is that pressure ratio typically rises along with increases in TRIT, which does improve the efficiency, but also increases engine power. The result of this is that there are no gas turbine engines available at the lower power levels, and diesels predominate in these applications. Figure 37 shows a plot of those same landbased and flight engines plotted vs. engine rated power, and as can be seen, there are no small and efficient gas turbines.

The ASCE engine concept is also shown on the same plot, indicating the potential for this engine to compete with small diesels. Diesels are purchased because they offer the best value in these sizes, even though their size, weight and maintenance costs are considered serious negatives.

The ASCE Engine is Unique - The reason why conventional axial gas turbines cannot be simply scaled down to these power levels is less obvious, and a function of aerodynamic limits related to Reynolds Numbers in combination with tip clearance effects.

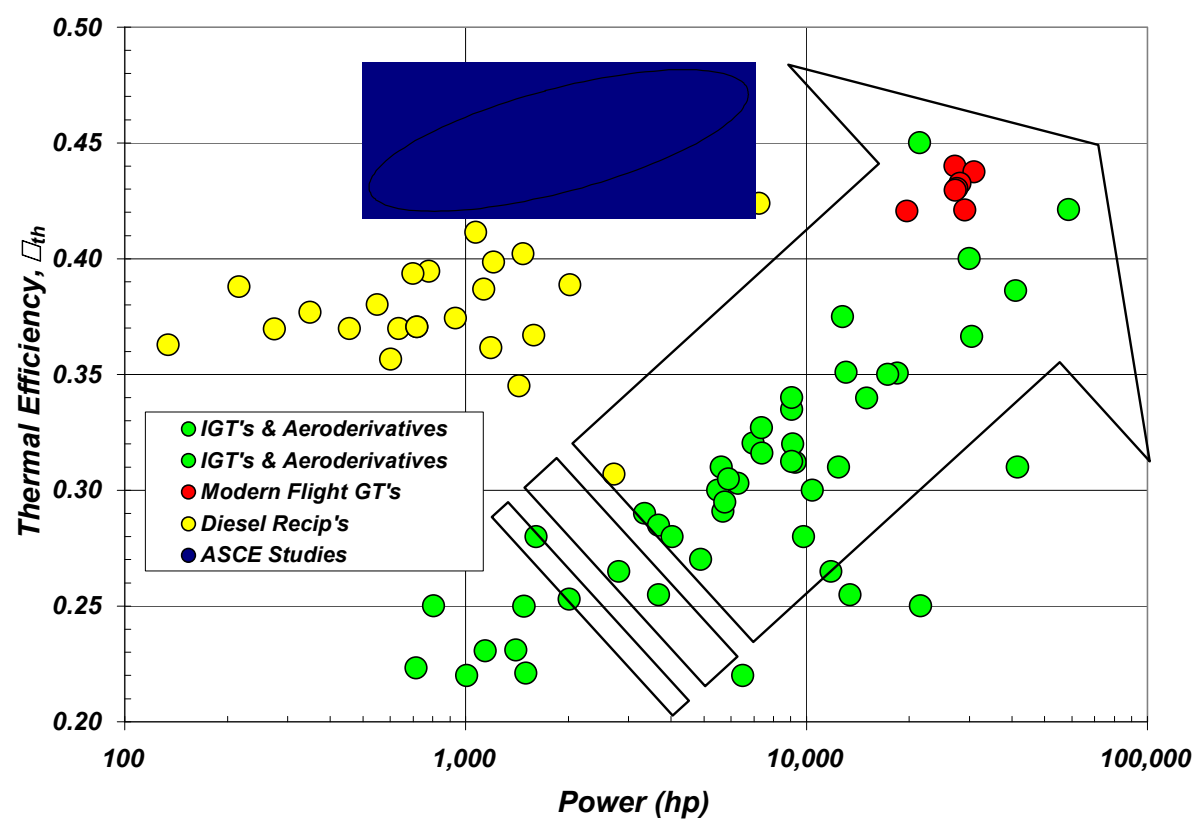

Figure 37. Thermal efficiency vs. rated power. 
Tip clearance effects are relatively straightforward. Rotor dimensions scale with power, but tip clearances do not scale proportionately. Mechanical design constraints moderate the scaling dimensions such that the effect of clearance is more pronounced in smaller sizes, and this shows up in the form of reduced engine efficiency.

Less obvious is the effect of the Reynolds Number. The Reynolds Number is an aerodynamic scaling parameter used to characterize the effect of aerodynamic boundary layer blockage in flow passages. Reynolds Number effects result in an efficiency degradation in smaller sizes, which, as a matter of practice, limits the minimum size of equipment offerings.

The National Aeronautical and Space Administration (NASA) has fully characterized the extent of performance degradation in several representative aerodynamic designs and has published those effects (Figure 38).

The GE-90/NASA E3 core compressor, which, at 94 to 96 percent, is arguably includes the most efficient axial compressor available today, is shown at its rated 43,000 horsepower. This engine is then also shown in a hypothetical scaled version to a nominal $1500 \mathrm{hp} \mathrm{rating}$, and equivalent to an ASCE engine at that size. The scaled version has been subjected to NASA's scaling parameters for the combined effect of tip clearance and Reynolds Number into the resulting 78 to 80 percent compressor efficiency at this size. The corresponding ASCE engine maintains its compressor efficiency because the Reynolds Number for its unique configuration is substantially higher than this corresponding scaled axial design.

As a result, the ASCE engine offers the promise of diesel engine efficiency with the size, weight and maintenance attributes of a gas turbine (Figure 39) compares the efficiencies of existing gas turbines under $5000 \mathrm{hp}$ and the proposed ASCE $1000 \mathrm{hp}$ engine, indicating improvements in efficiency by a factor of two.

The two-spool simple-cycle configuration will also allows Ramgen to configure the system with two different power settings to better match the specific mission profiles. Many of the military applications feature both a loitering power level and a maximum power level. While the lower-power fuel economy is of great interest, some of these applications require that full power be available instantaneously. Ramgen is exploring concepts that would provide a unique capability to satisfy these requirements 


\begin{tabular}{|c|c|c|c|c|c|c|}
\hline System & OPR & $\begin{array}{c}\text { Mass } \\
\text { Flow } \\
(\mathrm{lbm} / \mathrm{s})\end{array}$ & $\begin{array}{c}\text { Compressor } \\
\text { Discharge } \\
R_{\text {duct height }}\end{array}$ & $\eta_{c}$ \\
\hline GE-90 (NASA E $E^{3}$ Core Compressor) & 40 & 354 & $1.90 \mathrm{E}+06$ & $0.84-0.86$ \\
\hline GE-90 - Hypothetical Scaled System & 40 & 8.7 & $3.00 \mathrm{E}+05$ & $0.78-0.80$ \\
\hline ASCE-1500 & 30 & 8.7 & $1.50 \mathrm{E}+06$ & $0.84-0.85$ \\
\hline
\end{tabular}

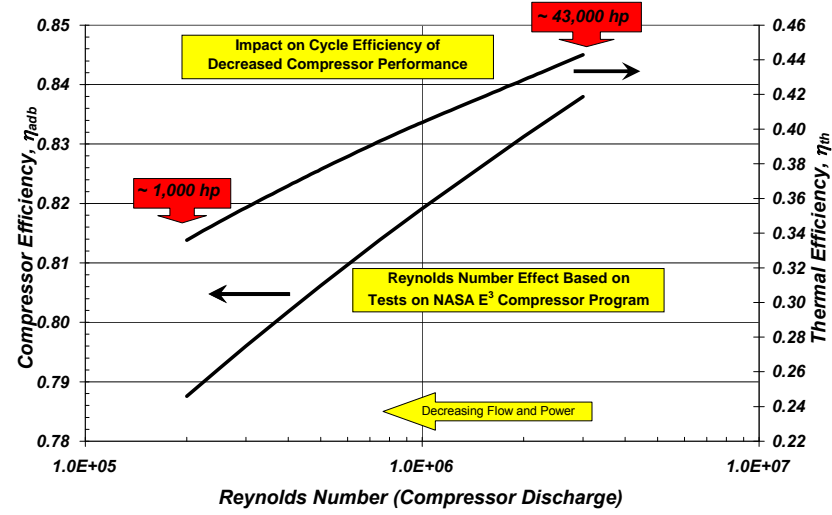

Figure 38. Performance degradation.

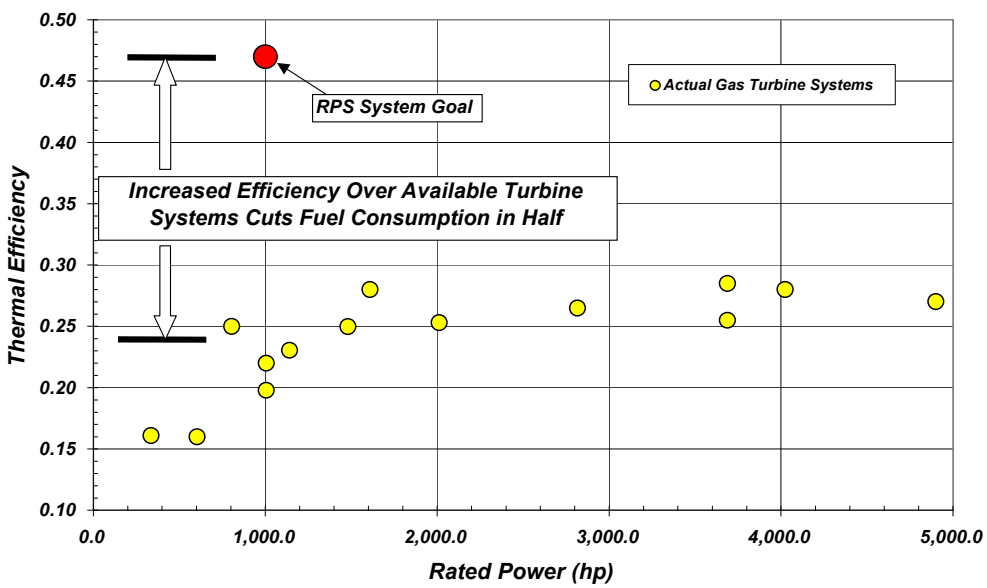

Figure 39. Comparison of ASCE and available turbine systems.

Figure 40 shows the use of these two spools and its impact on overall engine performance. The cross-over point can be tailored to specific applications by altering the respective Pr splits between the spools.

\subsection{Military Applications}

\subsubsection{Small Craft and Littoral Hybrid Electric Propulsion}

The size, weight and maintenance requirements of diesel engines now serving this application are seen as limitations on both the system design and the operational flexibility of these smaller surface craft. 


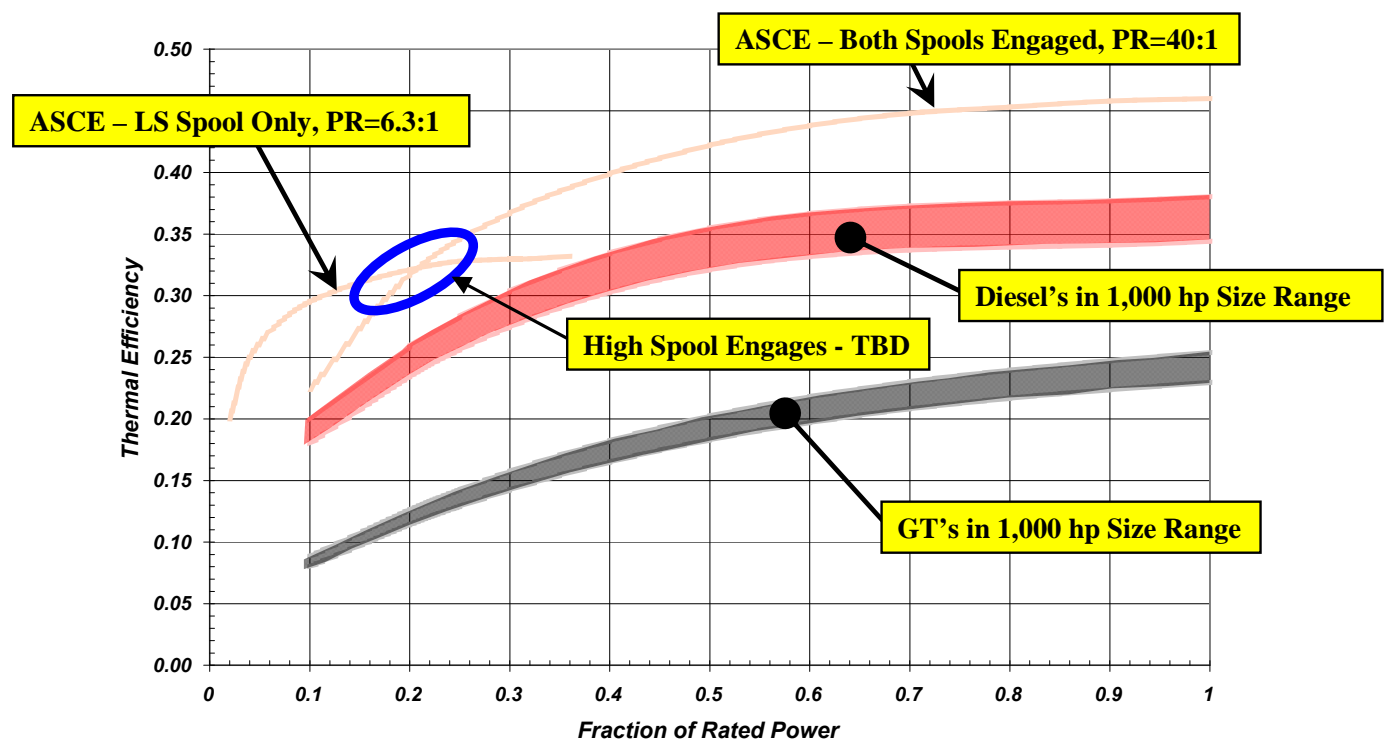

Figure 40. Impact of two spools on engine performance.

\subsubsection{Future Long Endurance Unmanned Surface Vehicles (USVs)}

USVs must operate semi-autonomously for long periods of time. Challenges to be overcome include: storing adequate energy for the mission assigned and efficiently converting that energy for use; reliability and affordability; self diagnostic and reconfiguration capability; and mission effectiveness. Much as hybrid gasoline internal combustion-electric power plants are leading the way to fuel-efficient automobiles, marine hybrid power systems can meet the requirements of long-endurance USVs.

\subsubsection{On-board "Hotel Power" APU's}

All naval vessels require some form of auxiliary power unit (APU) to support their "in port" requirements, as well as to serve as emergency back-up generators. These are not uninterrupted power system (UPS), but rather continuous duty Gensets that are sized to support the dockside power requirements, without operating the main engines. Power usage aboard ship has grown considerably as a result of expanded use of power electronics based weapons systems, and the importance of these APU's has grown considerably to support their quality power requirements as well as the HVAC loads to cool them. In general, the Navy is looking for more compact and efficient power sources to support these requirements. The current approach is to use an Allison/ RR 501 engines or equivalent that have an electric efficiency rating of only 30 percent. Figure 41 shows both the Allison/RR 501 and ASCE core engines, for comparison. Both of these engines are simple cycle designs. 


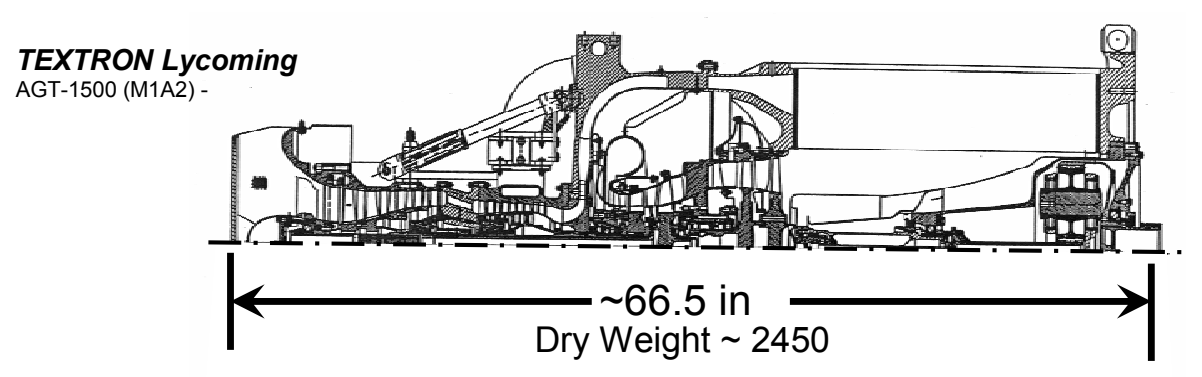

ASCE-1500

Gas-Path

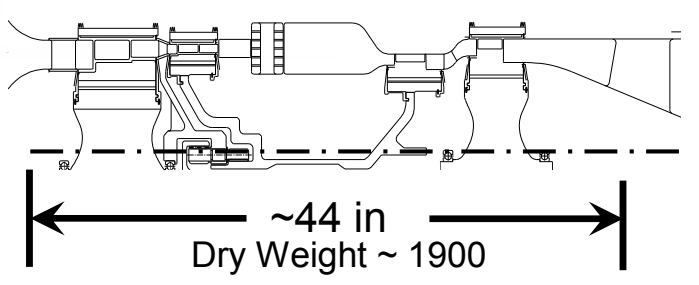

Figure 41. AGT-1500 gas turbine engine.

\subsubsection{Directed Energy Weapons Support Systems}

These are laser-based weapons systems that require substantial electric power to support their operation. These are typically in the form of an APU. Airborne applications have stringent space and weight constraints, whereas naval applications have somewhat more latitude. The typical airborne application is $2 \mathrm{MW}$, but can be as high as $20 \mathrm{MW}$. The operating envelope requires that the units be capable of these power outputs at a variety of altitudes, depending on the mission and/ or the host platform. The ASCE engine is seen as completely consistent with these design objectives.

\subsubsection{Hybrid Electric Vehicle Drives Systems}

There are a variety of hybrid drive systems and system concepts in various stages of development. The ASCE engine is viewed as a cross-service, enabling technology and well suited to most of these systems. This could be applicable to the Army's Future Combat Systems (FCS) efforts where the application power is approximately $350-400 \mathrm{~kW}$, and the current engine platform is the Daimler-Chrysler Series 890 Engine, available in 4 to 12 cylinders at power levels of 300 to $1100 \mathrm{~kW}$. Although Ramgen is not targeting direct mechanical drive propulsion systems, it is still worthwhile to draw size comparisons to the existing systems. Figure 41 shows the existing AGT-1500 gas turbine engine currently used in the Abrams M1A2 Main Battle Tank.

A key point of differentiation is that the ASCE engine achieves its efficiency in a simple cycle configuration. The AGT-1500 and its erstwhile successor, the LV-100 both feature a low pressure ratio, recuperated cycle. 
Not only does the ASCE engine offer superior performance in a smaller package, it does so by eliminating the controversial and high maintenance cost recuperator in its entirety.

\subsubsection{Conventional Stationary Gensets}

The Army also uses a 750kW diesel engine genset as its standard power block for field deployment. A 740KW continuous Caterpillar genset would be a model C32TA V-12 engine (Figure 42) with a package dimension of $15^{1} / 2 \mathrm{ft}$ long, $6 \frac{1}{2} \mathrm{ft}$ wide and weigh $17,500 \mathrm{lbs}$. It takes an entire C- 130 to transport a single genset. The space and weight savings through the use of the ASCE engine will reduce the logistics cost and speed the deployment of these "mission-critical" assets.

There appears to be numerous opportunities to apply the ASCE engine in military applications.

\subsection{Advanced Vortex Combustion Opportunities}

Since the mid 1970s the control of pollutant emissions from combustion processes has become of great public concern due to their impact on health and the environment. The combustion industry has witnessed rapid changes both in regulations for controlling emissions and in the technologies used to meet these regulations. These harmful emissions are carbon monoxide (CO), unburned hydrocarbons (UHC), particulate matter, oxides of sulfur ( $\mathrm{SOx}$ ), and NOx (nitrogen monoxide and nitrogen dioxide). Carbon dioxide $\left(\mathrm{CO}_{2}\right)$ and water vapor have not always been regarded as pollutants; however, they both contribute to global warming, which is now receiving tremendous international attention.

The reduction of NOx emissions has received particular attention due to its toxicity (precursor to chemical smog and acid rain) and the depletion of ozone in the stratosphere. Many scientists and consultants believe that NOx emissions pose more of a threat to public health and the environment than the other combustion emissions, although actual consequences may be more indirect and long-term. 


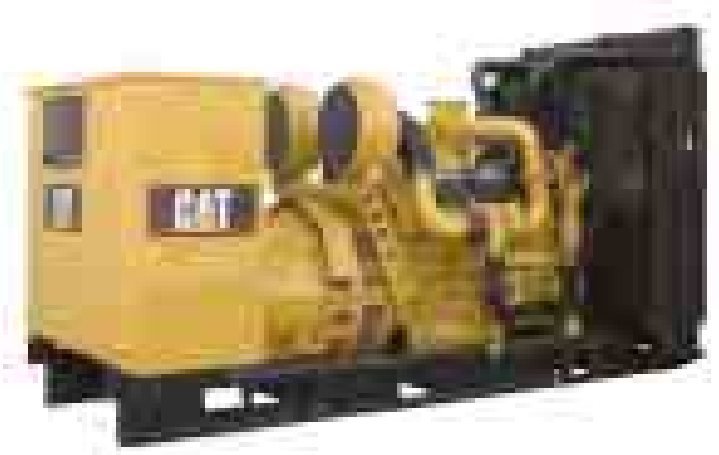

Figure 42. Caterpillar C32TA V-12 - 740kWe.

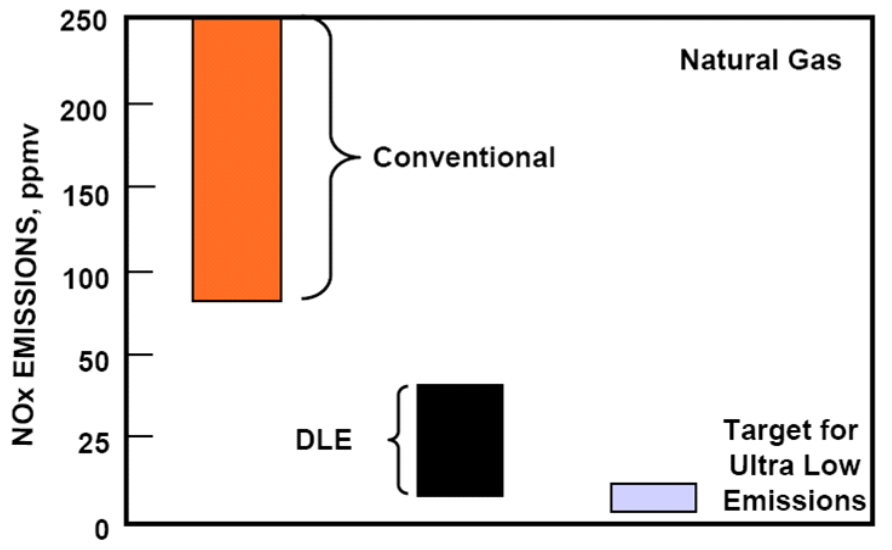

Figure 43. Target for ultra low emissions.

NOx emissions have been decreasing since the mid 1970s from levels of 90 to 250 ppmv (parts per million by dry volume at 15 percent Oxygen) for "conventional" combustion systems, down to less than 50 ppmv using water and steam injection (Figure 43).

In the late 1980s, the dry low emission (DLE) approach was introduced into the industry to eliminate the costly onsite requirement for water or steam injection to control the NOx emissions (Figure 44). The introduction and further development of the dry low emission (DLE) technology in the industrial gas turbine industry has reduced the NOx emissions to levels between 10 and 25 ppmv. A comparison of conventional and DLE (Figure 45).

The majority of industrial gas turbines are unable to achieve NOx emissions below 10 ppmv with the added expense of exhaust gas aftertreatment such as selective catalytic reduction (SCR). The SCR technique requires the injection of highly toxic ammonia into the exhaust stream for NOx abatement. This is a very costly and hazardous option when the storage and handling of ammonia in densely populated regions. 


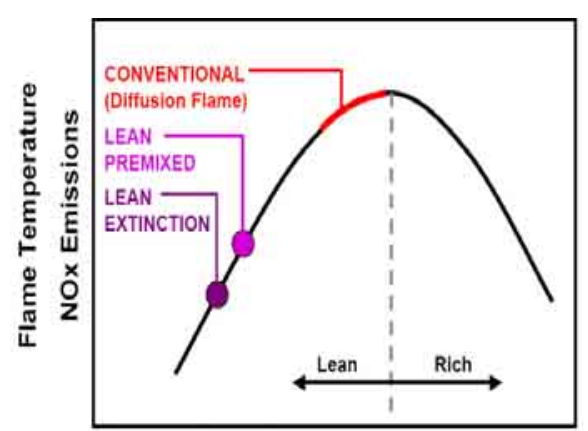

Fuel/Air Ratio

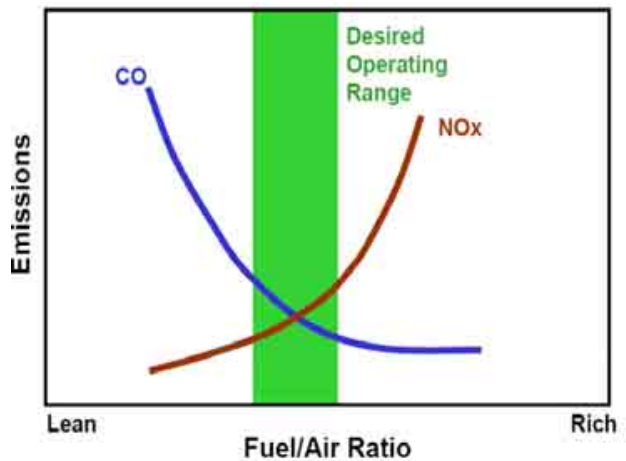

Figure 44. Low emission approaches.

NOx emissions form in the primary zone of the combustion chamber. The highest gas temperature and subsequent NOx emissions occur at the "stoichiometric" condition. This is the single point between too much fuel or "rich" conditions and not enough fuel or "lean" conditions. The decrease in temperature reduces the NOx emissions, but increases the CO emission as the combustor approaches "lean extinction."

To meet ultra low NOx emissions (below 10 ppmv) requirements without a SCR, the combustor must be operated near the lean extinction limit. The lean extinction limit is where the combustor temperature is low and the flame is extremely weak and very susceptible to sudden "flameouts." Since the early 1990s, the industrial gas turbine community has battled with balancing extremely low emissions with engine flameouts and unstable pressure fluctuations that can cause great damage to the engine. These instabilities occur when fluctuations in the heat release rate couple with the acoustics of the combustion system to produce pressure oscillations.

The AVC approach shows tremendous potential to provide flame stabilization at these extreme lean conditions and minimize the destructive pressure fluctuations.

Stationary gas turbines can be broadly classified into Industrial and Marine, Aero-derivative and Frame designs, and in recent years, micro and mini-turbines. All variations include combustors and fuel requirements of some description. 


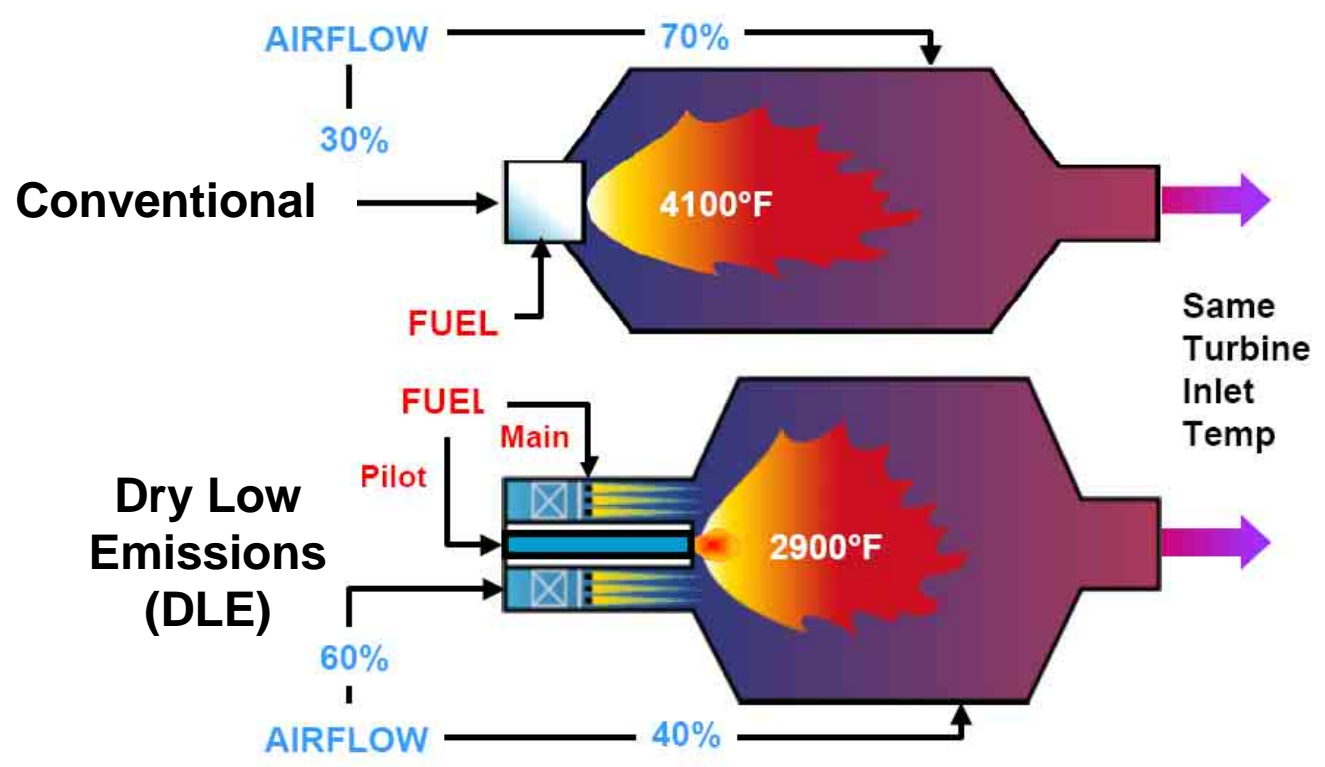

Figure 45. Conventional vs. dry low emission.

A gas turbine combustor is comprised of two components:

- fuel injectors or "nozzles"

- combustor liner or "can."

The cans are positioned in the gas turbine in three configurations:

- annular

- can-annular

- single can only.

The number of fuel injectors for each "can" configuration varies depending on the specific "can" design and preference of the gas turbine OEM. Typically, OEMs maintain the same combustor configuration throughout their product line (Figure 46).

The purpose of the fuel injector is to mix the liquid or gas fuel with the air required to support combustion, prior to entering the combustor can, and to provide a stable flame holding capability.

Ramgen's strategy is to "drop-in" Dry Low Emissions (DLE) combustor systems for both new and existing units that improve operability and durability, reduced costs, add fuel flexibility, and lower emissions. Ramgen's strategy is also to offer its technology in the form of a component sale for the gas turbine applications and retain control over the proprietary AVC hardware manufacturing, supply, and replacement (Figure 47). 


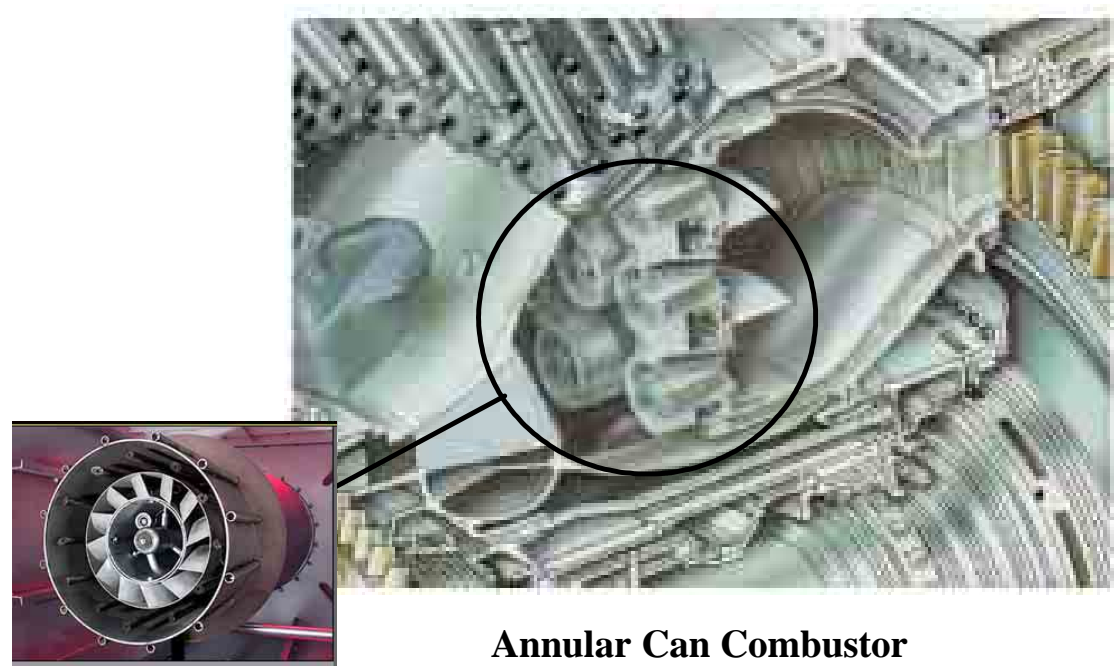

Fuel Injector

Figure 46. Fuel injector.

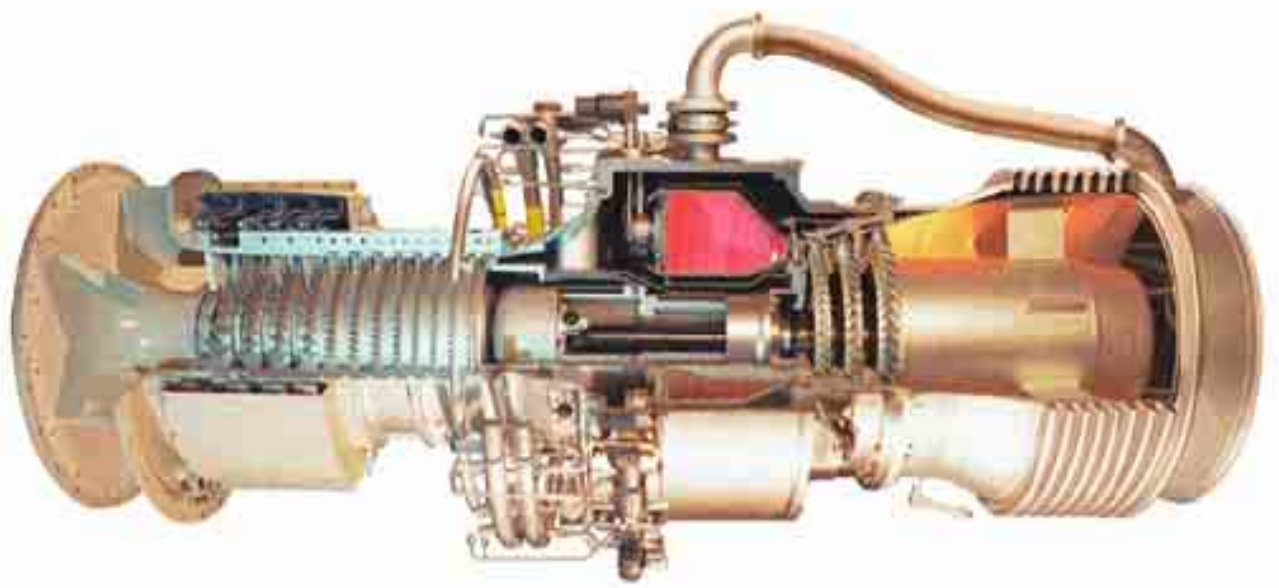

Figure 47. Industrial gas turbine.

\subsection{Unique $\mathrm{CO}_{2}$ Compressor}

Ramgen has been awarded a DOE grant to begin the development of a novel $\mathrm{CO}_{2}$ compressor capable of developing the required 100:1 pressure ratio in two stages of compression.

Ramgen's shock compression technology represents a significant advancement in the state of the art for all compressor applications, and specifically for $\mathrm{CO}_{2}$ compression. The principal advantage of Ramgen's shock compression is that it can achieve exceptionally high compression efficiency at very high single stage compression ratios, and this results in a product simplicity and size that will lower both manufacturing and operating costs. 
The $\mathrm{CO}_{2}$ compression Topic Area \#4 of the DOE Solicitation DE-PS2605NT42380 had defined a general set of requirements for IGCC systems with mass flow rate capacities of 600,000 - 700,000 lbm/ hr and capable of a pressure ratio of 100:1. Ramgen is developing a $\mathrm{CO}_{2}$ compressor system capable of meeting these pressure and flow requirements with improved efficiencies and dramatic reductions in package size, weight, and cost compared with existing technologies.

The novel Ramgen technology concept addresses the two greatest objectives identified by the Department of Energy for the Capture and Storage of $\mathrm{CO}_{2}$ - lower costs and better efficiency. Figure 48 shows a 2D drawing of one such candidate configuration, along with a dimensional scale to indicate its approximate size.

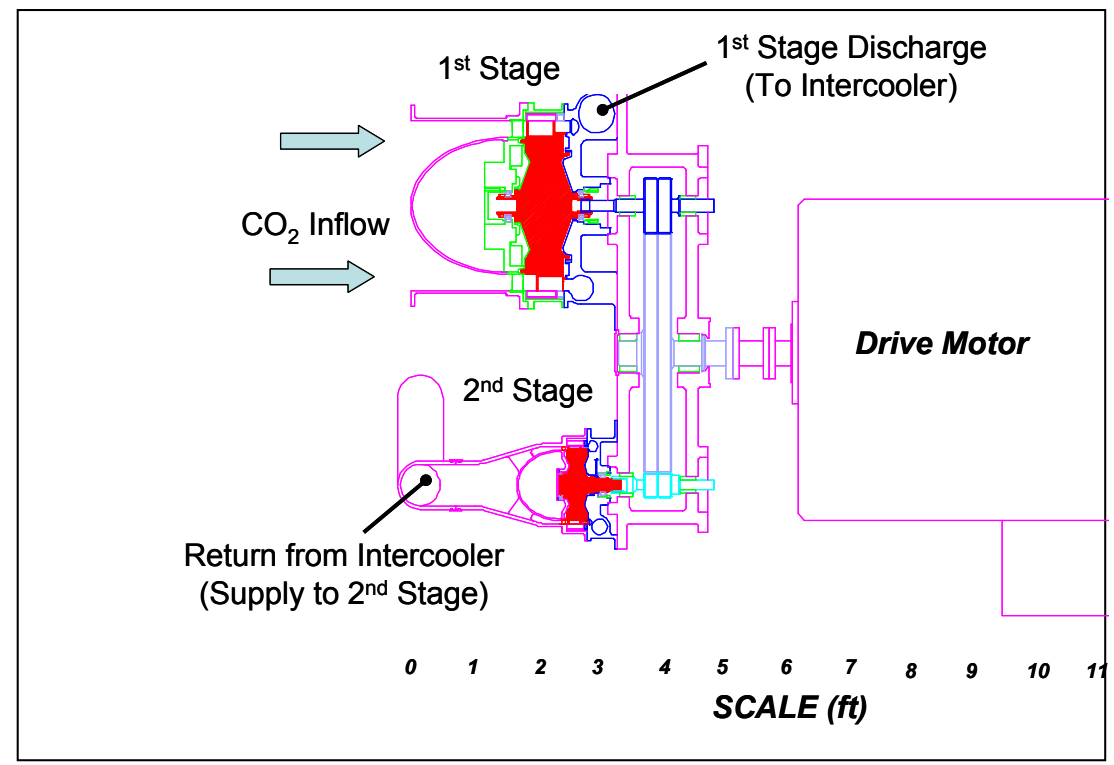

Figure 48. Ramgen's super-sonic shock wave $\mathrm{Co}_{2}$ compressor.

Nominal Specifications:

- Capacity:

$150,000 \mathrm{lbm} / \mathrm{h}$

- Capacity: $21,400 \mathrm{icfm}$

- Gas Composition: $100 \% \mathrm{CO}_{2}$

- Inlet Pressure: 15 psia

- Inlet Temperature: $70^{\circ} \mathrm{F}$

- Discharge Pressure: 1500 psia

- Power: $9830 \mathrm{bhp} / 7333 \mathrm{~kW}$

- Dimensions:

o Length $12 \mathrm{ft}$ (with drive motor)

o Width $4.5 \mathrm{ft}$

o Height $5.0 \mathrm{ft}$ 
The proposed product is rated at $150,000 \mathrm{lbm} / \mathrm{hr}$, or 21,400 icfm, based on an assumed 15 psia suction pressure and the specified nominal discharge pressure of 1500 psia. The size of the proposed 1/4-capacity unit is not dictated by any limits of the Ramgen technology, and we can design this unit at whatever capacity increment is appropriate to optimize the IGCC plant.

The final specifications of the system will be defined in Phases I and II as a deliverable of the program. Ramgen selected this size to allow for comparisons versus conventional centrifugal compression design approaches. The configuration shown uses a conventional turbo gearbox similar to those manufactured by BHS-Cincinnati. Depending on size, the compressor can also be configured with a direct drive high speed motor.

Current centrifugal and axial compressor design practice typically limits the inlet Mach \# to 0.90 to mitigate shock effects from occurring within the blade flow path, as both "lossy" and potentially destructive. In practice, this limits the achievable pressure ratio per stage of compression to approximately 1.7:1 for the heavier molecular weight $\mathrm{CO}_{2}$. Consequently, a conventional "high performance" integrally-geared centrifugal compressor processing $\mathrm{CO}_{2}$ at the specified pressure ratio of 100:1 will likely require eight stages of compression, along with a corresponding number of stainless steel intercoolers between each stage.

Ramgen, on the other hand, designs its rotors to create and manage these shock structures and can realize the full effect of their ability to generate substantial pressure ratios, efficiently. The proposed Ramgen $\mathrm{CO}_{2} \mathrm{com}-$ pressor concept would achieve the required 100:1 pressure ratio in two stages of compression, each rated at 10:1 $(10 \times 10=100)$. This configuration would feature a conventional intercooler between the first and second stages as well as an aftercooler, if required by the application.

Figure 49 shows a conventional 10-stage, 200:1 pressure ratio "high performance" integrally geared $\mathrm{CO}_{2}$ compressor as manufactured by MANTurbo in Germany. The pressure ratio per stage is 1.7:1, $(2001 / 10=1.698)$. We have assumed an eight-stage design for purposes of comparison, the corresponding T-s diagram (Figure 50) indicates that an eight-stage; seven-intercooler configuration would be required to reach the nominal specified 100:1 pressure ratio. For those not familiar with a T-s diagram, the processes that move up in this diagram are compression processes, where the pressure is increased and the temperature rises along with it. 
The processes that move down in this diagram are intercooler steps that cool the gas before entry into subsequent compression stages.

This particular unit has an inlet capacity of 13,800 icfm with dimensions estimated at $18 \mathrm{ft}$ long, $12 \mathrm{ft}$ wide, and $18 \mathrm{ft}$ high. Six or seven of these sized units would be required to deliver the $600,000-700,000 \mathrm{lbm} / \mathrm{hr}$ suggested by the specification, and this would not include any consideration for a back-up spare. It is likely that one or two additional units would be required to provide suitable back-up.

The limitations of the conventional approach are obvious, and the configuration seems very much misapplied for the $\mathrm{CO}_{2}$ compression service and would add significantly to the overall cost and complexity of carbon capture and sequestration.

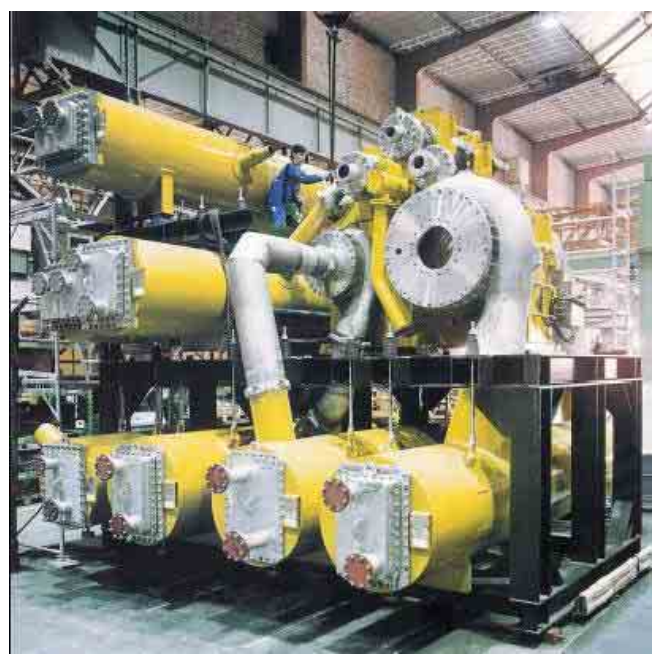

Figure 49. MAN Turbo 10-stage 200:1 $\mathrm{CO}_{2}$ compressor.

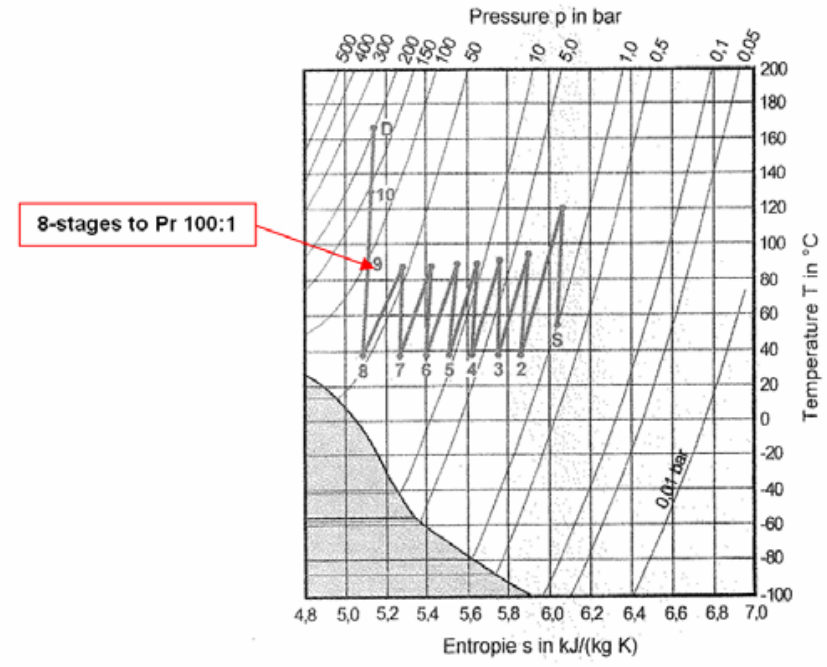

Figure 50. MAN Turbo T-s diagram. 

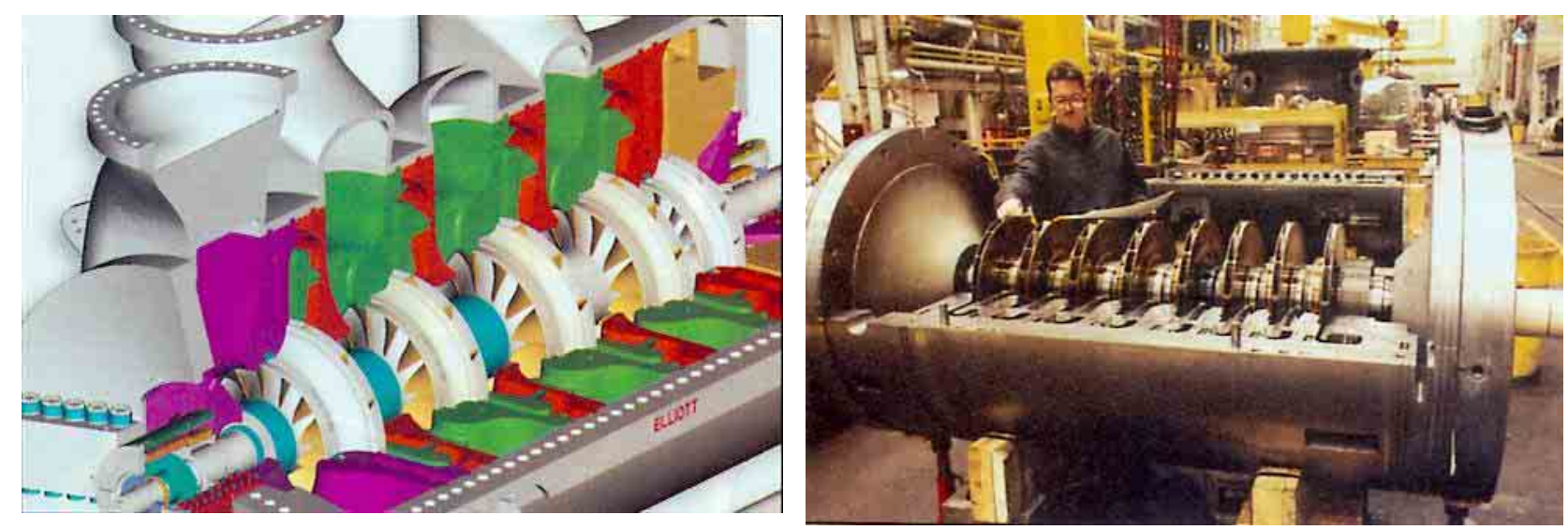

Figure 51. Elliott centrifugal compressor designs.

In addition to the geared designs shown above, there is an entire class of existing axial and centrifugal inline API-Type designs that serve a spectrum of hydrocarbon and hydrocarbon processing applications. Most of these units, whether axial or centrifugal, employ multi-stage configurations because of significantly lower pressure ratio capability per stage than is possible with the Rampressor technology.

The centrifugal process gas shrouded impeller designs (Figure 51) are commonly applied at heads of 10,000 $\mathrm{ft}$-head per stage, or the equivalent of a pressure ratio of 1.4 on air. The Ramgen compression technology can achieve 80,000-100,000 ft head per stage, effectively converting this eight stage design into a single-stage device. The efficiency is likely to be 85 percent vs. the nominal 77 to 81 percent advertised in the selection guide for this class of equipment. Since many of these applications involve high pressure and toxic gases, the number and control of casing splits is always a concern. The use of a single stage opens up considerable design latitude in dealing with this issue and in a more cost effective manner.

The other conventional approach for large volume $\mathrm{CO}_{2}$ compression is to use these conventional inline process compressor trains. This type of design uses similar aero components and would likely require a three-casing, 12-stage; two-intercooler compressor similar to the two casing design. Figure 52 shows an Elliott Turbo, two casing unit. A third, barrel-type casing would be required to achieve the 1500 psia discharge pressure. These units can be prohibitively expensive.

Mitsubishi recently announced their version of a high performance $\mathrm{CO}_{2}$ compressor offering, but one that still appears to require 10 stages of compression and use two intercoolers. They have managed to eliminate one of 
the casings by combining seven of these stages in a single barrel (Figure 53). The piping sizes suggest the unit has three stages followed by and intercooler; then four stages followed by another intercooler and, from their nomenclature, an assumed three stages to reach 203 bar ( $\operatorname{Pr} 200: 1)$.

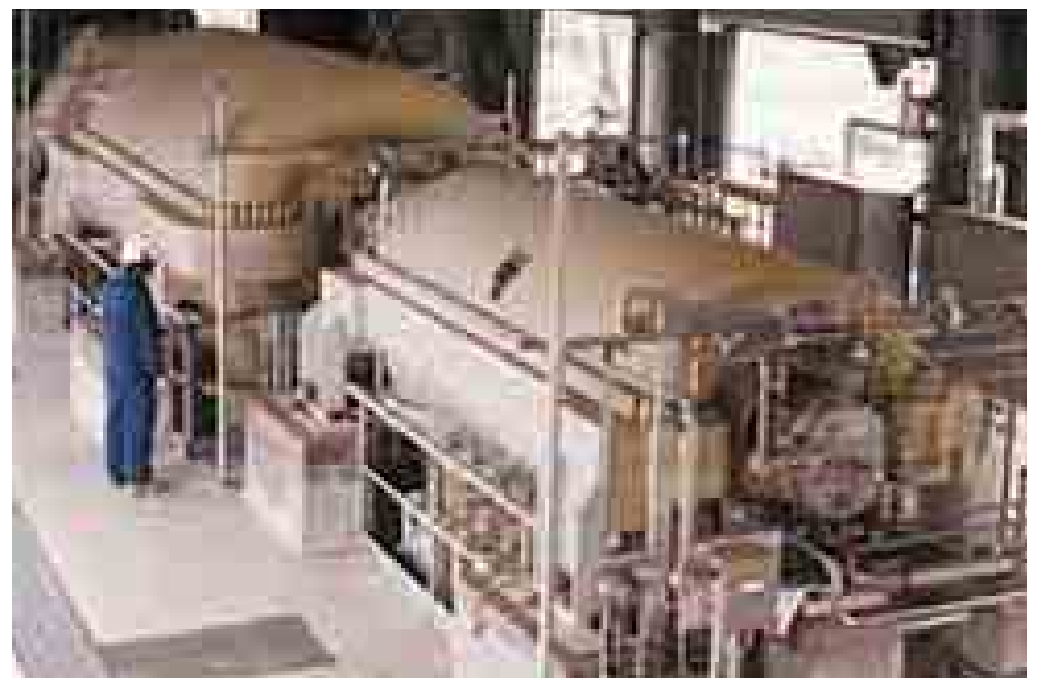

Figure 52. Elliott turbo process compressor train.

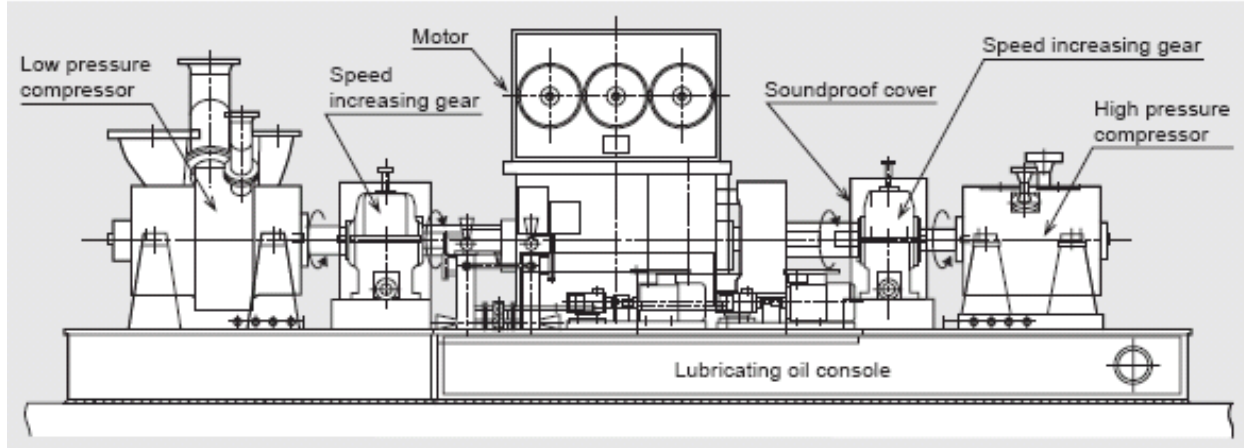

Fig. $1 \mathrm{CO}_{2}$ re-injection compressor train configuration

A both ends drive motor is installed in the center of the train, two speed increasing gears are provided at outer ends. with two compressors outside them.

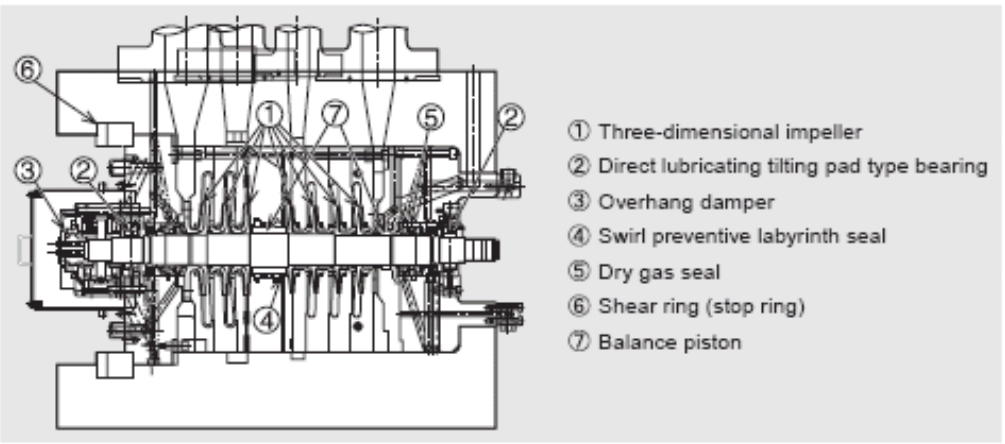

Fig. 2 A sectional view of $\mathrm{CO}_{2}$ re-injection compressor

Required advanced technology, and health, safety and environment protection features are shown in a sectional view of the $\mathrm{CO}_{2}$ re-injection compressor.

Figure 53. Mitsubishi advanced $\mathrm{Co}_{2}$ compressor. 
The data in technical publication further indicates power levels and other performance metrics associated with an elevated inlet pressure, which is why the application can be met in fewer stages. This $11.7 \mathrm{MW}$ offering is described as the largest $\mathrm{CO}_{2}$ compressor in the world, barely one third of the likely requirements for a full scale carbon capture and storage (CC\&S) system.

The size of the Ramgen unit, arbitrarily selected to provide one fourth of the $600,000 \mathrm{lbm} / \mathrm{hr}$ stated capacity, or 21,400 icfm, would be $4.5 \mathrm{ft}$ wide, $5 \mathrm{ft}$ high, and $12 \mathrm{ft}$ long, including the drive motor. Four operating units and one spare would occupy only about $1 / 20$ th of the space required by six operating and one spare unit of the integrally geared designs (Figure 53).

As indicated, the optimum design capacity of the actual Rampressor will be determined in Phase 1 of the program, but the Ramgen concept could be designed to handle any appropriate fraction of the plant requirement up to and including a single, full capacity unit rated for 700,000 lbm/ h.

By any benchmark, physical size and weight are primary indicators of cost. At 1/20th the size, the Rampressor will have a major impact on plant capital, space and operating costs, and do so without sacrificing efficiency.

In addition, and as a direct result of the Rampressor being able to achieve single stage compression ratios of 10:1, stage discharge temperatures are estimated to range between 450 and $500{ }^{\circ} \mathrm{F}$, depending on inlet gas and cooling water temperatures. This offers the potential for significant waste heat recovery, without compromising compressor performance. This combined compressor and heat recovery creates an even more impressive energy efficiency advantage by recovering 70 percent of the electrical input energy in the form of useful heat. Potential uses for this available heat are to regenerate amine solutions or pre-heat boiler feedwater.

Conventional $\mathrm{CO}_{2}$ turbocompressor designs, with their limited pressure ratio per stage, are therefore also limited to approximately a $100^{\circ} \mathrm{F}$ stage temperature rise per stage by comparison (Table 5). This eliminates any possibility to recover the heat of compression and necessitates an incremental cooling tower capital expenditure. 
Table 5. Comparison of Ramgen $\mathrm{CO}_{2}$ compressor to conventional machines.

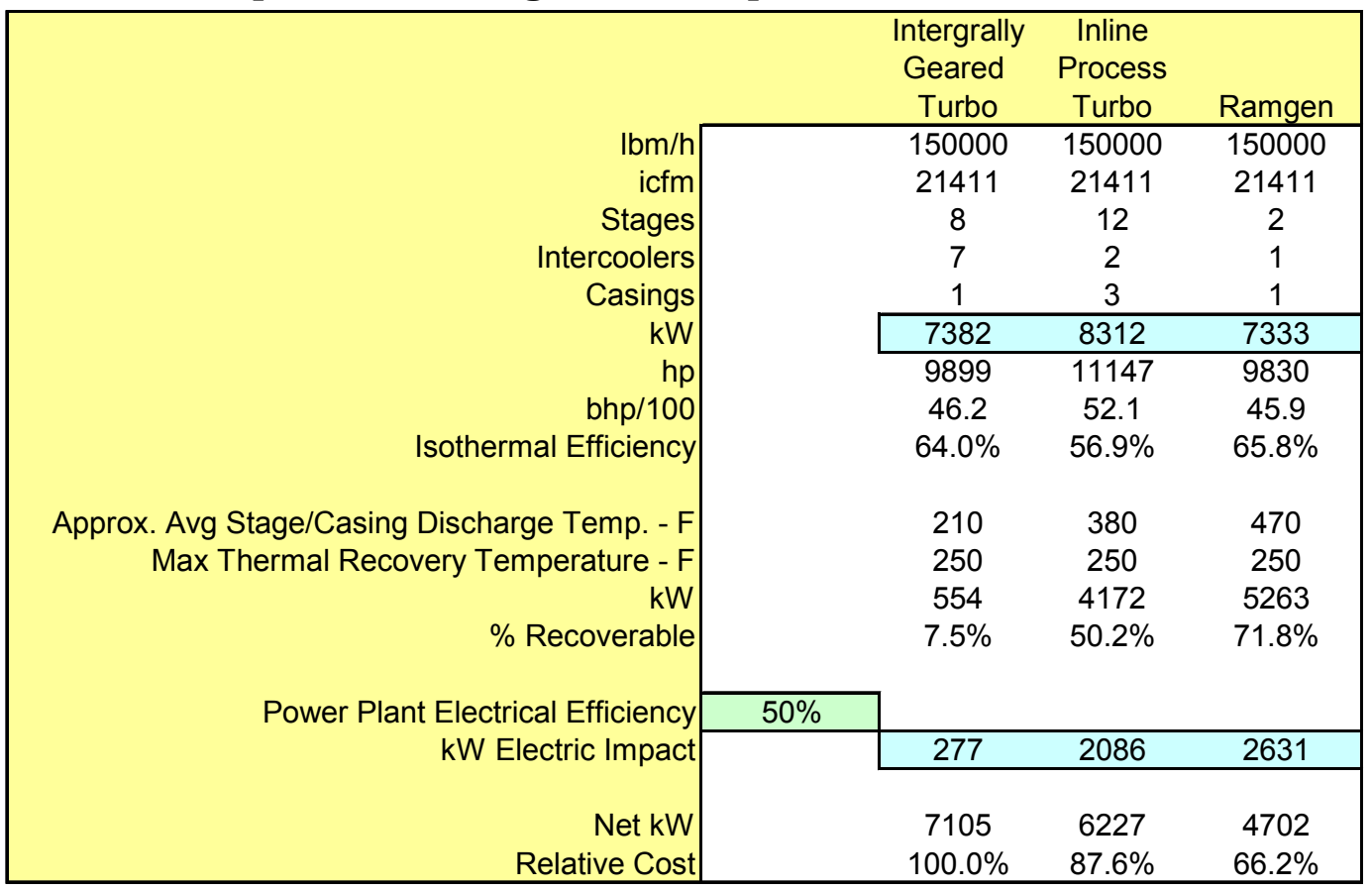

Both the input power and the combined heat recovery impacts are summarized in Table 5 above for the Ramgen technology as well as the theorized conventional integrally geared and inline process configurations. This analysis assumes that heat of compression can be recovered down to $250^{\circ} \mathrm{F}$. The integrally geared turbo is assumed to eliminate the intercooler between stages 7 and 8 , creating a minor heat recovery impact from the stage 8 discharge. The average stage discharge temperature is shown to make the point, but the heat recovery effect is based on actual stage by stage discharge temperature projections.

As can be seen, the input power requirement for the Ramgen and the conventional integrally geared design are similar, while the process turbo suffers from relatively poor aero efficiency. When factored by an assumed power plant efficiency, the heat recovery impact suggests that the net effect of successfully recovering the heat of compression can reduce the input power requirements from two-thirds that of the conventional designs. 


\section{Potential Warfighter Applications}

\subsection{Information Source}

This chapter reports research findings on the applicability of this novel technology to current and aging Army systems as well as further analysis of possible future systems. Two first-class (senior) cadets at the U.S. Military Academy (USMA), West Point, NY, coauthored this analysis as part of an advanced independent study in the Civil and Mechanical Engineering Department at USMA. Their objective was to assess Army systems for the applicability of supersonic components in gas turbines cycles. Technical information was gathered by interview from GEN(R) Kern, former Commander of the Army Materiel Command (AMC), to provide a comprehensive "big picture" on the Army's energy need.

\subsection{Tank Applications}

A possible application for the supersonic technology is a hybrid drive for the Army's M1 Abrams Main Battle Tank. The current engine in the Abrams is an inefficient and aging design by Honeywell, called the AGT1500 (Figure 54).

While the engine is still proving itself reliable during conducting current urban operations in Iraq and Afghanistan, it has not been produced since 1992. Therefore replacing parts, let alone whole engines, is becoming incredibly difficult and expensive. Currently, it will cost an Army unit more than $\$ 460,000$ when an AGT-1500 is destroyed in the field. The US Army recently awarded Honeywell a \$13.8 million contract for rebuilding the AGT-1500, but this is simply a contract to bring the war-worn units back to original production specifications. This contract does not include any money for the development of a replacement engine.

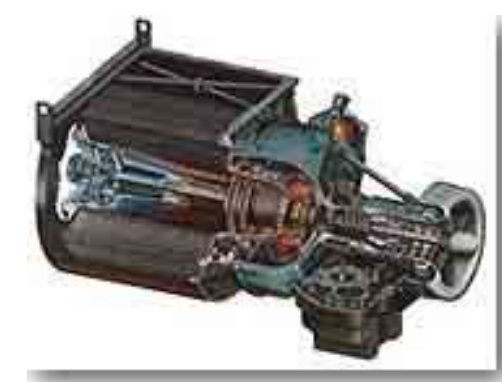

Figure 54. Honeywell AGT-1500. 
There was a study conducted by BG J ames Moran of Program Executive Officer (PEO) Soldier that would have resulted in an M1 engine replacement as a byproduct of designing an engine for a combat vehicle named the Crusader. However, this new combat vehicle project was terminated, and developing the replacement for the AGT- 1500 by itself was determined not to be cost effective (Kern 2006).

In addition to the issue of replacement parts, there are other benefits that a new power system could provide. Currently there are tanks operating in an overwatch mode that are idling their gas turbine engines simply to provide enough power to operate relatively small power draw systems, such as the thermal imaging sights. This is neither tactical from a standpoint of noise discipline, nor is it fuel efficient. This inefficiency is due in large part to tanks being used in manners other than those prescribed by their mission profiles. Tanks were designed for a long duration of sustained combat across the open fields of the Soviet Union. While the mission profile is changing, a replacement system should seek to improve on the current system specifications offered by the tank and its power plant. Table 6 lists current specifications for the AGT1500.

Despite the fact that tanks have a high power density that results in a need for considerable electricity production while stationary, this power does not need to come from the main engine. There are two ways to provide this power requisite to the tank without running the main engine.

Table 6. AGT1500 system specifications.

\begin{tabular}{|l|c|}
\hline \multicolumn{2}{|c|}{ AGT1500 System Specifications } \\
\hline Horsepower at 3000 RPM & $1500 \mathrm{hp}$ \\
\hline Length & $66.75 \mathrm{in}$ \\
\hline Width & $39 \mathrm{in}$ \\
\hline Height & $31.6 \mathrm{in}$ \\
\hline Dry Weight & $2528 \mathrm{lbs}$ \\
\hline Max Output Speed & $3,000 \mathrm{rpm}$ \\
\hline Max High Pressure Spool Speed & $43,500 \mathrm{rpm}$ \\
\hline Max Low Pressure Spool Speed & $33,000 \mathrm{rpm}$ \\
\hline Max Power Turbine Shaft Speed & $23,000 \mathrm{rpm}$ \\
\hline Minimum Output Speed & $950 \mathrm{rpm}$ \\
\hline Oil Capacity & $6.25 \mathrm{gal}$ \\
\hline Max Oil Consumption & $0.1 \mathrm{gal} / \mathrm{hr}$ \\
\hline Minimum Specific Fuel Consumption & $0.475 \mathrm{lbs} / \mathrm{hp}-\mathrm{hr}$ \\
\hline Transient Response (idle to 90\%) & $4 \mathrm{~s}$ \\
\hline Power Decay Rate (100\% to 20\%) & $5 \mathrm{~s}$ \\
\hline Engine Noise Level & $101 \mathrm{db}$ \\
\hline
\end{tabular}


An auxiliary power unit, or APU, can be used for this purpose. This technology was first debuted in commercial jet aircraft, allowing power generation for auxiliary systems. This allowed air travel to proliferate into suburban areas, as planes no longer had to land in cities that had substantial ground support assets.

While the design specifications vary, the APU is essentially a smaller gas turbine engine designed to provide a specific amount of power at low specific fuel consumption. Besides electricity, bleed air can also be produced by an APU and used for a variety of applications. Since APUs are similar in design to gas turbines, they can take advantage of the supersonic Ramgen technology in the compression and expansion portions of their design. If the supersonic componentry is as efficient as it initially has been shown to be, incorporating a system into a tank may be beneficial.

\subsection{Tank Mission Profile}

The requirements that supersonic gas turbine componentry would need to meet to replace or improve on current tank propulsion systems must be defined. Hence, Mr. Tim Milanov, lead engineer for Abrams testing and research with the Tank-automotive and Armaments Command (TACOM) was contacted regarding the current mission profile of an Abrams tank.

Testing for power train durability requires first that the system has a 0.5 probability of completing a 6,000 mile life. As the Abrams is an old design, the engine is the weakest part of the power train durability. The transmission is considerably more durable than the engine, and the final drive has a considerable lifespan.

Specific tests for durability of the Abrams are conducted at Yuma Proving Grounds (YPG). Tests are run for 600 engine hours, or 6,000 miles of testing using an average of 10 miles per hour for the tests. 21 percent of the tests are conducted on paved surfaces, defined as "concrete, macadam concrete, or asphalt. Operation shall not be accumulated on an oval or circular track or any other course where the vehicle is primarily being steered in one direction or another." Forty-five percent of the test is conducted on secondary roads, defined as grated gravel and sand, with the same turning requirement defined above. Finally, 34 percent of the testing is on crosscountry terrain. Half of the cross country tests are on hills, and half are on level ground. 
Table 7 lists vehicle ranges for variations of the Abrams under different test conditions. All tests were conducted using DF2 fuel, and not J P8, which is currently the conventional fuel used in tanks. JP8 will have approximately 10 percent less range for each test due to the lower heating value of the fuel.

This test regime has been in place for the life of the Abrams, and has been used to define the tank's mission profile. The testing structure, with regard to the percentages of travel on each of the surfaces, is a reflection of the Army's expectation of what kind of environment the tank is operated in.

It has been identified by tank operators who are using this vehicle in Iraq and other desert conditions that the operations mode for the vehicle needs an updated definition due to the discrepancy between test conditions and those conditions experienced by operators on a daily basis. While these suggestions have been acknowledged, they have not yet been implemented. However, in the testing community, there is some reluctance to change the testing cycle because all operational data for the tank for the past three decades has been based on the same design and system requirements. Additionally, if changes are made to the tank to improve performance in theater, it would be difficult to assess the effectiveness of these changes with metrics if we had a new set of benchmarks. For this reason, the plan is to maintain the current testing structure to maintain more constant benchmarks. However, this recommendation has not fallen on deaf ears. According to Mr. Mike Barton, working in the same office as Mr. Milanov and specializing in testing, new operational modes are being considered for future vehicles that will more accurately reflect the operating conditions in Iraq. This consists of short bursts of full power operation with long periods of idling operation. This would more closely align future vehicles with the current nature of warfare.

Table 7. Abrams fuel consumption test data.

\begin{tabular}{|l|l|l|l|}
\hline \multicolumn{1}{|c|}{ Test Surface } & \multicolumn{1}{|c|}{$\begin{array}{c}\text { Test } \\
\text { Conditions }\end{array}$} & $\begin{array}{c}\text { M1A1 } \\
\sim 60 \text { tons }\end{array}$ & $\begin{array}{c}\text { M1A2 } \\
\sim 70 \text { tons }\end{array}$ \\
\hline Paved & $\begin{array}{l}29 \mathrm{mph}, 4 \mathrm{th} \\
\text { gear lockup }\end{array}$ & $267 \mathrm{mi}$ & $258 \mathrm{mi}$ \\
\hline Secondary & $\begin{array}{l}24.9 \mathrm{mph}, 4 \mathrm{th} \\
\text { gear lock up }\end{array}$ & $209 \mathrm{mi}$ & $201 \mathrm{mi}$ \\
\hline Cross Country & $<10 \mathrm{mph}$ & $113 \mathrm{mi}$ & $108 \mathrm{mi}$ \\
\hline
\end{tabular}




\subsection{Hybrid Drive}

The overwatch power need for tanks or other vehicles can be addressed by incorporating a hybrid drive application. This hybrid drive system could not only be a solution to the current need for a new tank engine, but could also be one of the first widespread Army applications of hybrid technology.

As part of both direct and indirect fuel cell hybrid applications, there is both a turbine and compressor incorporated into the design. Ramgen's proposed supersonic components have implications on both of these parts.

The idea of a hybrid drive system is to use dual power generation to reclaim otherwise wasted energy to increase overall efficiency, thereby increasing a unit's mission time with regard to fuel constraints. Fuel cells are designed to operate at constant temperature, although heat is produced while fuel and oxidant are electrochemically combined to produce electricity. A high temperature fuel cell will produce high grade heat. This excess heat can be harnessed by a gas turbine cycle, effectively regulating the fuel cell temperature as well.

For a tank or tank replacement application, the system would need to match or exceed the current specifications put out by the AGT-1500. Currently, the AGT-1500 is capable of producing $1500 \mathrm{hp}$ and $2750 \mathrm{ft}-\mathrm{lbf}$ of torque in a 2,500 lbf dry weight package. This power requirement was based on a Cold War threat of the 1980s, where the M1 was envisioned engaging Soviets in the open field of the USSR.

Tanks are still relevant in urban operations; however their mission profile has obviously changed. Sustained travel over the Russian plains is not the primary concern. Instead, tanks need to be able to produce a lot of power quickly for a short sprint through urban terrain, followed by a transition into an overwatch state where primarily electrical power will be required from the power plant.

Therefore, quick start-up times, short-term mobility power, and power draw for electronics support are the three main criteria a replacement hybrid engine for the M1 would need to meet. The current engine bay area that holds both the AGT-1500 and its Allison transmission has a 119-in length, 80-in width, and a 47-in height. The current compressor size is approximately 8-in by 14-in, and develops a nominal pressure ratio of 14.0. The engine is capable of a transient response from idle to 90-percent rated 
power in 4.0 seconds, and can decay from 100-percent power to 20percent power in 5.0 seconds.

\subsection{Power Generation}

Currently, the most feasible use of supersonic gas turbine componentry for today's force would be in stationary power generation. The general progression for turbomachinery is to begin in a stationary phase and progress to more specific means, while usually becoming smaller and more powerful. The typical path taken by General Electric, the largest producer of turbomachinery in the United States, is to begin with stationary applications, move to vehicular or marine applications, and if needed, move finally to aerial use (Kern 2006). Each step results in a smaller product with more power produced per unit volume and mass.

This is a practice that has been used for many years, and with great success. Supersonic turbomachinery is a relatively new venture in gas turbine applications, and as such, should be eased into not only in the military, but industry in general. One of the primary concerns for our soldiers in the field is safety, as they have enough safety concerns to worry about as produced by the enemy, let alone their own equipment. Thus, the most sensible route for the Army to adopt if it were to incorporate this technology into its force would be to begin in an area with the lowest risk as ascertained by conducting a risk assessment of implementation into the force. This area would likely be in the realm of stationary power generation as it is not nearly as mission essential as would be power production for a moving vehicle or crew served weapon system.

Additional benefits to the Army of decreasing size and increasing efficiency of stationary power generation would be realized not only in cost savings on fuel, but in logistical areas such as transportation and weight. Smaller generation systems could possibly be transported on C-130s or on current larger transport systems, but in larger quantities. A more efficient machine would mean more possible power production per unit mass or volume, which decreases the logistical footprint necessary for our force to sustain itself.

Table 8 lists some of the sizes of prime power generation applications in the current Global War on Terror (GWOT). Generators in these facilities are 1.2 MW and are combined to total the overall production values. Currently, none of these generators are powered by gas turbine engines. This is one of the areas that the Ramgen technology could make an impact. 
Table 8. GWOT power production.

\begin{tabular}{|l|c|}
\hline \multicolumn{1}{|c|}{ Operation Iraqi Freedom } & Size \\
\hline LSA Anaconda & $21 \mathrm{MW}$ \\
\hline Al Asadd Airbase & $14 \mathrm{MW}$ \\
\hline Speicher & $16 \mathrm{MW}$ \\
\hline Q-West & none yet \\
\hline Victory Base Complex & $50 \mathrm{MW}$ total \\
\hline \multicolumn{1}{|c|}{ Talli (Adder) } & $14 \mathrm{MW}$ \\
\hline \multicolumn{1}{|c|}{} \\
\hline \multicolumn{1}{|c|}{ Operation Enduring Freedom } \\
\hline Bagram & $24 \mathrm{MW}$ \\
\hline Kandahar & $20 \mathrm{MW}$ \\
\hline Salerno & $12 \mathrm{MW}$ \\
\hline
\end{tabular}

\subsection{Future Combat Systems}

The energy system for the family of FCS vehicles has already been decided on. The decision process considered several alternatives including diesel engines, hybrid drives, and gas turbine engines. Figure 55 shows some benchmarks associated with the selected power system.

The two engines being compared here are the VTA-903 found in the Bradley Fighting Vehicle, and the 4L890, the four cylinder engine that FCS will model its engine on. The intent for FCS is to use the same engine, but in a 5 cylinder version.

\section{VTA-903 Vs. 4L890}

VTA- $903 \quad 14.8$ liter V8 4 Stroke / cycle $600 \mathrm{Hp}$ at $2600 \mathrm{Rpm}$

Best BSFC $.335 \mathrm{lbs} / \mathrm{Hp}-\mathrm{hr}$

Peak Cylinder Pressure 2400 Psi

Air Fuel Ratio at Rated 27.0

Air Flow at Rated $6610 \mathrm{lbs} / \mathrm{hr}$

BSHR at $600 \mathrm{Hp}-24.5 \mathrm{BTU} / \mathrm{Hp}-\mathrm{min}$

Coolant Temp 230F

Length 49 inches

Width 32 inches

Height 37.5 inches

Volume $34 \mathrm{cu} \mathrm{ft}$

Wet Wt. 2650 lbs
4L890 engine 4.4 liter I-6 4 stroke / cycle $550 \mathrm{Hp}$ at $4250 \mathrm{Rpm}$

Best BSFC .344 lbs / Hp- hr

Peak Cylinder Pressure 3074 Psi

Air Fuel Ratio at Rated 23.0

Air Flow at Rated $4514 \mathrm{lbs} / \mathrm{hr}$

BSHR at $738 \mathrm{Hp}$ - 26.4 BTU / Hp-min Coolant Temp 267F

Length 50 inches

Width 17.9 inches

Height 30 inches

Volume $12.7 \mathrm{cu} \mathrm{ft}$

Wet Wt. 939 lbs

Figure 55. Power system benchmarks. 
The VTA-903 is a good benchmark to use for comparison because the FCS is intended to be a relatively light combat vehicle, much like the Bradley. Comparisons of specific fuel consumption show only a small disparity between the two engines, while the advantages gained are an engine that takes up less than half the volume of the VTA-903 and weighs one third as much.

An area of particular interest is idle power. According to current estimates, the difference between fuel consumption in idle mode and for full systems draw is significant. Current analysis shows a no-load idle specific fuel consumption of $0.5 \mathrm{gal} / \mathrm{hr}$ of DF2 fuel, and a $3.0 \mathrm{gal} / \mathrm{hr}$ draw at a continuous $34 \mathrm{~kW}$ state needed to power electrical components. The option to run in idle mode would prove to be very useful for fuel economy, particularly in command vehicles where a majority of operation is in idle mode.

If Ramgen intends to put its supersonic componentry into vehicular applications, they would likely have to meet or exceed the above specifications, since these are the ones our future vehicles will rely on for power and propulsion.

The FCS system will include a series hybrid electric drive system, but it will be a very mild hybrid approach. It will likely be something to offset the estimated $34 \mathrm{~kW}$ continuous power draw for FCS onboard electrical systems. With command vehicles, this power requirement can jump up to an intermittent $70 \mathrm{~kW}$, where a temporary addition from hybrid electrical storage will prove useful. These batteries can power the vehicle themselves, but they will only have a 2 to $3 \mathrm{~kW}$-hr capability, which is only enough for very short durations.

\subsection{The Big Picture}

The desire to increase the efficiency of turbomachinery in the Army is merely a small subset of the greater goal of maintaining the most effective modern force on the battlefield, part of which is through the efficient production and use of energy. In FY06, the Department of Defense budgeted 1.7 billion dollars for energy (DoD Green Book FY06). The majority of this is used in providing fuel for active military applications. If the fuel efficiency can increase by just 1 percent in each of the applications, which may operate at 30 percent thermal efficiency, that would result in an annual energy savings of 3 percent, or over $\$ 30 \mathrm{M}$ annually, for the Department of Defense. The projected cost savings may not support the cost in replacing 
old components, but new equipment with more efficient components would provide extensive cost savings over their useful life.

There have been several attempts over the years to increase the efficiency of the force, but the Army currently holds such a conservative view on energy that progress is difficult to achieve. In a recent joint American and British study of a hybrid HMMWV, the American investigators completely discounted the input of the electric hybrid component in determining the efficiency of the vehicle, basing their results solely on the engine. The Army's dependence on and affinity for diesel fuel is creating a hurdle for possible progress in the future.

One of the largest issues according to GEN(R) Kern is that the Army does not have a defined mission profile for each of its vehicles. Current operations bear little resemblance to the Soviet-era fighting scenarios they were designed for. In most situations, vehicles operate in one of two capacities. They are either running at full throttle from one point to another, or they are sitting in place acting as a mobile field base attached to a generator. The use of a smaller APU would remove the stationary generator from outside the vehicle and locate it within the frame itself, reducing the dependence on an external energy source. A more mobile and modular force would result.

\subsection{Interview with GEN(R) Kern}

GEN(R) Kern was interviewed for feedback on the supersonic Ramgen technology, to probe for areas of application, and to gain insight into the direction of Army energy needs (Kern 2006). A summary of key points includes:

- GE and Pratt and Whitney are the primary producers for turbomachinery in the United States.

- GE goes through the following logical progression: stationary, marine applications, vehicular applications, and aircraft applications. Based on this, it would make the most sense to focus on stationary systems now, with the possibility of upgrading to vehicular use at a later stage.

- Any system must be proven with durability, reliability, and functionality before being adopted.

- ALCOA, Inc. may have interest in working with Ramgen, with regard to materials and manufacturability.

- The tank engine is the one system most in need of an upgrade

o AGT1500 is 1970s technology. 
o The AGT1500 is highly inefficient. A study done by BG Moran on use of a new system showed that the new system outperformed the old one and would have replaced the M1 engine as well as going into the Crusader. On cancellation of Crusader, the new engine was not considered because it would not have been cost effective.

o Positive pressure is necessary in tanks to ward off chemical and biological risk.

o Helicopters are already more efficient.

o Hybrid drives can be promising, in heating up fuel cell with turbine exhaust.

- APUs and backup power supplies

- The Army has not yet been able to configure a design to put one on the Abrams tank. The result is $1500 \mathrm{hp}$ running thermal sights as the tank sits still. There are issues of space and cost.

o Current systems were designed for high mobility operations in Russia or central Europe. Current mission profile demands quick bursts of speed and long periods of stationary operation.

- Future of Energy in the Army

- Army progress can be frustratingly slow. The prevailing Army view is very conservative. There is a desire to keep diesel or J P8 fuel.

o Three main problems

* Army needs an effective duty cycle description

* Army is too "hung up" on diesel

* Army has no electric motor expertise.

o The Federal government has tried to do work on alternative fuel sources, but it gets lost while between agencies (DOE, Department of Transportation [DOT], and DOD).

o There is a growing need for portable energy generation sources.

o Research has been done into batteries using fuel cells for radio systems that run on boron hydride fuel, producing water. Current research is focusing on hand-chargeable batteries.

o Batteries are a big concern. The Army ran out of batteries some years ago. Some questions to consider are: Can fuel cells replace batteries? From where will Army obtain usable fuel? Can an application be envisioned for the Ramgen technology in the portable, individual soldier power market?

o There are currently no clear energy goals, and energy policy is poorly defined.

o Energy policy often changes with leadership. 


\subsection{Analysis on a System Level}

In discussing the matter of supersonic componentry in vehicular applications with Dr. Dick McClelland, Director of TARDEC, the expected reduction size was discussed. While supersonic componentry might very well save space in the engine compartment, this may not have a net positive effect on the vehicle as a whole. In general, the AGT-1500 has a fairly high compressor efficiency as far as gas turbines go. For the sake of argument, assume that a supersonic compressor will cut the engine size in half. As far as the engine is concerned, this would be of tremendous advantage. However, when this improvement is taken into consideration with regards to the rest of the systems on a tank, the net result should be considered. Any additional components placed into the space where part of the engine used to be will require a redesign of the systems of the tank to function with this new piece of equipment or apparatus. This could end up costing more money than it saves given the expected life of a tank engine and the replacement of these vehicles with FCS vehicles some day.

Assuming that the extra space was used for fuel storage capacity, then an additional 5 gallons of fuel could be carried. The normal fuel tank for the Abrams holds over 500 gallons of fuel, so this would only be a 1 percent increase. Thus, to simply maintain the same level of performance, the new engine may not have any less than about 99 percent of the original AGT1500 efficiency. Hence, the savings in space must not be accompanied by a decrease in efficiency. More importantly, a significant increase in efficiency would be needed to outweigh the logistical burden of retrofitting the M1.

\subsection{Warfighter Recommendations}

The AGT-1500 is currently an effective power source for our Abrams tank (Honeywell 2006). The Abrams itself has undergone many costly overhauls and upgrades, and it does not appear that the engine will be replaced any time soon. In fact, Honeywell was awarded in J anuary 2006 a contract worth up to \$1.4 Billion in support of the AGT-1500 full life cycle management.

Helicopter or other vehicular applications also do not seem to hold much promise. These engines either are working well enough for the Army's current needs, or have been designed already in the case of the FCS vehicles. 
Thus, the most feasible and useful application for supersonic turbomachinery in the Army would be in stationary prime power generation units. Our deployed forces in Afghanistan and Iraq currently provide their own power for forward operating bases and other facilities due to the unreliable nature of the power infrastructure in theater. This requires that thousands of generators run continuously on a daily basis to sustain the energy requirements of our armed forces. These applications do not require a throttled process, such as vehicles do. If Ramgen can improve not only the compressor, but complete system efficiency as well, it may indeed be an advantage for the stationary power generation systems.

The largest portion of any logistical deployment is energy, which usually accounts for 70 percent of deployment weight. For an Army numbering in the hundreds of thousands, a one percent increase in fuel efficiency from stationary power generation could not only reduce the Army's reliance on fuel, but limit the amount of weight, materials, and shipping vessels needed for deployment. This could result in a more flexible and mobile force due to quicker deployment times or lighter logistical requirements.

As the latest Ramgen compressor is currently being tested on a lab scale and data is still being collected, it is not possible to make recommendations on its implementation. However, if testing suggests that the fuel efficiency is shown to significantly surpass that of current Army systems and other logistical factors are weighed, a further study should be performed on how to phase this novel technology into conventional Army systems. 


\section{Conclusions}

\subsection{Conclusions}

This work has reviewed the development of Ramgen power systems for military and commercial applications. Potential applications were presented from the perspectives of the technology supplier, Ramgen Power Systems, Inc., and from that of the warfighter. A macro roadmap of technology development and deployment from the former AMC commander and an exploration of specific issues related to the level of system development suggests a future direction for Ramgen power technology research and development. Current Ramgen research focuses on three areas:

- Rampressor compressor technology based on oblique shock

- expander technology optimal for the Rampressor

- combustion technology based on the advanced vortex combustion.

This work concludes that each of these technologies may potentially improve overall engine efficiency such applications as an auxiliary gas turbine for the hybrid fuel cell power plant and hybrid drive for the Army tank. Note, however, that these technologies are still in early stages of development. Potential military and commercial applications are yet to be realized through rigorous laboratory and field testing.

\subsection{Future Direction}

Energy and power source are critical resources for the Army to drive current and future forces. The Ramgen Power System offers a potential solution to the Army's need for energy resources. The current team of researchers, composed of the technology developer, technology development manager, and the warfighter, share the following near-term interests in developing this technology for military applications:

- Technology Developer (RPS). Ramgen is pursuing use of the turbine technology for a number of military applications, including (but not limited to) the hybrid fuel cell, standalone electric power generation, hybrid propulsion, and lightweight auxiliary power unit for laser-based weapons.

- Technology Manager (ERDC-CERL). ERDC-CERL will coordinate and manage the Congressional funding for the development of the Ramgen Power System. Of particular interest is application of the technology in the Army installations for fixed facilities. The hybrid fuel cell for sta- 
tionary power generation as a part of the distributed generation system is one example potential application.

- Warfighter (USMA). USMA strives to reduce the energy footprint of the Army by continuing to explore both current and future platforms for the Ramgen technology. Studies suggest that stationary systems should be the starting point for Ramgen technology development. For example, early candidate applications might include the use of Ramgen technology with hybrid fuel cells, or stationary power generation. 


\section{References}

DODFuelCell ERDC/ CERL Projects (2007). Website, accessible through URL: http://dodfuelcell.cecer.army.mil/intro.html

Honeywell Aerospace Products (2006). AGT1500. Abrams Main Battle Tank Operators Manual. Accessed 27 February 2006. Available through URL: http://www.honeywellaerospace.com/prod_byfamily_engines_agt1500.htm

Kern, Paul, GEN, retired (22 February 2006). Interview by CDT Dan Mahoney, Dr. Gunnar Tamm, and MAJ Wesley Williamson. Energy Systems in the Department of Defense

Lawlor, S. and P. Baldwin (2005) . "Conceptual Design of a Supersonic $\mathrm{CO}_{2}$ Compressor," Proc of ASME 2005, ASME TURBO EXPO 2005, 6-9 J une 2005, Reno, NV.

Lawlor, S. and R. Steele (2004). "Insertion of Shock Wave Compression Technology into Gas Turbines for Increased Efficiency and Reduced Costs," ASNE Advanced Naval Propulsion Symposium 2004, 16-17 November 2004, Hilton Washington Dulles Airport.

Lawlor, S., J. Hinkey, S. Mackin, S. Henderson, J. Bucher, P. Brown, and R. Pudupatty (2004). “Supersonic Compression Stage Design \& Test Results," Proc. of IMECE 2004, 2004 ASME International Mechanical Engineering Congress and Exposition, 14-19 November 2004, Anaheim, CA.

Sohn, C., F. Holcomb, P. Baldwin, R. Steele, K. Belshaw, and G. Tamm (2006). "Ramgen Power Systems-Supersonic Component Technology for Military Engine Applications," Proc. 25th Army Science Conference, 27-30 November 2006, Orlando, FL. 


\section{Acronyms and Abbreviations}

\begin{tabular}{|c|c|}
\hline$\underline{\text { Term }}$ & Spellout \\
\hline AMC & U.S. Army Materiel Command \\
\hline ANSI & American National Standards Institute \\
\hline API & American Petroleum Institute Recommended Practices \\
\hline APU & auxiliary power unit \\
\hline ASCE & American Society of Civil Engineers \\
\hline ASME & American Society of Mechanical Engineers \\
\hline ASNE & American Society of Naval Engineers \\
\hline AVC & Advanced Vortex Combustion \\
\hline CC\&S & carbon capture and storage \\
\hline CDT & central daylight time \\
\hline CEERD & U.S. Army Corps of Engineers, Engineer Research and Development Center \\
\hline CERL & Construction Engineering Research Laboratory \\
\hline CFD & computational fluid dynamics \\
\hline $\mathrm{CHP}$ & combined heat and power \\
\hline $\mathrm{CO}$ & carbon monoxide \\
\hline DLE & dry low emission \\
\hline DO & dissolved oxygen \\
\hline DOD & Department of Defense \\
\hline DOE & U.S. Department of Energy \\
\hline DOT & Department of Transportation \\
\hline EGT & exhaust gas temperature \\
\hline ERDC & Engineer Research and Development Center \\
\hline FCS & Future Combat System \\
\hline GE & General Electric \\
\hline GWOT & Global War on Terror \\
\hline HMMWV & high-mobility multipurpose wheeled vehicle \\
\hline HVAC & heating, ventilating, and air conditioning \\
\hline IGCC & integrated gasification combined cycle \\
\hline IMECE & International Mechanical Engineering Congress and Exposition \\
\hline LHV & lower heating value \\
\hline MW & megawatt \\
\hline NASA & National Aeronautics and Space Administration \\
\hline NETL & National Energy Technology Laboratory \\
\hline NOx & nitrogen oxide \\
\hline NSN & national supply number \\
\hline NTF & nozzle test facility \\
\hline ODDR\&E & Office of the Director, Defense, Research, and Engineering \\
\hline OEM & original equipment manufacturer \\
\hline
\end{tabular}




$\begin{array}{ll}\text { Term } & \text { Spellout } \\ \text { OMB } & \text { Office of Management and Budget } \\ \text { PEO } & \text { Program Executive Officer } \\ \text { PM } & \text { permanent magnet (electric generator) } \\ \text { PSN } & \text { pre-swirl nozzle } \\ \text { RMS } & \text { root mean square } \\ \text { RP } & \text { Rampressor } \\ \text { RPM } & \text { revolutions per minute } \\ \text { RPS } & \text { Ramgen Power Systems, Inc. } \\ \text { SCR } & \text { selective catalytic reduction } \\ \text { SFC } & \text { specific fuel consumption } \\ \text { SS } & \text { stainless steel } \\ \text { SSME } & \text { space shuttle main engine } \\ \text { TACOM } & \text { U.S. Army Tank-automotive and Armaments Command } \\ \text { TARDEC } & \text { Tank Automotive Research, Development and Engineering Center } \\ \text { TR } & \text { Technical Report } \\ \text { TRIT } & \text { turbine rotor inlet temperature } \\ \text { UAF } & \text { University of Alaska at Fairbanks } \\ \text { UHC } & \text { Unburned hydrocarbon } \\ \text { UPS } & \text { Uninterruptible Power Supply } \\ \text { URL } & \text { Universal Resource Locator } \\ \text { USAF } & \text { U.S. Air Force } \\ \text { USMA } & \text { U.S. Military Academy } \\ \text { USSOCOM } & \text { U.S. Special Operations Command } \\ \text { USSR } & \text { Union of Soviet Socialist Republics (USSR) } \\ \text { YPG } & \text { Yuma Proving Grounds } \\ & \\ \text { UPS } & \\ \text { SPS } & \end{array}$




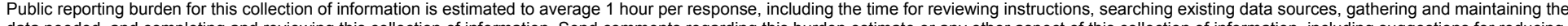

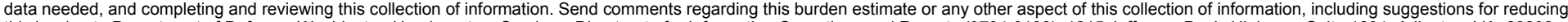

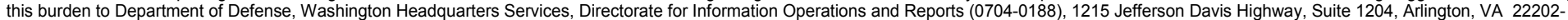

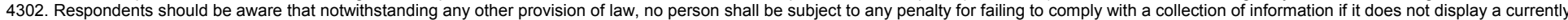
valid OMB control number. PLEASE DO NOT RETURN YOUR FORM TO THE ABOVE ADDRESS.
1. REPORT DATE (DD-MM-YYYY)
2. REPORT TYPE

17-05-2007

Final

4. TITLE AND SUBTITLE

Ramgen Power Systems for Military Engine Applications

5a. CONTRACT NUMBER

5b. GRANT NUMBER

5c. PROGRAM ELEMENT NUMBER

6. AUTHOR(S)

Franklin H. Holcomb, Chang W. Sohn, Gunnar Tamm, Daniel Brown, Daniel Mahoney, Peter Baldwin,

Karen Belshaw, Aaron Koopman, and Dennis Witmer

5d. PROJECT NUMBER

5e. TASK NUMBER

5f. WORK UNIT NUMBER

7. PERFORMING ORGANIZATION NAME(S) AND ADDRESS(ES)

U.S. Army Engineer Research and Development Center (ERDC)

Construction Engineering Research Laboratory (CERL)

PO Box 9005,

Champaign, IL 61826-9005

8. PERFORMING ORGANIZATION REPORT NUMBER

ERDC/ CERL TR-07-14

9. SPONSORING / MONITORING AGENCY NAME(S) AND ADDRESS(ES)

Office of the Director, Defense, Research, and Engineering

1777 N. Kent, Suite 9030

Rosslyn, VA 22209

10. SPONSOR/MONITOR'S ACRONYM(S)

ODDR\&E

11. SPONSOR/MONITOR'S REPORT NUMBER(S)

12. DISTRIBUTION / AVAILABILITY STATEMENT

Approved for public release; distribution is unlimited.

13. SUPPLEMENTARY NOTES

\section{ABSTRACT}

Ramgen Power Systems, Inc. (RPS) is developing two high efficiency gas turbine engine concepts that combine many of the proven features of supersonic compression and expansion systems, commonly used in supersonic flight inlet and nozzle designs, with conventional axial flow turbo-machinery practices to create two entirely new gas turbine engines. The superior efficiency is a result of high pressure shock wave compression and supersonic expansion phenomena to produce high component efficiencies, and a unique engine configuration that minimizes flow stream turning losses throughout the engine. The RPS engine concept can be configured as a high pressure ratio simple-cycle design for propulsion applications, or as a low pressure ratio recuperated engine either as a standalone component or combined with a hybrid fuel cell for stationary power applications. The anticipated compression and expansion efficiencies, decreased footprint, and reduced part count of the RPS technologies promise revolutionary new power generation and propulsion systems with decreased heat signatures resulting from lower exhaust temperatures. These unique aerodynamic features will open new options for engine designers and package integrators. This report documents research and development of the RAMGEN technology and potential applications toward military operations including warfighter applications.

\section{SUBJECT TERMS}

energy efficient fuel cells

military training fuel cells
Ramgen Power Systems

\section{SECURITY CLASSIFICATION OF:}

\begin{tabular}{|c|c|c|}
\hline \multicolumn{3}{|c|}{ 16. SECURITY CLASSIFICATION OF: } \\
\hline $\begin{array}{l}\text { a. REPORT } \\
\text { Unclassified }\end{array}$ & $\begin{array}{l}\text { b. ABSTRACT } \\
\text { Unclassified }\end{array}$ & $\begin{array}{l}\text { c. THIS PAGE } \\
\text { Unclassified }\end{array}$ \\
\hline
\end{tabular}

NSN 7540-01-280-5500 gas turbine engine

warfighters

\begin{tabular}{|c|c|c|}
\hline $\begin{array}{c}\text { 17. LIMITATION } \\
\text { OF ABSTRACT }\end{array}$ & $\begin{array}{c}\text { 18. NUMBER } \\
\text { OF PAGES }\end{array}$ & 19a. NAME OF RESPONSIBLE PERSON \\
\cline { 3 - 3 } SAR & 88 & $\begin{array}{c}\text { 19b. TELEPHONE NUMBER } \\
\text { (include area code) }\end{array}$ \\
\hline
\end{tabular}

Standard Form 298 (Rev. 8-98)

Prescribed by ANSI Std. 239.1 